
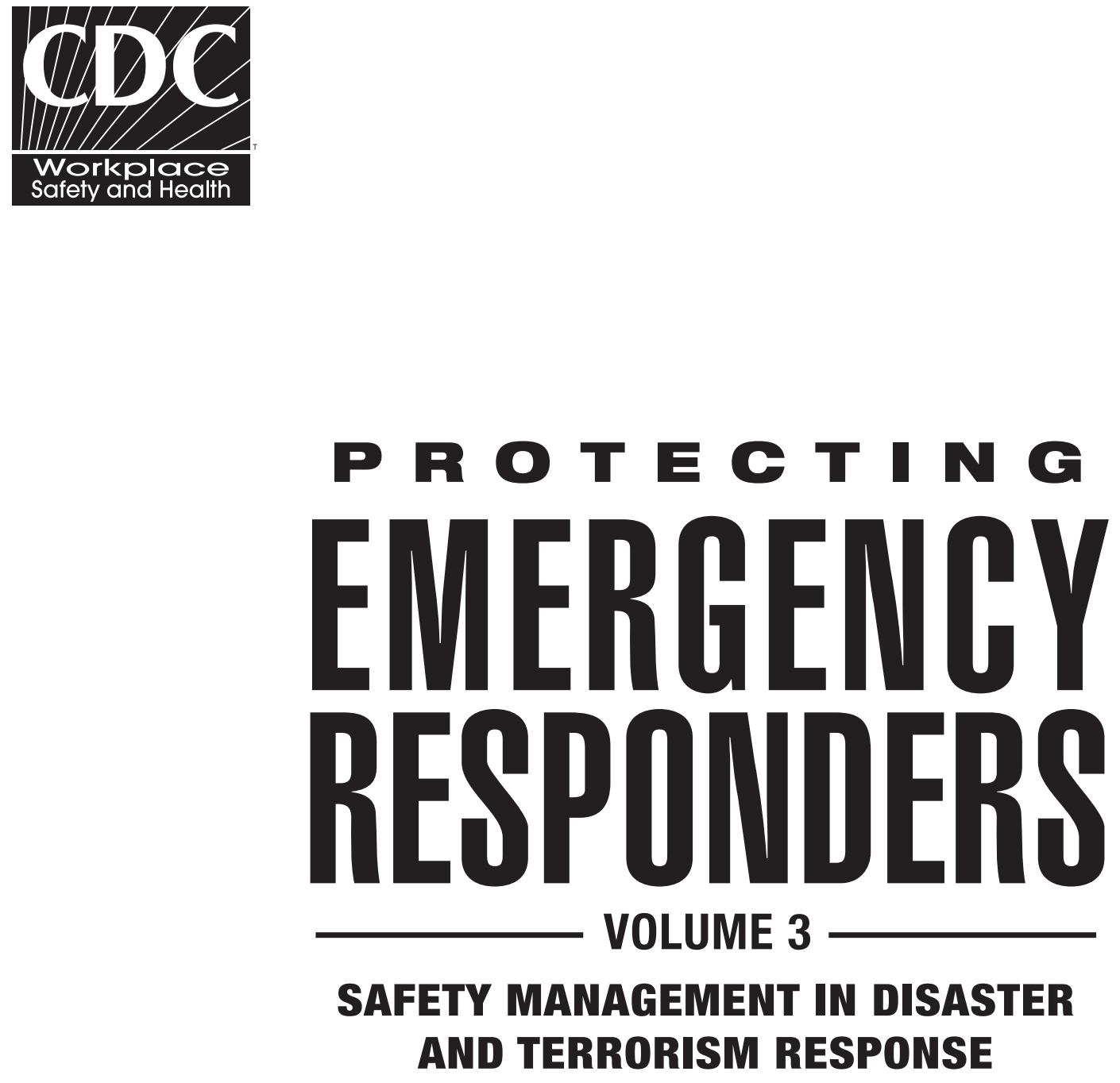

Brian A. Jackson

John C. Baker

M. Susan Ridgely

James T. Bartis

Herbert I. Linn 
The research described in this report was a joint effort of the Science and Technology Policy Institute (operated by RAND from 1992-November 2003 under Contract ENG-9812731) and the National Institute for Occupational Safety and Health.

\section{Disclaimer}

Mention of any company name or product does not constitute endorsement by the National Institute for Occupational Safety and Health or RAND.

This document is in the public domain and may be freely copied or reprinted.

Copies of this and other NIOSH documents are available from NIOSH.

For information about occupational safety and health topics contact NIOSH at:

$$
\text { 1-800-35-NIOSH (1-800-356-4674) }
$$

Fax: 513-533-8573

E-mail: pubstaft@cdc.gov

http://www.cdc.gov/niosh

National Institute for Occupational Safety and Health

Publications Dissemination 4676 Columbia Parkway

Cincinnati, OH 45226-1998

For information about RAND and its research contact:

\section{RAND Corporation}

1700 Main Street, P.O. Box 2138, Santa Monica, CA 90407-2138

1200 South Hayes Street, Arlington, VA 22202-5050

201 North Craig Street, Suite 202, Pittsburgh, PA 15213-1516

$$
\begin{gathered}
\text { 310-393-0411 } \\
\text { Fax: 310-393-4818 } \\
\text { http://www.rand.org/ } \\
\text { Cover design by Stephen Bloodsworth } \\
\text { Cover photograph @ Mark M. Lawrence/CORBIS }
\end{gathered}
$$

The RAND Corporation is a nonprofit research organization providing objective analysis and effective solutions that address the challenges facing the public and private sectors around the world. RAND's publications do not necessarily reflect the opinions of its research clients and sponsors.

$$
\text { RAND }{ }^{\circledR} \text { is a registered trademark. }
$$

DHHS (NIOSH) Publication No. 2004-144 RAND Publication No. MG-170 


\section{Foreword}

Every day across the nation, emergencies occur that threaten our lives, well-being, property, peace, and security. Every day, we rely upon our local police officers, firefighters, emergency medical technicians, public health professionals, and others to arrive quickly and do what needs to be done to restore the safety, the security, the peace, and the routine to our lives. These emergency responders are trained to handle such emergencies that occur day by day in our cities, towns, villages, and countrysides. On rare occasions, emergencies occur that are so large in scale and so severe that local responders may not have the resources-people, equipment, expertise, funds - to effectively and safely respond. Even in such cases, local responders do not hesitate to do what they have been trained to do-go to the site prepared to save lives, protect property, and remove the threat.

When a disaster, whether natural or manmade, overwhelms the resources and capabilities of local organizations, responders come in from other cities, counties, and states-jurisdictions near and far-as well as from federal agencies, to assist those with local responsibility. Skilled support workers are engaged for specialized activities, such as removing debris and restoring utilities and transportation. Neighbors and other volunteers may travel to the disaster site to try to do their part. Other concerned individuals and organizations send food, supplies, and equipment. Journalists press in to the closest possible vantage points to get the pictures and stories. Public officials arrive to examine the damage and consult with the responders. One characteristic of these large, rare, dynamic events is the rapidly evolving complexity that faces individuals trying to effectively manage all of the organizations and people, operations and tasks, equipment and supplies, communications, and the safety and health of all involved. Another characteristic is that all disasters present risks to emergency response workers-risks that may be familiar or unfamiliar, and that may vary widely depending on the nature of the event or the phase of the response.

This report addresses the protection of emergency responders against injury, illness, and death on just such rare occasions, when emergencies become disasters. It builds on a broad base of National Institute for Occupational Safety and Health programs and RAND Corporation research on protecting emergency responders. This 
report focuses on preparedness (especially planning and training) and management as means of controlling and reducing the hazards emergency responders face. It provides a set of recommendations on how disaster site safety and health management might be improved. Much of the information contained herein is based upon the firsthand experience and suggestions of emergency responders who were there at the World Trade Center and at the Pentagon on and after September 11, as well as those who responded to the Northridge earthquake (in California) and Hurricane Andrew (in Florida).

This report builds on systems and practices currently in use and was developed primarily for use by local emergency responders, those individuals and organizations who have been tasked with disaster site safety and health responsibilities. Additionally, the report should prove useful to legislators and other federal, state, county, and municipal officials; trade union officials; industry executives; safety and health professionals; and researchers who are engaged in and committed to efforts to make our nation more secure, to respond effectively and safely to disaster, and to protect a critically important resource-the community of emergency responders.

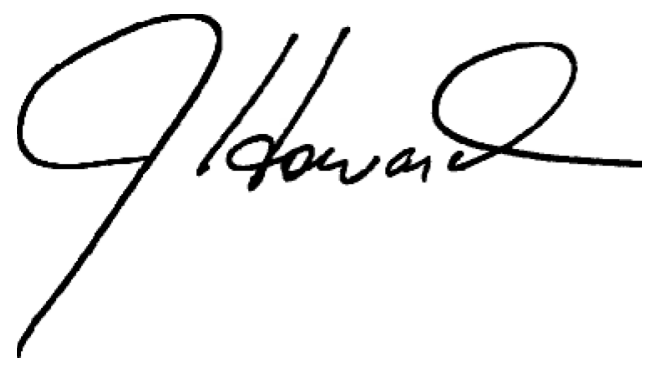

John Howard, M.D.

Director, National Institute for Occupational Safety and Health

Centers for Disease Control and Prevention

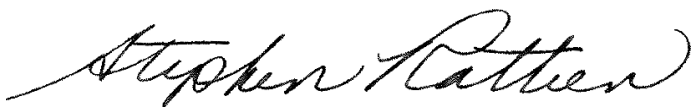

Stephen Rattien

Director

RAND Science and Technology, a division of the RAND Corporation 


\section{The RAND Corporation Quality Assurance Process}

Peer review is an integral part of all RAND research projects. Prior to publication, this document, as with all documents in the RAND monograph series, was subject to a quality assurance process to ensure that the research meets several standards, including the following: The problem is well formulated; the research approach is well designed and well executed; the data and assumptions are sound; the findings are useful and advance knowledge; the implications and recommendations follow logically from the findings and are explained thoroughly; the documentation is accurate, understandable, cogent, and temperate in tone; the research demonstrates understanding of related previous studies; and the research is relevant, objective, independent, and balanced. Peer review is conducted by research professionals who were not members of the project team.

RAND routinely reviews and refines its quality assurance process and also conducts periodic external and internal reviews of the quality of its body of work. For additional details regarding the RAND quality assurance process, visit http://www. rand.org/standards/. 



\section{Contents}

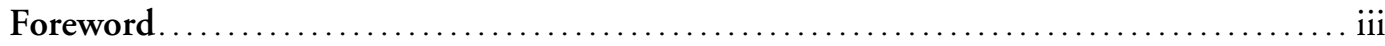

The RAND Corporation Quality Assurance Process $\ldots \ldots \ldots \ldots \ldots \ldots \ldots \ldots \ldots \ldots \ldots \ldots$ v

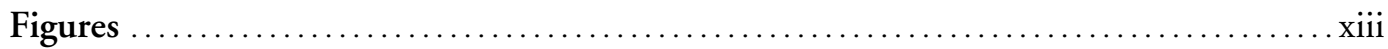

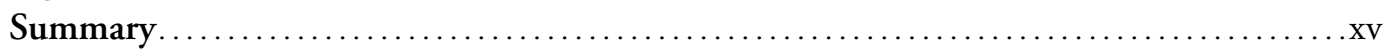

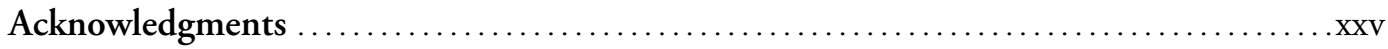

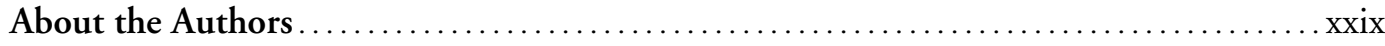

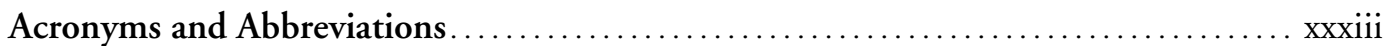

CHAPTER ONE

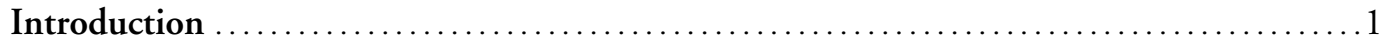

Major Disasters Present Special Challenges for Safety Management .................... 2

Large Number of People Affected, Injured, or Killed ............................ 2

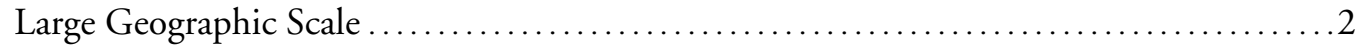

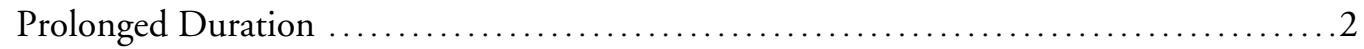

Multiple, Highly Varied Hazards ............................................ 3

Wide Range of Needed Capabilities ........................................... 3

Influx of Convergent Volunteers and Supplies .................................. 3

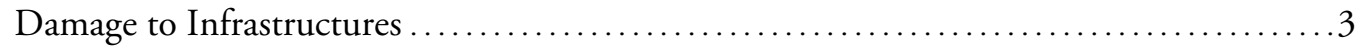

Direct Effects on Responder Organizations .................................. 4

Responder Safety Management Is Risk Management .............................. 4

The Response Community Recognizes a Pressing Need for Improved Safety

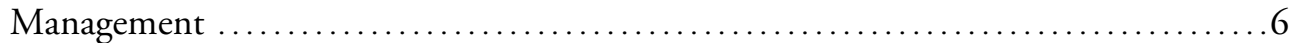

Tomorrow's Success Depends on Today's Preparations .............................6

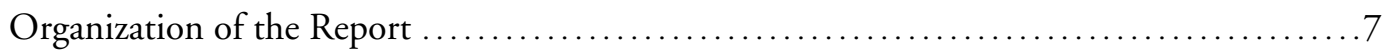

CHAPTER TWO

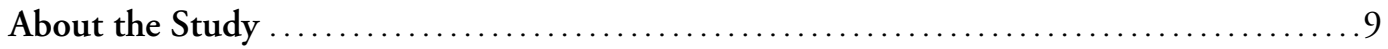

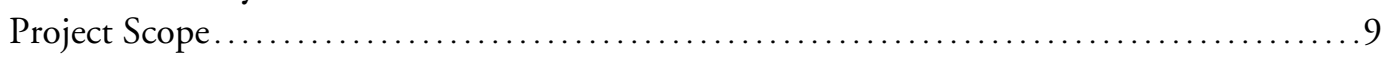

The Research Team .................................................. 11

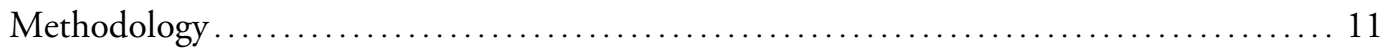


Review of the Professional and Technical Literatures $\ldots \ldots \ldots \ldots \ldots \ldots \ldots \ldots \ldots \ldots \ldots \ldots \ldots$

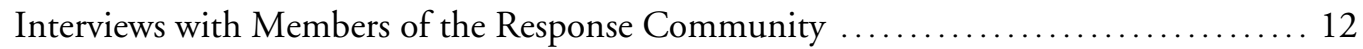

Responder Workshop................................................ 13

Analytical Framework ................................................... 14

\section{CHAPTER THREE}

Protecting Responder Safety Within the Incident Command System ............... 15

Origins of the Incident Command System .................................... 16

How the Incident Command System Works .................................. 17

The National Incident Management System ................................... 18

Safety Within the Incident Command System .................................. 19

\section{CHAPTER FOUR}

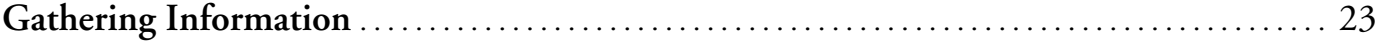

Hazard Information: Understanding the Disaster Environment .................... 24

Recommendation 4.1-As Part of Preparedness Efforts, Put in Place a

Coordinated, Multiagency Plan for Monitoring Hazards ..................... 26

Recommendation 4.2-Develop Assessment Methods, Checklists, Guidelines, and Standards to Assist in Hazard Monitoring Efforts Among Multiple Agencies

Recommendation 4.3-Develop Information Management Systems and Processes So That Response Organizations Can Use Hazard Data More Effectively ......... 30

Recommendation 4.4-Undertake Joint Exercises that Include Multiagency Hazard Monitoring Efforts..................................... 31

Information on the Responder Workforce: Maintaining Accountability Data on

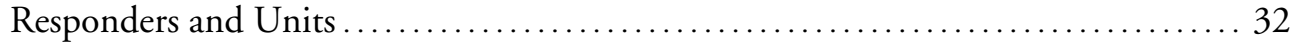

Recommendation 4.5-Bolster the Role of Response Units in Accounting for Personnel

Recommendation 4.6-Develop Personnel Identification and Credentialing Systems Better Suited to Major Disaster Response Operations ................... 34

Recommendation 4.7-Utilize Scene Control to Improve Cross-Agency Accountability

Recommendation 4.8-Develop Minimum Standards for Safety and Health Training for All Responders Involved in Disaster Response Operations ........... 36

Information on Responders' Health and Injuries: Collecting Injury, Exposure, and Health Status Data ............................................ 37

Recommendation 4.9-Develop Systems to Provide Timely Information on

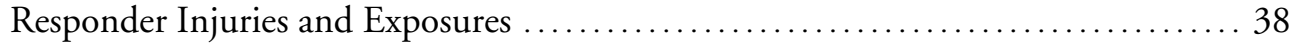

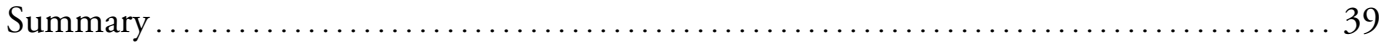




\section{CHAPTER FIVE}

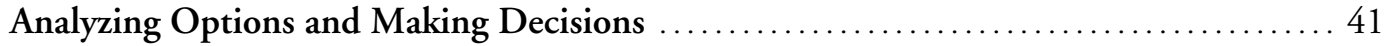

Assessing Hazards: Judging the Level of Risk Faced by Responders ................. 42

Recommendation 5.1-Identify and Connect with Experts in Hazard Assessment

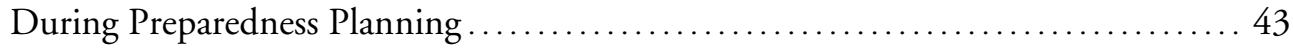

Recommendation 5.2-Develop a Better Understanding of Relevant Exposure

Thresholds and Guidelines for Disaster Response Conditions ................. 44

Managing Risk: Balancing Risks and Benefits in Response .................... 45

Recommendation 5.3-Address the Transition Between the Rescue and

Recovery Phases of Disaster Response Operations in Preparedness Planning ...... . 46

Choosing Protective Options and Planning for Safety Needs: Supporting Effective

Decisionmaking in Responder Protection and Risk Mitigation ............... 47

Recommendation 5.4-During Disaster Planning, Address Issues Concerning

Safety Equipment and Multiagency Coordination of Safety Logistics ........... 47

Recommendation 5.5-Develop Guidelines for Selecting Protective Equipment

to Use in the Early Phase of Response

Recommendation 5.6-Develop Guidelines for Estimating the Safety Equipment

Requirements for Disaster Response Operations . ....................... 49

Summary

\section{CHAPTER SIX}

Taking Action

Effective Mechanisms for Implementing Safety Decisions: Improving Safety

Implementation During Multiagency Response Operations . .

Recommendation 6.1-As Part of Multiagency Preparedness Efforts, Address the

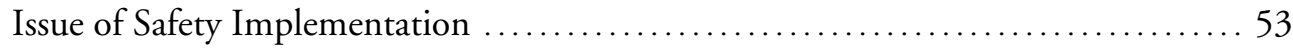

Recommendation 6.2-As Part of Preparedness Planning, Include Safety and Risk

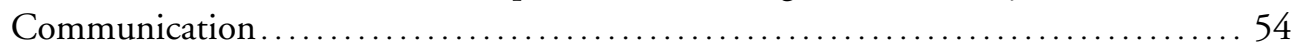

Recommendation 6.3-Pursue Effective Scene Control As a Safety Enforcement

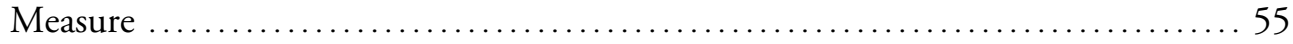

Recommendation 6.4-Provide On-Site Training, But Not As a Substitute for Pre-

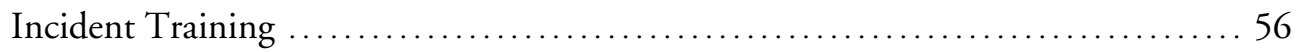

Measures to Protect the Health of Responders: Adopting a Force Health Protection

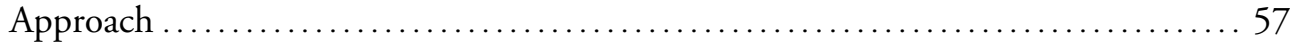

Recommendation 6.5-Improve Health Maintenance by Preparing and Implementing Sustainability Measures.......................... 58

Recommendation 6.6-Provide Medical Care to Responders During the Early Phase of a Disaster Response Operation . .........................61

Recommendation 6.7-Protect the Mental Health of the Response Workforce by Managing Critical Incident Stress. 
Recommendation 6.8-Improve Long-Term Surveillance of Responders' Health

Following Major Response Operations

Human Resource and Equipment Management: Safety Effects of Responder

Deployment and Supply Logistics

Recommendation 6.9-Adopt Better Measures to Manage the Recall and

Mutual Aid Processes for Responders

Recommendation 6.10-Implement Better Mechanisms to Utilize and

Manage Disaster Volunteers

Recommendation 6.11-As Part of Preparedness Efforts, Establish Systems

for Managing the Logistics of Safety Equipment ........................ 68

Summary

\section{CHAPTER SEVEN}

Integrated, Incident-Wide Safety Management ............................. 71

Benefits of an Integrated, Incident-Wide Safety Management Approach ................ 72

Access to the Specialized Safety Capabilities of Multiple Organizations ............... 73

A Strategic Approach to Safety Management................................. 73

A Mechanism to Address Inherently Multiagency Safety Issues.................... 74

A Route to Take Advantage of Diverse Response Capabilities ....................... 75

Implementing Integrated, Incident-Wide Safety Management .................... 75

Recommendation 7.1—Build an Integrated Safety Function into the Incident

Command System............................................... 76

Recommendation 7.2-As Part of Preparedness Efforts, Coordinate Plans for Implementing Safety Management .................................... 78

Recommendation 7.3—Develop a Group of Highly Trained Safety Managers to

Facilitate Coordination at Major Incidents ........................... 83

Recommendation 7.4-Improve Joint Exercises and Training by Incorporating Realistic Safety and Health Issues ..................................... 85

Recommendation 7.5-Develop a Common Terminology for Disaster Safety and Health Issues and Processes for Use During Response Operations . . . . . . . . 86

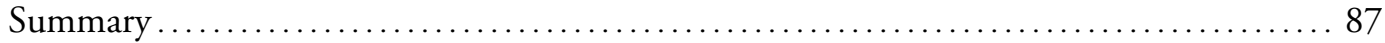

\section{CHAPTER EIGHT}

Moving Forward: Improving Preparedness Efforts for Responder Safety ............ 89

Immediate Implementation Opportunities ................................. 90

Long-Term, Potentially High-Payoff Safety Implementation Opportunities ............ 91

Pilot and Validation Efforts ................................................ 92

Building a Core Group of Major Disaster Safety Managers ...................... 93

Integration of Safety into Disaster Exercises................................... 94

Areas Requiring National Coordination and Leadership ......................... 94

Concluding Remarks ............................................... 95 
APPENDIX

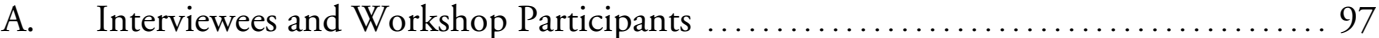

B. Workshop Agenda ................................................ 109

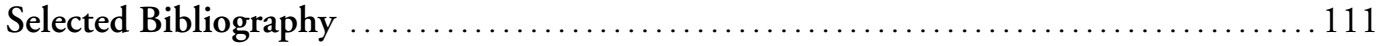





\section{Figures}

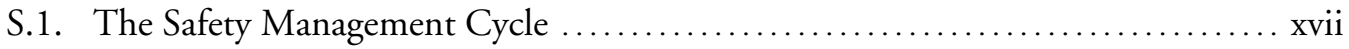

1.1. Response Safety Management Cycle ...................................... 5

3.1. Incident Command System Structure .................................... 17

3.2. Safety Responsibility in the Incident Command System .................. 20

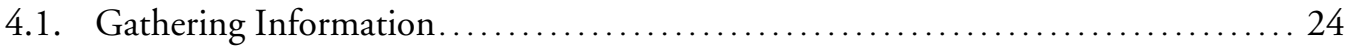

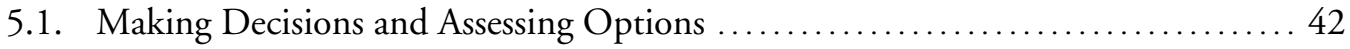

6.1. Taking Action ................................................. 51 



\section{Summary}

When disaster strikes, the nation depends on the emergency response community. No events demonstrated this truth as dramatically as the catastrophic terrorist attacks of September 11, 2001. But the same holds true every time the nation faces a major natural disaster or industrial incident. Emergency responders are an indispensable part of the country's homeland security system. To ensure that this system can meet the challenges of major disasters, the nation must take every measure to protect emergency workers from the safety and health risks inherent in their work.

In the aftermath of the September 11 terrorist attacks, the National Institute for Occupational Safety and Health (NIOSH) and the Science and Technology Policy Institute (S\&TPI), formerly managed by the RAND Corporation, organized a conference in New York City on the protective equipment needs of emergency responders during responses to terrorism. Over the course of this meeting, participants repeatedly emphasized that, in addition to protective equipment, responders need effective safety management to ensure their well-being as they bring these devastating situations under control.

As a result, NIOSH and S\&TPI undertook this study to develop a better understanding of safety management in major disasters, both manmade and natural, and to develop recommendations for improving safety management for emergency responders. Through an extensive literature review, interviews with members of the response community, and workshop discussions including more than 100 participants, the research team determined areas for improvement and developed recommendations to guide needed changes. This report provides a comprehensive set of strategies and tactics for enhancing the safety of responders by preparing thoroughly before an event and managing effectively afterwards.

\section{Major Disasters Make It Difficult to Safeguard Responders}

Unlike the smaller-scale emergencies normally handled by one or more local response organizations, major disasters have special characteristics that present unique safety risks and management challenges. Major disasters can 
- affect, injure, or kill large numbers of people

- cover large geographic areas

- require prolonged response operations

- involve multiple, highly varied hazards

- require a wide range of capabilities and resources not routinely maintained by local response organizations

- attract a sizeable influx of independent ("convergent") volunteers and supplies

- damage vital transportation, communications, and public works infrastructures

- directly affect the operational capacity of responder organizations.

These characteristics make it particularly difficult to manage the safety of responders. ${ }^{1}$

\section{Safety Management Is Risk Management}

Because the work of emergency responders is inherently dangerous, managing their safety is more accurately described as managing their level of risk. When handling safety issues at the scene of a major disaster, decisionmakers must weigh the potential benefits of a responder's action against the risks involved in carrying it out. This risk management process can be broken down into three functions: (1) gathering information about the situation, (2) analyzing available options and making decisions, and (3) taking action to implement decisions. As shown in Figure S.1, decisionmakers carry out these three functions continuously until the response operation ends. Most response organizations have their own standard procedures for carrying out these activities during smaller-scale events. But in the unfamiliar, chaotic, and complex environment of a major disaster, their methods may not be practical, creating real problems for efforts to ensure responder safety. To improve responder safety in major disasters, mechanisms must be put in place to allow safety management to readily scale up to meet the needs of the more complex and hazardous circumstances.

\footnotetext{
${ }^{1}$ Disaster response operations involve large numbers of responders. In addition to traditional responders such as firefighters, police, emergency medical services, and emergency managers, they also require many other workers such as federal, state, and local personnel; public health professionals; skilled support personnel (including construction/demolition workers, transit workers, and utility services workers); disaster relief workers; and members of volunteer organizations. For the purposes of this study, these workers are referred to collectively as "emergency responders."
} 
Figure S.1

The Safety Management Cycle

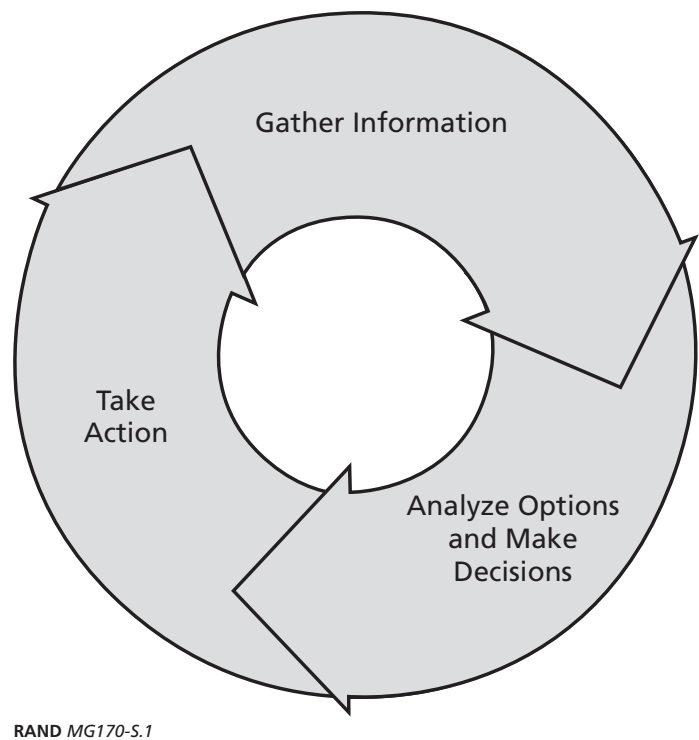

\section{Making Safety Management Better: Overcoming the Challenges of Major Disasters}

Significant systems and capabilities are already in place to protect emergency responders as they carry out their critical missions. But the results of this study show that opportunities exist to build upon those foundations-by both improving functional capabilities to protect responders and improving the organizational structures needed to manage the effort. Indeed, during a major disaster, when potentially hundreds of agencies ${ }^{2}$ must work side by side to cope with a barrage of situations, safety concerns cannot be fully resolved without effective multiagency coordination. To improve responder protection, steps must be taken to address problems that can arise in executing the three functions of the safety management cycle and to adopt a more fully integrated, incident-wide approach to protecting the welfare of responders.

\section{Improving Effectiveness Within the Safety Management Cycle}

Gathering Information. Decisionmakers responsible for safeguarding responders at the scene of a major disaster depend on accurate, comprehensive information to as-

\footnotetext{
2 Throughout the text, we use the term "multiagency" to describe disaster response operations. This term is intended to convey the involvement of not just many government agencies but nongovernmental and private organizations as well.
} 
sess the risks that workers face. But the scale and complexity of a major disaster can prevent response organizations from gathering all the information they need. For example, local agencies may have difficulty

- identifying, measuring, and monitoring unfamiliar hazards

- maintaining and coordinating information on responding individuals and units, especially those from other jurisdictions

- collecting and communicating timely data on responders' injuries, illnesses, and exposures to toxic substances and physical hazards.

Hazard Information. Collecting information about existing and potential hazards at a major disaster site is a critical component of safety management. Safety managers need timely, unambiguous information. However, major disasters present numerous impediments to the information collection process. For example, most response agencies lack the capabilities needed to monitor the wide variety of hazards potentially involved in disasters of this magnitude, and the involvement of many separate agencies in monitoring efforts can present problems coordinating hazard data. Over the course of the study, the following recommendations for hazard information were developed. ${ }^{3}$

\section{Recommendations: Hazard Information}

4.1. As part of preparedness efforts, put in place a coordinated, multiagency plan for monitoring hazards (p. 26).

4.2. Develop assessment methods, checklists, guidelines, and standards to assist in hazard monitoring efforts among multiple agencies (p. 29).

4.3. Develop information management systems and processes so that response organizations can use hazard data more effectively (p. 30).

4.4. Undertake joint exercises that include multiagency hazard monitoring efforts (p. 31).

Information on the Responder Workforce. To assess risks, implement safety decisions, and account for responders, managers need to know which emergency workers are taking part in the operation, where they are, what they are doing, and what capabilities they bring. However, because major disaster scenes cover such large areas and require the involvement of so many response organizations, it is difficult to account for all responders.

\footnotetext{
${ }^{3}$ Page numbers refer to the corresponding discussion of the recommendation in the main body of the report.
} 


\section{Recommendations: Information on the Responder Workforce}

4.5. Bolster the role of response units in accounting for personnel (p. 33).

4.6. Develop personnel identification and credentialing systems better suited to major disaster response operations (p. 34).

4.7. Utilize scene control to improve cross-agency accountability (p. 35).

4.8. Develop minimum standards for safety and health training for all responders involved in disaster response operations (p. 36).

Information on Responders' Health and Injuries. Data on responders' injuries, illnesses, and exposures to toxic substances and physical hazards-as well as the general status of their health-is another critical information category. It enables safety managers to address the health and safety issues of specific workers and to intervene to reduce risks for the responder force as a whole as an operation evolves.

\section{Recommendation: Information on Responders' Health and Injuries}

4.9. Develop systems to provide timely information on responder injuries and exposures (p. 38).

Yet in a major disaster, with so many people seriously injured or killed, responders frequently focus on victims' medical needs instead of monitoring and reporting on their own health. The large number of response organizations that take part in large-scale operations further complicates the collection and coordination of information about injuries and health status.

Analyzing Options and Making Decisions. With reliable information in hand, safety decisionmakers can assess its importance and decide on a course of action to protect responders in the trenches. But in the aftermath of a major disaster, this process may encounter serious obstacles. Major disasters make it challenging for decisionmakers to

- assess hazards

- manage risks

- choose among protective options

- plan for safety needs.

Assessing Hazards. Effective safety decisionmaking requires managers to draw together the technical expertise to evaluate the hazards present at the disaster site and the risks these hazards pose to responders. But because of the wide variety of hazards involved in major disasters, individual response organizations frequently lack the ex- 
pertise needed to assess every possible danger. The many different response organizations taking part in an operation of this scale may also use different criteria to assess hazards, providing an uneven foundation on which to base decisions.

\section{Recommendations: Assessing Hazards}

5.1. Identify and connect with experts in hazard assessment during preparedness planning (p. 43).

5.2. Develop a better understanding of relevant exposure thresholds and guidelines for disaster response conditions (p. 44).

Managing Risk. To evaluate any possible action, decisionmakers must weigh its potential gains in protecting lives against its level of risk, factoring in the overall needs of the operation. But in a major disaster, where the extent of the destruction can be so great and the number of victims so high, it is hard to establish a clear boundary between when "rescue" is still possible and when the operation needs to move into the "recovery" phase. When many different organizations bring separate approaches to this issue, determining the appropriate transition point becomes even more problematic.

\section{Recommendation: Managing Risk}

5.3. Address the transition between the rescue and recovery phases of disaster response operations in preparedness planning (p. 46).

Choosing Protective Options and Planning for Safety Needs. Effective safety management involves selecting appropriate protective equipment for responders. Managers must understand the options available and how to choose among them. They must also be able to determine what additional safety resources the many different participating organizations may need when an operation begins and as it

\section{Recommendations: Choosing Protective Options and Planning for Safety Needs}

5.4. During disaster planning, address issues concerning safety equipment and multiagency coordination of safety logistics (p. 47).

5.5. Develop guidelines for selecting protective equipment to use in the early phase of response (p. 49).

5.6. Develop guidelines for estimating the safety equipment requirements for disaster response operations (p. 49). 
evolves. However, the high degree of uncertainty about the hazard environment during a major disaster complicates efforts to select among protective options and project future needs.

Taking Action. The most effective efforts to gather information, analyze options, and make decisions would not benefit responder safety without the ability to turn those decisions into actions. Implementing and enforcing a course of action during a major disaster can prove to be highly problematic, however. Crises of this magnitude can prevent safety managers from having access to

- effective mechanisms for implementing safety decisions

- measures to protect the health of responders

- human resource and equipment management.

Effective Mechanisms for Implementing Safety Decisions. Putting decisions into action during the response to a major disaster depends on the ability to coordinate the efforts of multiple agencies. Safety managers must have successful strategies for communicating safety information, policies, and procedures to all participating response organizations. Mechanisms to enforce standard procedures incident-wide are also critical. But with so many independent response organizations involved, each taking its own approach to safety management, it is difficult to consistently implement safety measures across an operation.

\section{Recommendations: Effective Mechanisms for Implementing Safety Decisions}

6.1. As part of multiagency preparedness efforts, address the issue of safety implementation (p. 53).

6.2. As part of preparedness planning, include safety and risk communication (p. 54).

6.3. Pursue effective scene control as a safety enforcement measure (p. 55).

6.4. Provide on-site training, but not as a substitute for pre-incident training (p. 56).

Measures to Protect the Health of Responders. Safety managers need to be able to meet the medical needs of responders at every stage of a response operation. Meeting these needs entails not only caring for responders after injuries happen, but doing everything possible to keep responders out of harm's way-for example, enforcing reasonable work shifts and providing decontamination.

Yet the prolonged duration of operations during a major disaster requires response organizations to implement unfamiliar sustainability measures. In addition, the effects of many hazards stemming from major disasters may not appear until well after the response operation has ended. 


\section{Recommendations: Measures to Protect the Health of Responders}

6.5. Improve health maintenance by preparing and implementing sustainability measures (p. 58).

6.6. Provide medical care to responders during the early phase of a disaster response operation (p. 61).

6.7. Protect the mental health of the response workforce by managing critical incident stress (p. 62).

6.8. Improve long-term surveillance of responders' health following major response operations (p. 64).

Human Resource and Equipment Management. To protect responders, safety managers must be able to control the flow of volunteers, safety resources, and safetyrelated equipment to an incident. But in addition to a huge influx of responders from multiple organizations, major disasters typically draw large numbers of independent, or convergent, volunteers. The large number of volunteers makes it difficult to manage human resources during extended disaster operations, particularly if no mechanism exists to connect them with the incident command system. Moreover, the complex hazards at the scene of a major disaster complicate efforts to manage safety logistics.

\section{Recommendations: Human Resource and Equipment Management}

6.9. Adopt better measures to manage the recall and mutual aid processes for responders (p. 66).

6.10. Implement better mechanisms to utilize and manage disaster volunteers (p. 67).

6.11. As part of preparedness efforts, establish systems for managing the logistics of safety equipment (p. 68).

\section{Implementing Integrated, Incident-Wide Safety Management}

Instituting better ways for organizations to carry out the three functions of the safety management cycle is a key step toward improving responder safety during responses to major disasters. But for operations that demand the involvement of multiple organizations, these measures are not enough. Indeed, many of the preceding functional recommendations require some form of multiagency coordination. To optimize safety management during an operation of this magnitude, in our judgment it is vital to integrate the safety resources of multiple organizations into a single, incident-wide effort. 
During routine operations, response organizations tend to regard safety management as an activity carried out primarily by individual organizations. But the ad hoc efforts to coordinate safety management during the World Trade Center and Pentagon responses show that response organizations recognize a need for multiagency safety efforts during major disasters. To build on these models of integrated, incident-wide safety management, safety must be viewed as a multiagency function within the response management structure. After that, there are a number of important initiatives that are needed to formalize this approach in disaster preparedness efforts.

\section{Recommendations: Implementing Integrated, Incident-Wide Safety Manage-} ment

7.1. Build an integrated safety function into the Incident Command System (p. 76).

7.2. As part of preparedness efforts, coordinate plans for implementing safety management (p. 78).

7.3. Develop a group of highly trained safety managers to facilitate coordination at major incidents (p. 83).

7.4. Improve joint exercises and training by incorporating realistic safety and health issues (p. 85).

7.5. Develop a common terminology for disaster safety and health issues and processes for use during response operations (p. 86).

\section{Next Steps: Preparing Now to Protect Responder Safety}

To better protect responders to the next potential natural disaster or terrorist attack, the nation has the opportunity to improve preparedness for responder safety management. Many of the recommendations emerging from this study can be pursued right away by individual response organizations, with immediate gains. Others involve a longer-term effort but may provide greater gains. These include recommendations that are still conceptual and consequently require pilot projects and other evaluation efforts, those that require the coordinated efforts of multiple agencies, and those that need leadership and coordination at the national level.

Every time emergency responders take action, they put their lives on the line. The risks to their health and safety are particularly intense during responses to major natural disasters and terrorist attacks. Although the dangers can never be eliminated, much can be done to manage the risks involved and protect the nation's responders as fully as possible. 



\section{Acknowledgments}

An effort of this scope would clearly not be possible without the assistance of many people and organizations. A large number of individuals gave generously of their time and expertise to participate in both data-gathering discussions and the workshop held as part of the project. They are listed in Appendix A of the report.

In addition, a range of organizations assisted in the project by direct participation of their leadership or staff in topical discussions and/or by helping the project team connect with critical expertise within the response community. Their assistance was invaluable in ensuring that an effort of this breadth could tap needed expertise from the response community. In particular, we would like to thank the following organizations:

International Association of Chiefs of Police
International Association of Fire Chiefs
International Association of Fire Fighters
National Association of Emergency Managers
National Association of Emergency Medical Technicians
National Emergency Management Association
National Fire Protection Association
National Voluntary Organizations Active in Disasters
Oklahoma City Memorial Institute for the Prevention of Terrorism
United States Fire Administration

We would like to single out several individuals who gave very generously of their time in both speaking to us and helping us connect with other individuals and information sources. They are Chief Allen Hay of the Fire Department of New York, Tania Hedlund of the New York Police Department, Bill Johnson of the MiamiDade Fire Rescue Department's Office of Emergency Management, Kirby Kiefer of the United States Fire Administration, Frank Koutnik of the Florida Department of Community Affairs' Division of Emergency Management, Joseph Morris of the Port Authority of New York and New Jersey, and Vicki Lee of the International Associa- 
tion of Fire Chiefs. Mike Tammilow, from the National Urban Search \& Rescue Response System, also generously provided information to the study team. In addition, we would like to thank the staff of the Learning Resource Center, United States Fire Administration, for their research assistance. The authors would also like to gratefully acknowledge the many individuals and organizations that participated in review of the draft report.

Many individuals within the National Institute for Occupational Safety and Health made important contributions both to guiding the study effort and to the content of the research as well. We would like to acknowledge Kathleen Rest, deputy director for programs of NIOSH; Scott Deitchman, assistant director for emergency preparedness; Nancy Stout, director of the Division of Safety Research; and Tim Pizatella, deputy director of the Division of Safety Research, for their leadership and support of the project. We would particularly like to acknowledge Thomas Hodous, the initial NIOSH project officer for the study. In addition to his management roles, he participated closely in the research effort and made important contributions to the study. The project also benefited from access to a distinguished team within NIOSH that brought together a broad range of expertise on occupational safety and health. Beyond those who have already been mentioned, they were Dawn Castillo, Terrence Cloonan, Robert Koedam, Ken Mead, Paul Middendorf, Kara Perritt, Carol Merry Stephenson, Jim Spahr, Jon Szalajda, and Ralph Zumwalde. Through project discussions and other input, they provided the study with the benefit of a much broader body of knowledge than would have otherwise been available.

The success of this project would also not have been possible without the involvement of a range of RAND colleagues as both direct participants in data gathering or as contributors of their own subject matter expertise. Given the interdisciplinary nature of the topic, the project team drew on the talents of researchers across RAND with experience in military command and force protection, health care issues, and the science and technology field. Beginning with the initial literature review and interview process, Ari Houser, Suzannah Sennetti, Sophia Washam, and Irene Brahmakulam played critical roles.

Later in the project, a larger group of individuals participated in discussions as moderators and subject matter support to the project workshop and in other roles. They included Donna Barbisch, Gary Cecchine, Noreen Clancy, Robert Howe, David Howell, David Johnson, David Kassing, Debra Knopman, Beth Lachman, Henry (Chip) Leonard, Ralph Masi, David Mosher, David Mussington, D. J. Peterson, Steve Rattien, Helga Rippen, Liz Sloss, Jerry Sollinger, Bradley Stein, Terri Tanielian, Michael Tseng, Mike Wermuth, and Henry Willis. Lieutenant Colonel Scott O'Neil, an Army fellow at RAND who participated in the project, made important contributions. We also benefited from support and input from Bruce Don, Jeff Isaacson, Tom McNaugher, Bernie Rostker, Mark Wang, and Kathi Webb. We 
would also like to thank Aarti Dalal, Aryn Thomas, and Leigh Stallings for their administrative efforts on behalf of the project.

In particular, we would like to acknowledge the efforts of Susan Bohandy of the RAND Research Communications group in the preparation and refinement of the project report. Susan's efforts were instrumental in improving the quality of the report during the intense final stages of the project. The project team is grateful for her hard work in helping bring the study to a successful conclusion. 



\section{About the Authors}

\section{Brian A. Jackson}

Brian Jackson is a physical scientist at RAND and coprincipal investigator of this study. Recent research areas include equipment and technology needs of emergency responders, terrorism preparedness, critical infrastructure protection, and cyber security. He holds a bachelor's degree in chemistry from Haverford College, a master's degree in science, technology, and public policy from the George Washington University, and a $\mathrm{PhD}$ in chemistry from the California Institute of Technology.

\section{John C. Baker}

John C. Baker is a policy analyst at RAND and coprincipal investigator of this study. Recent research areas include homeland security and remote sensing. He is a graduate of American University (bachelor of arts in international studies) and Columbia University (master of philosophy in political science).

\section{Susan Ridgely}

M. Susan Ridgely is a senior policy analyst at RAND. In addition to contributing to the health and behavioral health components of this study on safety management, her recent research activities have focused on patient safety in health care settings; access to health care by ethnic minorities; and the implementation of federal health care policy on states, local communities, health plans, and health care providers. She holds a bachelor's degree in psychology from Bryan College, and the degrees of MSW and JD from the University of Maryland.

\section{James T. Bartis}

James T. Bartis is a senior policy analyst at RAND. His research interests are in the areas of national security, including terrorism response, energy policy, and research and development planning. He is a graduate of Brown University ( $\mathrm{ScB}$ in chemistry) and the Massachusetts Institute of Technology (PhD in chemical physics).

\section{Herbert I. Linn}

Herbert I. Linn is associate director for Communications at the NIOSH Division of Safety Research and project officer for this study. His principal efforts focus on 
communicating information on the risk and prevention of traumatic occupational injuries. Recently, he has conceived and participated in studies on the use of computer tailoring in preparing risk and prevention information, and the use of narratives in toolbox training programs. He holds a bachelor's degree in English from Fairmont State College and a master's degree in safety from Marshall University.

\section{The National Institute for Occupational Safety and Health}

The National Institute for Occupational Safety and Health (NIOSH) is the federal agency responsible for conducting research and making recommendations for the prevention of work-related injury and illness. NIOSH is part of the Centers for Disease Control and Prevention (CDC) in the Department of Health and Human Services.

The Occupational Safety and Health Act of 1970 created both NIOSH and the Occupational Safety and Health Administration (OSHA). OSHA is in the U.S. Department of Labor and is responsible for developing and enforcing workplace safety and health regulations. NIOSH is in the U.S. Department of Health and Human Services and is an agency established to help assure safe and healthful working conditions for working men and women by providing research, information, education, and training in the field of occupational safety and health. NIOSH provides national and world leadership to prevent work-related illness, injury, disability, and death by gathering information, conducting scientific research, and translating the knowledge gained into products and services. NIOSH's mission is critical to the health and safety of every American worker. Each day, an average of 9,000 U.S. workers sustain disabling injuries on the job, 16 workers die from an injury suffered at work, and 137 workers die from work-related diseases. The Liberty Mutual 2002 Workplace Safety Index estimates that direct costs for occupational injuries in 1999 rose to $\$ 40.1$ billion, with indirect costs reaching over $\$ 200$ billion.

The Institute's responsibilities include:

- Conducting a focused program of research to reduce injuries and illnesses among workers in high-priority areas and high-risk sectors, including mining, agriculture, construction, and health care.

- Implementing and maintaining a system of surveillance for major workplace illnesses, injuries, exposures, and health and safety hazards.

- Increasing prevention activities through workplace evaluations, interventions, and recommendations. 
- Providing workers, employers, the public, and the occupational safety and health community with information, training, and capacity to prevent occupational injuries and illnesses.

$\mathrm{NIOSH}$ is headquartered in Washington, DC, with research laboratories and offices in Cincinnati, OH; Morgantown, WV; Pittsburgh, PA; Spokane, WA; and Atlanta, GA. NIOSH is a professionally diverse organization with a staff of over 1,400 people representing a wide range of disciplines including epidemiology, medicine, industrial hygiene, safety, psychology, engineering, chemistry, and statistics.

For further information regarding the National Institute for Occupational Safety and Health or worker safety and health, please contact:

John Howard

Director, National Institute for Occupational Safety and Health

Hubert H. Humphrey Building

Room $715 \mathrm{H}$

200 Independence Avenue, S.W.

Washington, DC 20201

Web: http://www.cdc.gov/niosh

Phone: 1-800-35-NIOSH (1-800-356-4674)

\section{The Science and Technology Policy Institute}

Originally created by Congress in 1991 as the Critical Technologies Institute and renamed in 1998, the Science and Technology Policy Institute is a federally funded research and development center sponsored by the National Science Foundation. The S\&TPI was managed by the RAND Corporation from 1992 through November 30, 2003.

The institute's mission is to help improve public policy by conducting objective, independent research and analysis on policy issues that involve science and technology. To this end, the Institute

- supports the Office of Science and Technology Policy and other Executive Branch agencies, offices, and councils

- helps science and technology decisionmakers understand the likely consequences of their decisions and choose among alternative policies

- helps improve understanding in both the public and private sectors of the ways in which science and technology can better serve national objectives. 
xxxii Protecting Emergency Responders, Volume 3

In carrying out its mission, the Institute consults broadly with representatives from private industry, institutions of higher education, and other nonprofit institutions.

Inquiries regarding the work described in this report may be directed to the address below.

Stephen Rattien

Director

RAND Science and Technology

1200 South Hayes Street

Arlington, VA 22202-5050

Web: http://www.rand.org/scitech/

Phone: (703) 413-1100 x5219 


\section{Acronyms and Abbreviations}

\begin{tabular}{|c|c|}
\hline ALSAC & Air Land Sea Application Center \\
\hline CISD & Critical Incident Stress Debriefing \\
\hline DHHS & Department of Health and Human Services \\
\hline DMAT & Disaster Medical Assistance Team \\
\hline EMS & Emergency Medical Services \\
\hline EPA & Environmental Protection Agency \\
\hline FEMA & Federal Emergency Management Agency \\
\hline GIS & Geographic Information Systems \\
\hline GPS & Global Positioning System \\
\hline HSPD & Homeland Security Presidential Directive \\
\hline IAFC & International Association of Fire Chiefs \\
\hline ICS & Incident Command System \\
\hline IMS & Incident Management System \\
\hline ISO & Incident Safety Officer \\
\hline JIC & Joint Information Center \\
\hline LIDAR & Light Detection and Ranging \\
\hline MIPT & $\begin{array}{l}\text { Oklahoma City National Memorial Institute for the Prevention of } \\
\text { Terrorism }\end{array}$ \\
\hline NFPA & National Fire Protection Association \\
\hline NFSIMC & National Fire Service Incident Management Consortium \\
\hline NIMS & National Incident Management System \\
\hline $\mathrm{NIOSH}$ & National Institute for Occupational Safety and Health \\
\hline NMRT & National Medical Response Team \\
\hline NRP & National Response Plan \\
\hline NVFC & National Volunteer Fire Council \\
\hline
\end{tabular}


xxxiv Protecting Emergency Responders, Volume 3

OSHA Occupational Safety and Health Administration

S\&TPI Science and Technology Policy Institute

US\&R Urban Search and Rescue

USCG U.S. Coast Guard 
Since our nation's beginnings, emergency responders have helped protect the people of the United States from the effects of natural and manmade disasters. From the bucket brigades of colonial times to today's highly complex, multiagency response community, response workers have taken action in emergencies to save lives, preserve property, and protect the public good. The devastating attacks on the World Trade Center and the Pentagon on September 11, 2001, cast a powerful new spotlight on the vital role that responders play in containing and mitigating unexpected crises. Members of the response community disregarded injuries and fatigue, and even gave their lives in their effort to reduce the initial impact of these disasters and bring the situations under control.

The tragic events of September 11 showed that response organizations are a central component of our homeland security system against both natural and manmade threats. This renewed reliance on emergency responders has focused fresh attention on the imperative to protect these individuals from the hazards inherent in their work, not just for the good of the community, but of the nation. While responders should be protected for their own sakes, their safety is also crucial to the effectiveness of the response force as a whole. Injuries to individual members affect their organizations' ability to perform overall, both immediately and in the long term. A responder injured is not only prevented from assisting in today's emergency, but may also be unavailable to respond to an attack tomorrow.

In the military context, this understanding is embodied in the concepts of force protection and force health protection. In applying these concepts, the military aims to preserve its force's fighting strength by protecting individual servicemen and women against the threat of enemy action and by taking steps to minimize the effect of hazards on unit effectiveness, readiness, and morale. The unprecedented potential for multiple terrorist attacks drives home the need for comparable thinking in the response community. Sustainability becomes key: Incidents must be managed with an eye on ensuring the readiness of response organizations to meet future challenges. 


\section{Major Disasters Present Special Challenges for Safety Management}

Fortunately, disasters of the magnitude of the September 11 events are rare. Usually emergency responders confront incidents on a comparatively small scale that can be handled on a local level and pose more limited safety risks. But a major disaster presents a significant challenge to a locality, a state, a region, and sometimes even a nation. Responding to such an incident tests the capacity of responding organizations and can place large numbers of emergency responders in harm's way. Protecting the safety of responders in those situations is much more difficult.

In contrast to the types of incidents that emergency responders normally face, major disasters share a number of characteristics that create unique difficulties for response organizations. ${ }^{1}$

\section{Large Number of People Affected, Injured, or Killed}

While small-scale emergencies involve a few individuals or small groups of people, major disasters severely affect large numbers of citizens across communities, cities, or entire regions. The Northridge earthquake caused more than 60 fatalities and 9,000 injuries and displaced 17,000 to 18,000 people from their homes [Stratton et al. 1996]. The attack on the World Trade Center claimed the lives of more than 2,800 individuals and put many thousands more at risk ["The Numbers" 2002].

\section{Large Geographic Scale}

Most emergency incidents involve only a single building or other well-defined site. Major disasters, however, often extend over very large areas. In 1992, Hurricane Andrew left a trail of devastation that extended over 1,000 square miles [Lewis 1993]. Responders to the Oklahoma City bombing confronted a rubble pile more than 35 feet deep made up of approximately one-third of the federal building structure [Oklahoma Department of Civil Emergency Management 2000].

\section{Prolonged Duration}

Average emergency response operations are relatively short, lasting only minutes or hours from first responders' arrival on scene to completion of response actions [Study Interviews]. ${ }^{2}$ In contrast, activities in major disasters can stretch into days, weeks, or even months. Although the total repair and clean up after Hurricane Andrew lasted much longer, the U.S. military relief operation lasted for 50 days [Higham and Donnelly 1992]. In New York City after September 11, 2001, the response was not officially completed until eight months after the attack [Barry 2002].

\footnotetext{
${ }^{1}$ For a comprehensive list of potential disasters, see NFPA, $2000 \mathrm{~b}$.

2 All citations of "Study Interviews" are to not-for-attribution interviews held with members of the response community between November 2002 and March 2003.
} 


\section{Multiple, Highly Varied Hazards}

Whereas common emergencies usually present emergency responders with a limited number of risks, major disasters involve multiple hazards that can vary widely in nature. The World Trade Center site, for example, exposed response workers to a complex mixture of physical and respiratory perils [Lioy and Gochfeld 2002]. Responders to the Northridge earthquake confronted active fires, collapsing buildings, and hazardous materials [Federal Emergency Management Agency (FEMA) 1994a]. Because of this wide variety, few responders will have experience with everything they might encounter in the aftermath of a major disaster.

\section{Wide Range of Needed Capabilities}

Major disasters require supplementary response capabilities not routinely maintained by local response organizations. ${ }^{3}$ Many natural disasters and major terrorist incidents require extensive rubble removal and management operations that local response organizations are not equipped to carry out. FEMA-sponsored urban search and rescue teams were needed to respond to both the Northridge earthquake and the September 11 attacks. Such requirements frequently turn the response effort after a major disaster into a multiagency operation that can span all levels of government, nongovernmental organizations, and the private sector. ${ }^{4}$

\section{Influx of Convergent Volunteers and Supplies}

In contrast with smaller emergencies generally handled by a local response organization, major disasters often attract large numbers of independent, or "convergent," volunteers. These volunteers may be members of other response organizations that come to a disaster site spontaneously or ordinary citizens who come out of a desire to help [Maniscalco and Christen 2001].5 Likewise, a major disaster also frequently prompts individuals and organizations to send large quantities of food and other supplies. Hurricane Andrew was a prominent example, where the influx of people and supplies was so overwhelming that responders referred to it as "the disaster after the disaster" [Study Interviews].

\section{Damage to Infrastructures}

While localized disasters leave infrastructures vital to effective emergency response intact, major disasters can damage or destroy them. Hurricane Andrew severely dam-

\footnotetext{
3 See Auf der Heide, 1989, p. 34, for further discussion.

${ }^{4}$ Throughout the text, we adopt the term "multiagency" to describe disaster response operations. This term is intended to convey the involvement of not just many government agencies but nongovernmental and private organizations as well.

5 Operating outside of the established command or management structure, generally termed "freelancing," is widely criticized in the responder community.
} 
aged the local transportation infrastructure, with road signs destroyed and major roads blocked. The Northridge earthquake caused numerous ruptures in water mains and citywide power outages.

\section{Direct Effects on Responder Organizations}

Unlike routine incidents, major disasters can directly affect the operational capacity of response organizations. The emergency responders lost in the World Trade Center collapse are one tragic example. Another occurred in Hurricane Andrew where the homes of at least 128 police officers were damaged or destroyed. Many of the officers reported for duty not knowing what had happened to their families [Taylor 1992].

\section{Responder Safety Management Is Risk Management}

The inherently hazardous nature of any emergency situation necessitates that safety be approached from a risk management perspective. Rather than eliminating risk altogether, response managers aim to shield responders from hazards to the greatest extent possible. When making decisions, the level of risk in any given action should be weighed against the potential benefit. ${ }^{6}$ This process of safety management can be broken down into three central components, as shown in Figure 1.1:7

- gathering information about the nature of the situation, the responders at the scene, and the hazards involved

- analyzing response options and potential protective measures and making decisions

- taking action to implement safety decisions, reduce hazards, or provide health protection to responders.

These three activities take place in a continuous cycle until the response effort comes to a close. ${ }^{8}$ As part of this continuous management effort, safety managers constantly reexamine and evaluate their efforts to protect responders as operations at an incident scene continue. ${ }^{?}$

\footnotetext{
${ }^{6}$ See NFPA, 2000a, for a more detailed discussion of risk management.

${ }^{7}$ Command of any incident "is essentially about information: getting it, judging its value, processing it into useful form, acting on it, and sharing it with others, so it percolates throughout the whole command structure" [Smitherman 2000]. This statement applies equally to safety management specifically and forms the basis of our model.

${ }^{8}$ This type of basic model is similar to many other decisionmaking models in the safety [NFPA 2000a], military [Rielage 2001], and other contexts.

${ }^{9}$ It should be noted that the safety management process described here focuses on the activities of response safety managers during response operations. Although the cyclic nature of the safety management process shown above
} 
Figure 1.1

Response Safety Management Cycle

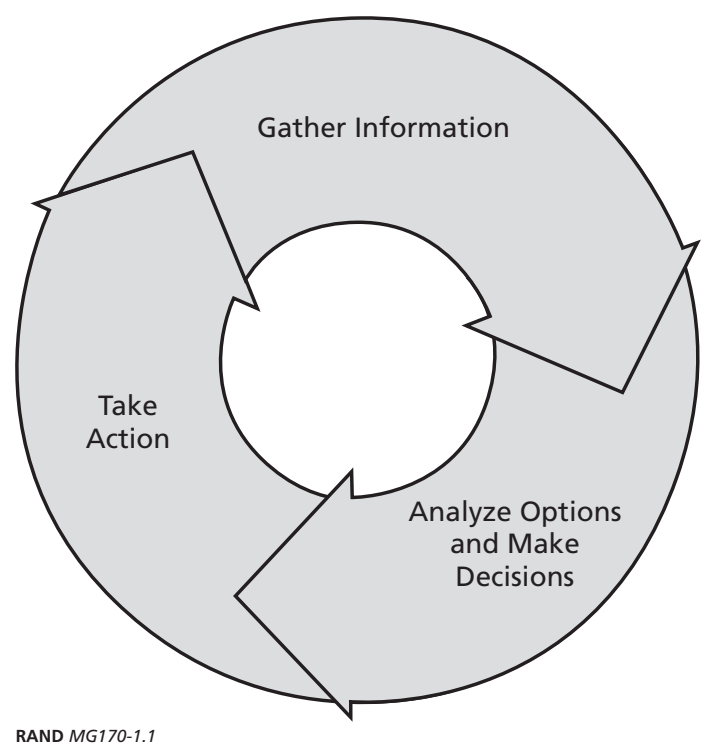

In the course of their routine activities, organizations develop standard approaches for carrying out these functions. But safety management during the response to a major disaster is a far larger and more complex undertaking. Safety management practices that are well developed and effective for standard response activities will very likely be insufficient. In short, the highly demanding and unfamiliar environment after a major disaster makes it difficult, or even impossible, for individual responder organizations to effectively perform the three functions of the safety management cycle.

Major disasters create substantial hurdles on the organizational level as well. For example, the multiagency nature of responses to major disasters makes safety management significantly more complex. In an effort of this magnitude, where many different organizations unfamiliar with each other's operating practices are working side by side, a new set of secondary hazards can arise from the response operation itself. These secondary hazards, such as those generated by fire or law enforcement activities occurring simultaneously with ongoing construction or utility operations, can pose serious risks to all involved responders. In addition, the management problems arising from operations involving many different organizations can also result in communications failures, logistical problems, and other conflicts that can directly or indirectly impact responder safety. These only compound the broad range of primary hazards stemming directly from the disaster.

does point out that safety efforts must be constantly evaluated during an incident, there is also a learning process that must occur after an incident is concluded to improve preparedness for future incidents. 


\section{The Response Community Recognizes a Pressing Need for Improved Safety Management}

The events of September 11 brought these safety challenges to the fore with an urgency that the emergency response community, and the nation, had not known before. As one of many initiatives that took place in the disaster's aftermath, the National Institute for Occupational Safety and Health (NIOSH) joined with the Science and Technology Policy Institute (S\&TPI), formerly managed by the RAND Corporation, to organize a conference in New York City on protecting emergency workers during responses to conventional and biological terrorist attacks [Jackson et al. 2002]. During the discussions, participants frequently expressed deep concern over safety management practices during major crises in general. The research presented in this report is a direct outgrowth of that concern.

In the following pages, we offer recommendations that response organizations can put in place at both the functional and organizational levels to improve safety management in future response operations. In accordance with an all-hazards perspective, we consider the full range of natural and manmade disasters to ensure that the approach we suggest is flexible and comprehensive.

\section{Tomorrow's Success Depends on Today's Preparations}

The emotionally charged, chaotic environment in the immediate aftermath of a major disaster is not the time to start working on procedures or guidelines to improve responder safety. Strategic planning and management well before the event, along with standardized systems and procedures, are key. Preparedness is the crux of effectiveness.

The distinctive characteristics of major disasters make the case for preparedness especially strong. The multiple hazards inherent in situations of this magnitude call for a flexibility from the response community that can only come through preplanning. That major disasters take so many different forms underscores this point. The response community will inevitably be called upon to carry out substantially different activities - that pose highly varied hazards - as different crises arise. Effective safety management requires having the capabilities and resources in place to deal with this variety.

In addition, because major disasters are rare and the safety risks responders face may be unprecedented, response organizations get little to no practice managing them. In this context, scenario-based planning and training assume added value. Similarly, it is also important to build safety management practices that can meet the needs of disasters into organizations' standard operating procedures to the extent possible. While use of safety management practices during smaller-scale events will never 
be directly analogous to applying them in disasters, the experience will nonetheless make it more likely they can be effectively applied when they are needed most. Although no disaster situation is entirely predictable, the more prepared safety managers are to deal with expected hazards, the more attention and energy they will be able to devote to handling unanticipated issues as they arise.

Finally, the fact that major disasters demand a multiagency response operation makes a common understanding of the needs of different organizations-and the parts different response organizations can play in safety management-a precondition for successfully protecting responders.

The recommendations we present in this report focus on the changes organizations can begin making today-both individually and collaboratively-to lay the groundwork for better serving responders' safety needs and managing multiagency safety efforts in the future.

\section{Organization of the Report}

Chapter Two describes study methodology. Chapter Three explains disaster management and safety within disaster management systems. Chapters Four to Six discuss the study's functional safety management recommendations in detail, organized according to the decisionmaking cycle described above. Chapter Seven presents the central organizational finding of the study - that providing effective safety management during major disaster response requires an integrated, multiagency and multiorganizational approach. Chapter Eight discusses preparedness and presents suggestions for the way forward. Appendixes A and B include a list of the interviewees and the workshop participants, as well as the workshop agenda. 

The objective of this study was to develop a framework for thinking about safety management in major disasters, both manmade and natural, and to use this framework to develop recommendations for improving safety management for a wideranging group of emergency responders. During that process, the study team remained cognizant of the fact that disasters are extraordinary events for individual jurisdictions. Recognizing the difficulty of dedicating significant resources to building event-specific capabilities for rare events, the team sought recommendations to deliver needed safety management capabilities by drawing on the resources in a range of response organizations rather than advocating building every capability in all organizations.

In carrying out this project, the research team drew extensively on a range of sources of information and analytical expertise. Beyond information available in the published literature and within RAND and NIOSH, the study relied heavily on expertise from the responder community on emergency response operations, incident management, safety and health, and related areas.

\section{Project Scope}

In our examination of responder safety management during disaster response, we defined the scope of the study with the following terminology:

- Emergency Responders. Because of the nature of large-scale response operations, we adopted a broad definition of disaster rescue and recovery workers. Beginning with the career responders and volunteers typically labeled as emergency responders-emergency management, fire service, law enforcement, and emergency medical service responders-we also included a range of other workers likely to be involved in disaster response. These individuals encompass federal, state, and local personnel; public health professionals; skilled support personnel 
(including construction/demolition workers, transit workers, and utility services workers); disaster relief workers; and members of volunteer organizations. ${ }^{1}$

- Convergent Volunteers. In addition, we looked at "convergent" volunteers-individuals who respond to a disaster but who are not connected to an organization involved in the response or who are not directed by their organization to participate.

- Safety Management. We defined "safety management" as the methods, principles, and organizational structures through which the manager or managers of a response operation protect the safety and health of the responders. We understand the focus of safety management to be risk management-ensuring that responders clearly understand the risks involved in their activities, eliminating or reducing as many of those risks as possible, recognizing any risks that cannot be fully controlled, and weighing the need for responders to carry out their duties against the dangers involved. Effective risk management ensures that a response organization accepts no unnecessary risk, makes risk decisions in a way that guarantees clear accountability, and manages risk by planning [ALSAC 2001]. ${ }^{2}$

The focus of the study was to develop recommendations directed at the strategic goal of improving safety management. An analysis of the practical details of how each recommendation should or might be implemented is beyond the scope of this project and requires consideration of regional- and locality-specific factors. The overall issues associated with implementation are briefly discussed in the final chapter of the report.

Because of the project's focus on safety management, a range of important issues fall outside the scope of the study. For example, responders raised a number of technical issues during the research-specific concerns about protective equipment, problems with communications interoperability, specific techniques for monitoring hazards, and individual technical solutions for management issues. We recognize such issues briefly in this report if they pertain to our central theme of safety management structures and processes, but we do not discuss them in depth.

\footnotetext{
${ }^{1}$ In addition to "emergency responders," we also use the term "emergency response community," particularly in discussions of previous efforts in disaster management and safety planning. By this, we mean both individuals currently employed by or active in response organizations and the larger group of people who have contributed to the existing body of knowledge on response strategy, operations, and tactics.

${ }^{2}$ We also use the term "operational management," by which we mean the processes, methods, and organizational structures used to manage response activities at a disaster. Central to that discussion is the Incident Command System, which is described in Chapter Three. While operational management is not the topic of this study, how safety management fits into overall disaster management and comparisons between the way safety is managed and the management of response operations overall were important in developing the study's findings.
} 


\section{The Research Team}

Recognizing the multidisciplinary nature of safety management, the research team was composed of a mix of researchers whose work is based in the NIOSH Division of Safety Research; RAND Science and Technology; RAND Health; RAND National Security Research Division; and RAND Arroyo Center, which supports the United States Army and provided important expertise on command structures and processes, along with a very useful understanding of how military organizations have wrestled with problems similar to those facing civilian responder organizations.

\section{Methodology}

Having established the scope of the project, we took three approaches to gathering information and data:

1. review of the professional and technical literature

2. interviews with members of the response community

3. discussions at a workshop focused on improving safety management in disaster response.

\section{Review of the Professional and Technical Literatures}

We examined more than 800 published sources on topics including:

- emergency response strategies and tactics

- incident command and management

- safety issues during emergencies

- characteristics of individual disaster responses

- command of major multiagency operations

- health and medical care issues in disasters.

The literature review captured relevant safety lessons from previous disasters and provided the study team access to the formidable body of previous work on incident management and command. The review also enabled identification of areas that would require specific attention in later phases of the study. ${ }^{3}$

3 The bibliography presents a selection of the literature relevant to the analyses and recommendations of this report. 


\section{Interviews with Members of the Response Community}

Interviews with experts from the responder community were utilized as a major source of safety management information. To provide a structure for the interview process, we used information that we assembled during the literature review to select four major disaster-response operations:

- the September 11, 2001, attack on the World Trade Center (New York) ${ }^{4}$

- the September 11,2001, attack on the Pentagon (Virginia) ${ }^{5}$

- Hurricane Andrew (Florida) 6

- the Northridge earthquake (California). ${ }^{7}$

We chose these four crises because of their scale, national impact, and the challenges they presented for responder safety. Our aim was not to produce case studies, but to provide relevant examples that would elicit important insights from interviewees. These four disasters formed the basis of an extensive interview process with individuals who had been directly involved in the operational and safety management of each event.

We interviewed approximately 70 emergency responders about these four operations and supplemented these interviews with approximately 20 more with other experts from the response community on the general topic of safety management. ${ }^{8}$ We then combined analysis of the information developed in these interviews with data drawn from the literature review to develop a set of preliminary recommendations for improving safety management in future incidents.

\footnotetext{
${ }^{4}$ On September 11, 2001, the World Trade Center's twin towers collapsed after being struck by two hijacked commercial airliners, with the result that more than 2,800 people were killed and many more injured. Among the fatalities were more than 400 emergency responder (fire, police, emergency medical services, and Port Authority) personnel, while many more emergency workers were exposed to multiple hazards while subsequently working at the collapse site.

${ }^{5}$ On September 11, 2001, a third hijacked airliner crashed into the Pentagon and caused 189 deaths, including all aboard the aircraft and personnel working in the Pentagon. Emergency responders involved in rescue operations contended with substantial damage to the Pentagon structure from the impact of the aircraft crash, a partial building collapse that occurred later that day, and protracted fire suppression operations.

${ }^{6}$ Hurricane Andrew, which struck Florida and Louisiana in August 1992, was one of the most destructive natural disasters to occur in the United States and presented an overwhelming event for local and state emergency response organizations. The greatest devastation occurred in south Florida, resulting, both immediately and during the storm's aftermath, in more than 45 deaths and thousands of injuries, over $\$ 25$ billion in property and infrastructure damage, and a need for protracted recovery efforts.

7 The Northridge earthquake occurred in the predawn hours of January 17, 1994, with its epicenter located under the suburban communities northwest of Los Angeles. The earthquake damage covered a large area (hundreds of square miles); included building collapses, major fires, and infrastructure damage; and resulted in 57 deaths and the displacement of numerous people [FEMA 1994a].

${ }^{8}$ The names of the interviewees are included in Appendix A.
} 


\section{Responder Workshop}

A workshop was held at RAND's Washington, D.C., office on February 27, 2003. We sought participants for their experience, expertise, and interest in safety and health management issues. ${ }^{9}$ More than 100 members of the responder community attended the workshop, representing organizations from the emergency management, firefighting, law enforcement, emergency medical service, public health, skilled support and trades, public works, and disaster relief communities. Representatives from local and state governments and professional organizations also participated. Key federal organizations relevant to disaster and terrorism response were represented as well, including NIOSH; the Centers for Disease Control and Prevention; the U.S. Coast Guard (USCG); the Department of Defense and three defense services-the Army (including the Army Corps of Engineers), the Navy, and the Marine Corps; the Department of Justice; the Environmental Protection Agency (EPA); FEMA; the National Institute of Environmental Health Sciences; the Occupational Safety and Health Administration (OSHA); and the White House Office of Science and Technology Policy.

We drew the main topics for workshop discussions from the results of the initial phases of our research, including our preliminary recommendations for improving safety management. Attendees participated in three groups of their choice from among the following five:

- safety management within disaster incident management/command systems

- improving coordination and control of personnel and resources during disaster response

- hazard information, intelligence, and risk assessment

- improving training for disaster response

- responder health care.

A RAND researcher with subject matter expertise in the topic guided each panel. The groups were free to focus attention on the topics within each area that they felt were most interesting or important. To encourage candid discussion, the breakout sessions were held with the understanding that no statements would be attributed to specific individuals or organizations. ${ }^{10}$ Not only were the workshop discussions an effective way of gathering information and input from the disaster re-

\footnotetext{
${ }^{9}$ The names and affiliations of workshop attendees are included in Appendix A.

10 Therefore, all citations of "Study Workshop" are to study workshop discussions at the RAND-NIOSH workshop Protecting Emergency Responders: Safety Management in Major Disaster and Terrorism Response in Arlington, VA, on February 27, 2003. In addition, all citations of "Study Interviews" are to not-for-attribution interviews held with members of the response community between November 2002 and March 2003.
} 
sponse community, they also provided an invaluable opportunity to obtain comments and feedback on our preliminary recommendations.

\section{Analytical Framework}

In examining the data collected from the literature and the responder community, the study team relied on the three-stage model of safety management shown in Figure 1.1 to structure the analytical effort. The model's core components-gathering information, analyzing options and making decisions, and taking action-are similar to those found in a range of other management decisionmaking models. By providing a framework to systematically examine the management practices and requirements to effectively manage responder safety, the model helped assure that the study fully explored both the opportunities and shortfalls associated with responder safety in disaster response. 


\section{Protecting Responder Safety Within the Incident Command System}

Safety management is one aspect of a multifaceted set of functions that need to be carried out during the response to any emergency. Without effective management of the overall operation, safety management cannot be successful. As a response operation involves increasing numbers of responders or response units, it becomes all the more imperative to run the operation from an overarching strategic perspective. Without such leadership, even responders from a single organization are less effective in anything they do, including protecting responder safety [Brunacini 2002].

At a major disaster, the magnitude of the hazards, the urgent threat to public safety, and the involvement of scores of organizations further amplify the importance of having managers and structures in place to deal with the barrage of situations and coordinate multiple responders. Even if conducted with the best of intentions, efforts to respond to such incidents in the absence of strategic management have been described as "nothing more than well-meaning chaos" [Maniscalco and Christen 2001, 25].

Recognizing this need, response organizations in recent years have increasingly employed a comprehensive framework for managing the many different activities that organizations carry out during a response operation. Called the "Incident Command System" (ICS), it is broadly recognized within today's response community as the preferred approach to disaster management. One of its hallmarks is its flexibility: Not only can it be used in small-scale emergencies, it is also designed to be scaled up as events increase in size and complexity. Accordingly, responders have employed it during both local crises and major catastrophes.

Built into the ICS is an approach to managing the safety of responders. Response organizations carry out the three functions of the safety management cycle-gathering information, analyzing options and making decisions, and taking action-within this framework. Because the ICS is a recognized standard for managing emergency response operations, we used the ICS approach to managing responder safety as the baseline for our research. As we explored how the emergency response community can build upon its existing strengths and further expand its capabilities, we considered the ICS as the benchmark. 


\section{Origins of the Incident Command System}

Initial efforts to create a systematic approach to managing emergency response operations grew out of the wildland firefighting community, which historically had faced serious problems managing multiagency participation in responses to major fires. These issues included

- lack of common command structures

- lack of common terminology and communications practices

- lack of a mechanism to effectively assign resources

- no means of coordinating functions and tasks

- lack of a clear leader

- unproductive competition for resources among responding organizations [Maniscalco and Christen 2001; Christen et al. 2001].

In 1972, Congress charged a group of firefighting agencies named the FIRESCOPE coalition "to develop a system for multiagency coordination of complex emergencies that exceeded the capabilities of any single jurisdiction" [Cole 2000].

In response, FIRESCOPE developed the ICS. Since its inception, ICS has evolved considerably through a range of initiatives [Kipp and Loflin 1996]:

- integrating command systems designed for smaller-scale, single organization operations [Brunacini 2002]

- incorporating components to address the needs of different types of operations - for example, multicasualty incidents, hazardous materials response, highrise fires, and marine operations

- supplementing the core command system with training and doctrine for particular types of operations [U.S. Forest Service 2003]

- codifying the system into standards and model practices [National Fire Protection Association (NFPA) 2002c; National Fire Service Incident Management Consortium (NFSIMC) 2000]

- adapting the system for use by different response disciplines, such as law enforcement and hospital response operations [Christen et al. 2001; Cardwell and Cooney 2000]. ${ }^{1}$

\footnotetext{
${ }^{1}$ In some areas and jurisdictions, the ICS is referred to as the incident management system [e.g., Christen et al. 2001]. The recommendations for improving safety management in this report are intended to be relevant to all jurisdictions whatever terminology they currently use.
} 


\section{How the Incident Command System Works}

The ICS includes five major sections, each with a defined function [FEMA 1998], as shown in Figure 3.1:

- Incident Commander and Command Staff

- Operations

- Logistics

- Planning

- Administration/Finance.

These operational sections provide a template for organizing activities and resources during a response. By providing a standard organizational structure, the ICS facilitates interagency coordination: Agencies can "plug" their resources and assets into the appropriate ICS sections and coordinate with other responder organizations as they carry out their tasks. ${ }^{2}$

To accommodate the great variation in emergency incidents, the ICS is flexible and scalable. The roles shown in Figure 3.1 are only filled as required during a response. For example, at smaller-scale incidents, not every position will need to be staffed. In contrast, given the scale and duration of major disaster operations, all the elements of the command structure will likely be filled.

The four functional sections of the ICS-Operations, Logistics, Planning, and Administration/Finance—can be subdivided as needed into different branches, divi-

Figure 3.1

Incident Command System Structure

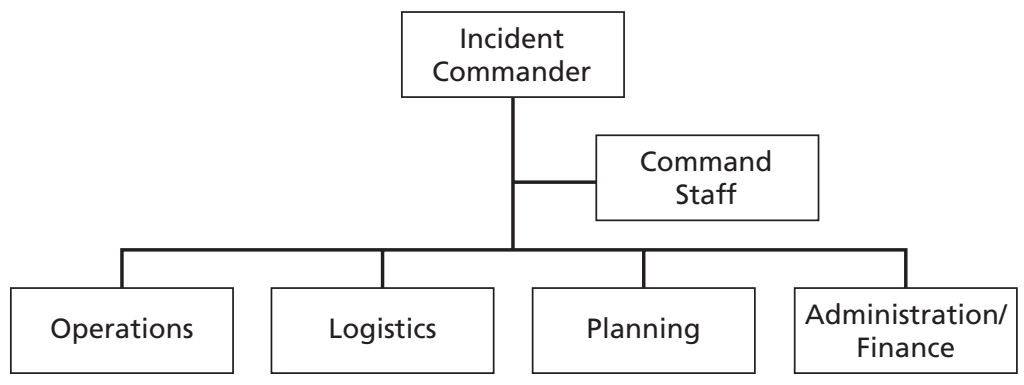

RAND $M G 170-3.1$

\footnotetext{
2 While a common structure is a necessary condition for effective coordination, it is not sufficient on its own. Also required are common terminology; integrated communications; and designated incident facilities, such as command posts and staging areas, used by all responding organizations [FEMA 1998].
} 
sions, groups, or task forces. Such breakdowns can be used to group types of resources or organize resources that have been assigned to particular roles within an incident response. By building in intermediate levels of management, the ICS provides a mechanism to ensure that individual managers have a reasonable number of individuals and responsibility areas under their command. Maintaining a workable span of control is critical for effective management. ${ }^{3}$

Unified Command. To further facilitate multiagency coordination, the ICS includes the concept of "Unified Command." This concept provides a mechanism for a response to be managed by a command team of representatives from multiple organizations, rather than by a single Incident Commander. ${ }^{4}$ In essence, a Unified Command team brings together Incident Commanders from response organizations that have disparate jurisdictional or other responsibilities. ${ }^{5}$ In this way, a Unified Command provides a mechanism for response agencies to determine a collective set of strategies, which ideally prevents agencies from working at cross purposes and ensures that all available resources are effectively applied to deal with the disaster [Auf der Heide 1989].

Use of a Unified Command does not necessarily mean that all participating organizations will be equally involved in all management decisions. Depending on the nature of the incident, there will likely be a lead agency with primary authority or responsibility. ${ }^{6}$ In that case, representatives from other agencies would defer to the Incident Commander from the agency with primary authority and responsibility at the incident [U.S. National Response Team, not dated]. In other cases, different individuals might take on this role of "focal point" of the Unified Command during different phases of the incident [Kane 2001].

\section{The National Incident Management System}

On February 28, 2003, during the later phases of data gathering for this study, the White House released Homeland Security Presidential Directive (HSPD)-5, 2003.

\footnotetext{
${ }^{3}$ Span of control refers to each manager having a reasonable number of individuals whose activities they are supervising. To ensure effective oversight, managers should only have between three and seven individuals under their command [FEMA 1998].

${ }^{4}$ Participation in a Unified Command does not take away the authority, responsibility, or accountability of those organizations for activities in the response [FEMA 1998, 1-13].

5 The requirements to participate in an operational Unified Command have been defined primarily in terms of legal responsibilities for the incident. See USCG, 2001, for an exemplary set of such requirements.

6 The details of implementing a Unified Command in response operations-such as organizational roles, responsibilities, and relationships — can differ significantly from area to area and among types of response operations. As a result, the details must be defined during multiagency preparedness planning to ensure that response operations can be managed effectively.
} 
This directive aims to further institutionalize a standard management approach to major incidents by establishing a "single, comprehensive national incident management system" [HSPD-5 2003]. The Secretary of Homeland Security is charged with administering a National Incident Management System (NIMS) as part of the National Response Plan (NRP). The NRP is intended to integrate federal government activities involving domestic prevention, preparedness, response, and recovery plans into a single, all-discipline, all-hazards plan.

According to the presidential directive, the NIMS will provide a nationwide approach that enables federal, state, and local government agencies to "work effectively and efficiently together to prepare for, respond to, and recover from domestic incidents, regardless of cause, size, or complexity" [HSPD-5 2003, 2]. The NIMS is expected to provide concepts, terminology, coordination systems, training, and other features (including Unified Command) that will encourage interoperability and compatibility among federal, state, and local agencies. ${ }^{7}$ At this writing, initial versions of the NIMS and NRP had been released.

\section{Safety Within the Incident Command System}

Responding organizations using the ICS assemble the overall command structure at an emergency scene as needed. In the same way, they put together the staff and structure for managing responder safety as an incident evolves and needs become apparent. When a response begins, responsibility for the entire operation-including responder safety-lies with the Incident Commander. For small and relatively straightforward incidents, the Incident Commander may retain safety responsibility throughout the response. But for larger, more complex incidents-though "the Incident Commander's first priority" ultimately remains "the life safety of the emergency responders and the public" [FEMA 1998, 1-10] ${ }^{8}$ - he or she may simply be unable to devote as much attention to the task as it demands. To accommodate such situations, the ICS provides a mechanism for the Incident Commander to delegate authority to an Incident Safety Officer (ISO). ${ }^{9}$ This ensures that sufficient attention is focused on the safety, health, and welfare of responders.

\footnotetext{
${ }^{7}$ More specifically, HSPD-5, 2003, directs that the NIMS include a core set of concepts, principles, terminology, and technologies covering the ICS; multiagency coordination systems; Unified Command; training, identification, and management of resources (including systems for classifying types of resources); qualifications and certification; and collection, tracking, and reporting of incident information and incident resources [HSPD-5 2003, 2].

${ }^{8}$ See also NFPA, 2002a, p. 8.1.5.

9 "As incidents escalate in size and complexity, the incident commander shall . . . assign an incident safety officer to assess the incident scene for hazards or potential hazards" [NFPA 2002a, 8.1.6].
} 
Within the ICS structure, the ISO is part of the Command Staff (Figure 3.2), reporting directly to the Incident Commander. ${ }^{10}$ In this role, the ISO serves as risk manager for the incident, with immediate authority to stop unsafe acts or hazardous activities in order to protect responders [FEMA 1999a].

As the risk manager, the ISO evaluates response activities in light of the evolving hazard environment. This activity includes carrying out all phases of the safety management cycle described above. Specifically, he or she

- assesses hazards and reports them to the Incident Commander

- provides the Incident Commander with risk assessments

- communicates instances of injury, illness, or exposure to the Incident Commander

- makes predictions about issues for responder safety that could arise during the incident

- ensures that safety systems (such as personnel accountability/tracking, rehabilitation, etc.) are in place and safety policies are followed

- monitors incident communications for events that pose safety concerns

- confirms that needed hazard information is being communicated effectively to all responders. ${ }^{11}$

Figure 3.2

Safety Responsibility in the Incident Command System

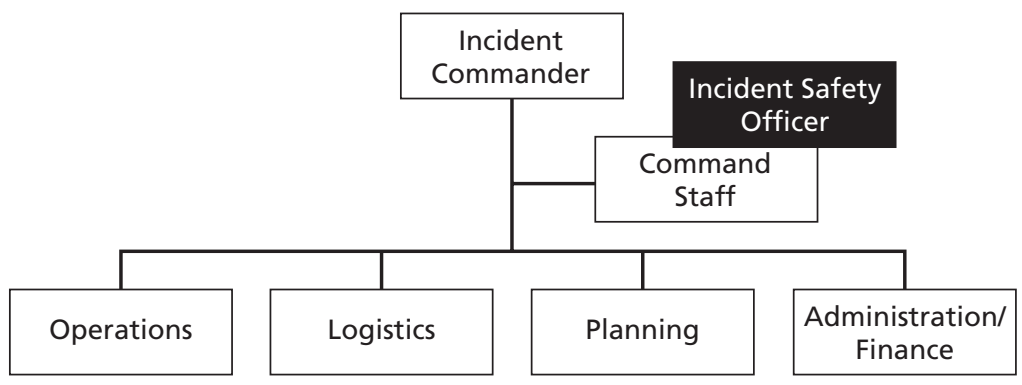

RAND $M G 170-3.2$

\footnotetext{
10 The Command Staff also includes a liaison officer, an information officer, and other command aides that support the commander and contribute to protecting responder safety. The liaison officer serves as the connection between the command structure and supporting or cooperating agencies that are not under the ICS [USCG 2001].

${ }^{11}$ Adapted from NFPA, 2002c, pp. 9-10; FEMA, 1999a; NFSIMC, 2000; and Kipp and Loflin, 1996.
} 
By maintaining awareness of the overall scene and how its changing circumstances affect responder safety, an effective ISO provides a vital strategic-level view of the safety concerns inherent in all the diverse response activities taking place at an incident. However, the nature of disaster response situations significantly increases the demands on an ISO and, in the absence of supplementary resources and capabilities, makes it much more difficult to effectively fill this role. The recommendations in the following chapters seek to build the needed functional capabilities and organizational structures to allow safety management to effectively scale up for large-scale, multiorganizational disaster response operations. 

In the world of emergency response, managing safety is fundamentally a question of managing risk. Because dangers are inevitable, decisionmakers must weigh the potential benefits of response activities against the risks involved. The ability to perform such risk-benefit analysis effectively depends on ready access to accurate and comprehensive information. Incident Commanders need to be able to base their assessments and decisions about responder safety on the right balance of relevant knowledge: "Too little information results in poor risk assessment by the decision maker and results in error, injury, and death. Too much information overloads the decision maker and makes it difficult to make effective decisions" [IAFC 2002, 5].

This first vital step of risk management, gathering information, initiates the safety management cycle. Managers depend on three types of information (see Figure 4.1):

- Hazard Information. Timely and accurate facts on the range of potential hazards present and expected at a disaster scene.

- Information on the Responder Workforce. Knowledge of the responders involved at an incident scene, coupled with information on their capabilities, equipment, and training.

- Information on Responders' Health and Injuries. Information on injuries and illness suffered by responders, hazardous exposures encountered by responders, and other data related to responders' health status.

While gathering these types of information may be fairly straightforward within the limited scope of a small-scale emergency, a major disaster is a very different story. When multiple hazards and a multiagency responder workforce increase the complexity of a response operation, the difficulty of collecting and managing any information balloons. However, the risks posed to responders by disaster situations make doing so increasingly critical. 
Figure 4.1

Gathering Information

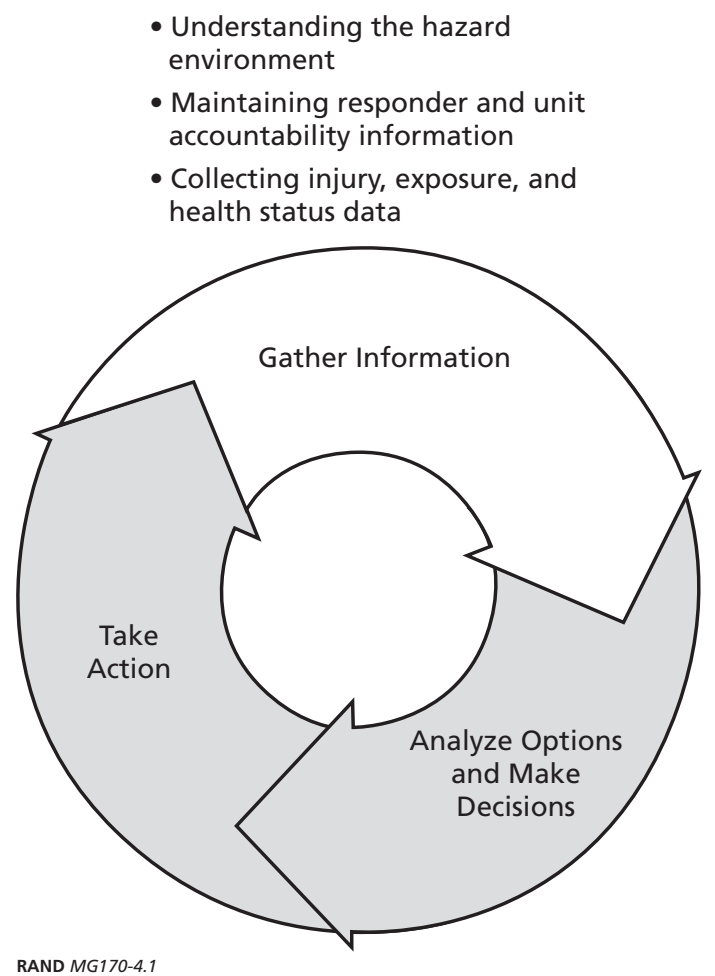

\section{Hazard Information: Understanding the Disaster Environment}

To protect responders during a response operation, safety managers must have information on the hazards at the disaster scene. They need a reliable and comprehensive understanding of the situation - what hazards are present and what others could arise. This information is equally critical as response managers plan operational actions and responders begin to treat victims. However, several key characteristics of major disasters prevent responders from gaining sufficient information on the hazard environment.

Large Geographic Scale. When a disaster scene covers a large geographic area, collecting and managing hazard information becomes problematic because of the difficulty of getting an overview of the scene. For example, responders to the World Trade Center reported individuals near the base of the buildings had problems even seeing what was going on, much less systematically collecting information on the hazard environment [Study Interviews]. Similar problems exist in hurricane and 
earthquake response operations where it is difficult to amass needed information for the entire affected area.

Large Numbers of People Affected, Injured, or Killed. Efforts of local organizations to gather hazard data can be further hindered by operational demands, such as the need to devote responder resources to aiding substantial numbers of victims. This was a real issue during Hurricane Andrew, when response units tasked with assessing hazards could not complete their tasks because so many victims in the areas these units were surveying urgently needed immediate assistance [Paulison et al. 1993, 72]. ${ }^{1}$

Multiple, Highly Varied Hazards. Because the numerous hazards at the site of a major disaster are so diverse, they will inevitably go well beyond the experience of single response agencies. This makes it very difficult for individual organizations to characterize threats. At the World Trade Center site, responders faced ongoing fires, two collapsed skyscrapers, significant airborne hazards, large numbers of casualties, and the possibility of additional terrorist attack. The Northridge earthquake involved collapsed and weakened structures, hazardous materials, electrical hazards, and fires [FEMA 1994a]. The threat of violence to responders during some disasters, such as major civil unrest or terrorist events, is particularly problematic since many responders do not encounter it during their day-to-day operations and, as a result, cannot readily assess it [FEMA $1994 \mathrm{c}$ ]. ${ }^{2}$ In addition, the traumatic nature of many postdisaster environments also presents critical incident stress issues that are poorly understood by some responding organizations and are very difficult to assess.

Furthermore, the hazard environment itself at disaster sites can inhibit attempts to collect needed information. The loss of electric power in many natural disasters hinders hazard assessment and monitoring. At the World Trade Center, the large amounts of particulate matter in the air interfered with environmental monitoring equipment that had not been designed to operate in disaster situations [Lioy and Gochfeld 2002, 77].

Wide Range of Needed Response Capabilities. The involvement of many independent response organizations in responding to a major disaster can complicate efforts to amass accurate hazard data. ${ }^{3}$ If many agencies independently carry out hazard monitoring efforts, problems in coordinating either assessment methods or the guidelines used to interpret results can produce inconsistencies in the data. If no

\footnotetext{
${ }^{1}$ This problem has also been observed in earthquake response operations [Collins 1999].

${ }^{2}$ For example, in the Los Angeles riots in 1992, ten firefighters were injured by violence, including two who were shot [Taylor and Sanchez 1992]. The risk of violence is particularly pronounced during some terrorism incidents where follow-on attacks may target responders. This has occurred in attacks in Russia, Israel, Northern Ireland, and in bombings at both an abortion clinic and a nightclub in Atlanta, Ga. [RAND and Oklahoma City National Memorial Institute for the Prevention of Terrorism (MIPT) 2003; Thomas 1997].

${ }^{3}$ Multiple agencies may gather hazard information to inform their own safety management efforts or they may have statutory or other responsibilities to collect and disseminate the information.
} 
good method exists to resolve these differences and determine the source of any apparent contradictions, hazard monitoring results become much less useful. This was a particular problem at the World Trade Center, where federal, state, local, nongovernmental, and private-sector organizations all conducted hazard assessment [Lioy and Gochfeld 2002]. By one estimate, no fewer than nine agencies had significant roles in environmental monitoring at the site [Nordgrén et al. 2002]. Similar problems were cited at the Pentagon [see Jackson et al. 2002].

Damage to Infrastructures. Difficulties in collecting needed information are exacerbated by damage to or disruption of critical infrastructures. In many disaster situations, communications systems are damaged or overloaded with traffic, preventing responders from collecting and sharing information [Arlington County 2002, A-36; Weber et al. 2002; Auf der Heide 1989].

Direct Effects on Responder Organizations. Disasters can similarly damage response organization assets needed to gather information after an incident occurs. Response planning by the Miami-Dade Fire and Rescue Department called for aerial assessment of the damage and hazards after a hurricane by members of its air rescue division. However, during Hurricane Andrew, both of the department's only two helicopters were damaged [Paulison et al. 1993].

\section{Recommendation 4.1-As Part of Preparedness Efforts, Put in Place a Coordinated, Multiagency Plan for Monitoring Hazards}

Although gathering information on some hazards after a disaster is straightforward-for example, determining the locations of collapsed buildings after a tornado-other hazards, such as airborne contamination or the presence of particular pathogens, are much more difficult to identify and measure. Currently there are no technological solutions able to "simply measure all possible disaster hazards simultaneously" [Study Interview]. Consequently, to acquire information on the full range of foreseeable hazards that might be present during or after a disaster, safety managers must have, or be able to access, the assessment capabilities, supplies, and expertise needed to identify, understand, and monitor those potential hazards.

To make this possible, hazard monitoring must be a critical element of preparedness activities. Response organizations must put plans in place to carry out hazard assessment in disaster situations. The preparedness effort must include the following:

1. Define the types of hazards that major disasters may present and determine the timeframes over which safety managers will need information about each hazard.

2. Put capabilities in place at the local level to enable safety managers to gather the information they will need immediately.

3. For capabilities that will not be available at the local level, establish ways for individual agencies to access hazard assessment resources from other response organizations. 
Define Hazard Types and Information Needs. Because not all hazards can be measured simultaneously, choices must be made about what hazards are examined first at particular events. By defining how rapidly hazard information will be needed, local planners can determine which assessment capabilities will be needed immediately and therefore must be provided locally. Other assessment capabilities, perhaps less critical or not needed immediately, could be provided by reinforcing organizations coming from beyond the local area. Responders identified the immediate need to monitor the environment for chemical agents, biological agents, radiation, flammable gases, and oxygen deficiency as key [Study Interviews]. Such a list provides a clear strategy for what hazards should be examined as assessment resources arrive at a scene.

Develop Local Hazard Monitoring Capabilities. When a major crisis hits, safety managers will need certain hazard data immediately. Capabilities must be in place at the local level to gather that information. Data on facilities and locations that could present safety and health risks for responders is one key example of this kind of information [Study Interviews]. Such data can be acquired through facility inspections, regulatory filings, or other data collection. ${ }^{4}$ Because such information is only useful if it is immediately available and up to date, the importance of keeping this type of information current and readily accessible to responders cannot be overemphasized [Study Interviews].

Local response organizations also need capabilities for collecting information about hazardous or infectious materials in the air, water, ground, or debris following a disaster-for example, direct-reading instruments, field tests, and laboratory assay methods. Certain response units will routinely have some hazard assessment technologies used for these purposes-e.g., gas monitors used by firefighters. Local hazardous materials responders and other specialized response teams may have access to more sophisticated devices to measure the presence of chemicals, weapons of mass destruction, and other hazards. ${ }^{5}$ Other hazard assessment capabilities are based on individual responder training; for example, the capability of responders to assess the risks posed by moving water in a flood situation [FEMA 1994b]. But where local or-

\footnotetext{
${ }^{4}$ For example, during Hurricane Andrew there were problems with responders not being fully aware of hazardous materials at hurricane-damaged sites [Lewis 1993, 72; Study Interviews]. In light of what they learned during the aftermath of the hurricane, local responders indicated that the availability of regulatory information on such materials would make it much easier to assess potential hazards. Other responders cited the usefulness of inspection information on construction and building contents for hazard assessment [Study Interviews].

${ }^{5}$ Although significant technology is available, assessment methods to provide first responders with needed information do not exist for all hazards or may not be broadly accessible to response organizations because of technical, resource, or other limitations. As a result, beyond the management issues, significant technical issues exist in this area as well. Improvements to the capabilities of current monitoring technologies, broader diffusion of the equipment in the response community, or the development of new strategies or technologies could contribute to providing responders with more rapid and accurate information on post-disaster operating environments.
} 
ganizations do not have the capabilities needed to gather necessary information, the resources must be put in place.

Finally, major disasters require responders to have access to "big picture" hazard information. To handle this issue, systems can be put in place to ensure rapid access to overhead imagery [Study Interviews]. For example, response organizations could maintain access to public or private helicopters to provide Incident Commanders with a quick overhead perspective of a disaster scene. ${ }^{6}$

Access to Needed Hazard Assessment Resources in Other Organizations. The diversity of hazards that can exist after a major disaster means that individual response organizations must often rely on external organizations to provide supplemental hazard assessment capabilities and expertise. ${ }^{7}$ For example, external organizations possess technology and expertise to measure hazards such as airborne pollutants, heavy metals, asbestos, particulates, and others. In addition, external organizations can also provide access to technical assets that local response organizations could never support on their own. Beyond the helicopters discussed above, a range of other sophisticated overhead monitoring platforms can also contribute to management of responder safety. Depending on the disaster type, information from weather and imaging satellites, airborne infrared sensors, thermal sensors, LIDAR (light detection and ranging) instruments, or other monitoring systems can provide useful overhead viewpoints. ${ }^{8}$ Consequently, agreements—such as memoranda of understanding, formal plans, or mutual aid agreements - must be put in place before a major disaster occurs to enable local response agencies to coordinate efforts to assess hazards and access resources from other agencies. ${ }^{9}$ Agreements must also be in place to ensure that information produced by these varied sources can be effectively shared and used among response organizations. ${ }^{10}$

Safety managers at a major disaster need points of contact in key organizations at the local, state, and federal agency levels, as well as relevant nongovernmental organizations. With these contacts in place, they will have resources to call on when

\footnotetext{
${ }^{6}$ In planning for airborne assessment, it is important to include backup options if adverse weather, flight restrictions, or disaster damage hinder the use of aerial assets.

7 This need to rely on capabilities maintained by a range of other organizations was a key driver for recommending the integrated, incident-wide approach described in Chapter Seven.

${ }^{8}$ Immediately following the September 11 attacks, satellite imaging and aerial overflights of the World Trade Center and Pentagon sites were undertaken for damage assessment and hazard monitoring purposes [Williamson and Baker 2002, 870 873].

${ }^{9}$ To ensure that critical monitoring tasks are performed, planning must include the requirements for activating agreements or calling on outside resources. Because not all contingencies can be predicted during planning, backup sources for critical monitoring capabilities should be identified where possible.

${ }^{10}$ Failure in sharing information among response organizations can pose significant safety issues. In the California wildfires of 1993, breakdowns in communications between response services meant that some responders were not sufficiently aware of the speed and direction of movement of the wildfires [California Office of Emergency Services 1993].
} 
they face a specialized hazard assessment need. This requires developing contact lists and information about the assessment capabilities of relevant organizations, as well as building the interorganizational relationships needed to make such coordinated hazard monitoring function effectively. ${ }^{11}$

\section{Recommendation 4.2-Develop Assessment Methods, Checklists, Guidelines, and Standards to Assist in Hazard Monitoring Efforts Among Multiple Agencies}

Following a disaster, responders may not know all the potential health and safety risks that should be examined or where to obtain monitoring capabilities for unfamiliar hazards. As a result, tools and resources to provide responders with guidance on hazard monitoring needs and facilitate access to outside resources are needed. As described above, development of lists of potential hazards is a critical element of disaster response planning. Beyond their utility in preparedness efforts, such lists can also provide first responders at a disaster scene with information on potential hazards that require assessment. Study discussion participants indicated that such lists-by alerting responders to the types of questions they should be asking after particular disasters - are needed to better define safety efforts, especially in the early phases of disaster operations. In addition, such common lists can also help ensure that responders from different organizations have a uniform understanding of hazard monitoring needs. To ensure that such assessment tools are readily at hand when a disaster occurs, ideally they should be tailored to be relevant to routine response operations as well.

Assessment methods are also needed to manage and assure that hazard information produced in large-scale assessment operations is uniform and comparable enough to be useful for safety management. Direct observation of the disaster aftermath is always a major source of hazard information for safety management. Although a few responders may be able to collect the necessary information at a small incident, directly assessing a hurricane or earthquake impact zone could require hundreds of individuals. To perform such an assessment effectively, many individuals must be coordinated in information gathering efforts. This need also applies to assessments performed by technical experts; for example, there were issues with consistency of the building stability assessments performed by structural engineers drawn from many organizations after the Northridge earthquake [Collins 1999]. Interviewees reported use of standardized "score cards" or templates for damage assessment by

\footnotetext{
${ }^{11}$ Such contact lists could be developed at the local level as individual response organizations identify hazard assessment resources they need; alternatively, for national level assets in particular, such contact lists could be developed at the federal level as part of national preparedness efforts.
} 
response units to ensure consistency among the efforts of many individual responders. ${ }^{12}$

Monitoring guidelines and standards can also contribute to ensuring that technical hazard assessment efforts — in areas such as air quality, water contamination, or other environmental threats - of different organizations can effectively contribute to safety management. Problems with different organizations using incompatible analytical methods or producing data that are not comparable can significantly undermine hazard assessment efforts. Responders indicated that efforts to standardize analytical methods and protocols to the extent possible should therefore be an important part of preparedness [Study Workshop].

\section{Recommendation 4.3-Develop Information Management Systems and Processes So That Response Organizations Can Use Hazard Data More Effectively}

The scale and multiagency nature of disaster response operations result in a requirement for information management tools to focus and integrate safety management. To make it possible to use information from different response organizations' monitoring efforts, hazard data must be produced and presented so it can be easily compared and utilized by safety managers. In presenting the results of assessments, standard forms and formats would make it easier for Incident Commanders to readily absorb needed information [Study Workshop]. ${ }^{13}$ When different hazard assessment organizations present their results in markedly different ways, it is more difficult for safety managers to use the information under time-limited conditions. ${ }^{14}$ If data are presented in a uniform manner, recognizing and resolving any disagreement among different data sources are also more straightforward. Addressing such issues is particularly important when the hazard situation at an incident scene is uncertain enough that appropriate monitoring and assessment strategies are not clear.

For multiagency hazard monitoring efforts, rapidly examining and assessing hazard data produced by a range of different response organizations can be difficult. Examination and assessment under high-pressure disaster situations require databases to collate data and rapidly deliver needed hazard information. ${ }^{15}$ Appropriate data-

\footnotetext{
12 Such tools and training are particularly important if volunteers or other nontraditional responders participate in the hazard assessment process [Lewis 1993, 71].

13 Such standardized hazard assessment tools could be beneficial in routine emergency response as well as major disaster operations. In addition, use during routine events would increase familiarity with the tools and help ensure that they could be used effectively during large-scale response operations.

${ }^{14}$ In general, safety managers must filter out needed safety-related information from the larger body of available information. The challenge is converting the quantity of information inherently involved in large-scale incidents to the quality information needed to manage responder safety.

15 During the World Trade Center response, for example, the Environmental Protection Agency developed a "Multi-Agency Data Management System" in an attempt to rationalize different organizations' monitoring efforts [EPA 2002].
} 
bases would make it possible for safety managers to quickly examine data produced by different response organizations to identify discrepancies, track the evolution of the hazard environment over time, and flag potential problems that require follow-up examination. ${ }^{16}$

Because disaster response operations frequently take place over large areas that involve significant differences in hazard environments, management tools that allow responders to track data spatially can also contribute to safety management. To both deliver assistance and protect responders after a major incident, it is critically important to understand differences in the hazard environment across the entire site. Depending on details of an incident, some areas might be very hazardous to responders while others pose no major safety concerns. Because of the potential for destruction of landmarks and other location indicators after a major event, strategies based on the global positioning system (GPS) to assist in locating and defining hazard areas would be valuable. ${ }^{17}$ Geographic information systems (GIS) can provide a useful tool to organize hazard information for an entire incident scene and make it readily accessible to safety managers [Greene 2002]. By building a framework to consistently present data, such technologies can make available the "panoramic view" of an incident that responders indicated can be elusive at major incidents. ${ }^{18}$

\section{Recommendation 4.4-Undertake Joint Exercises that Include Multiagency Hazard Monitoring Efforts}

To put multiagency monitoring capabilities in place rapidly after a major disaster, hazard assessment activities must be practiced and relationships built among cooperating organizations. As a result, disaster exercises should include hazard assessment components that test the adequacy of assessment plans and exercise multiagency coordination processes. All relevant organizations should be involved as a way of building relationships and experience in joint operations that pose realistic, safetyrelated issues for responders.

\footnotetext{
16 The common data presentation methods described above could significantly facilitate any effort to produce such hazard information databases by providing a common input format for all organizations' monitoring information.

${ }^{17}$ For example, Hurricane Andrew stripped road signs from a significant fraction of the roads making it difficult for even local responders to navigate the response area [Lewis 1993, 19].

${ }^{18}$ Because specialized database or mapping systems may not be sufficiently applicable to response organizations' day-to-day operations, these assets might be better built within states, regionally, or nationally and deployed rapidly to large-scale incident scenes.
} 


\section{Information on the Responder Workforce: Maintaining Accountability Data on Responders and Units}

Along with an accurate sense of the types of hazards present, Incident Commanders need reliable and timely information on the responders operating at the disaster scene. This accountability information on both individual responders and their units is integral to effective safety management. The study recommends several ways of overcoming existing shortfalls in responder accountability during response operations. A combination of standard operating procedures, identification systems, and emerging technologies can strengthen the capability of Incident Commanders to know which responding entities are at the disaster scene, what functions they are performing, and where their personnel are located.

The nature of disaster response operations presents significant barriers to obtaining and maintaining sufficient information on the response workforce.

Large Geographic Scale. Large and complex disaster scenes undermine efforts of response managers to maintain accountability information for response units and effectively track response resources. Responding to incidents over large areas requires more responders, increasing the challenges in maintaining an awareness of individuals' locations and activities. Complex and widespread disaster scenes also make establishing scene perimeters difficult, thereby reducing the opportunity to collect accountability information as workers enter and leave the scene.

Prolonged Duration. Because major disaster response operations often require action over days, weeks, or even months, responding organizations must manage responder shift changes and work-to-rest rotations. The evolution of responders operating at the scene over time further complicates obtaining and maintaining accurate accountability information.

Wide Range of Needed Capabilities. The involvement of responders from many organizations also makes it difficult to collect information on the capabilities, activities, training, and equipment of responders at the incident. For example, after Hurricane Andrew, the Miami-Dade Fire Department alone estimated that it received mutual aid from 100 Florida departments and 25 out-of-state departments [Paulison et al. 1993, 68]. Over 100 organizations participated in the response to the attack on the Pentagon [Institute for Crisis Disaster and Risk Management 2002] and the number of organizations involved in the World Trade Center response has been estimated to exceed 400 [Harrald 2002]. ${ }^{19}$ Although individual organizations will be familiar with the capabilities of their members and have mechanisms to monitor re-

\footnotetext{
19 The response to the September 11, 2001, plane crash in Shanksville, Pa., involved over 74 organizations
} [Grant and Hoover 2002]. 
sponder accountability, few mechanisms exist to provide that information effectively to Incident Commanders. ${ }^{20}$

Influx of Convergent Volunteers and Supplies. Accounting for volunteersmany of whom are not connected to any organization-is even more problematic. Since they are generally not organized in a way that would allow response managers to collect and manage information on individual volunteers' capabilities, training, and activities, it is particularly difficult to integrate convergent volunteers into safety management efforts. ${ }^{21}$

\section{Recommendation 4.5-Bolster the Role of Response Units in Accounting for Personnel}

For responders who are organized into defined response units, connection to the incident command structure at the unit level is a promising means for ensuring personnel accountability. Information on personnel accountability can be collected and utilized through mechanisms to link responding units to the incident command structure. Having units "report in" upon arrival at the scene is the first step. Then the Incident Commander is aware of their presence at the site and can coordinate their activities. $^{22}$ Once assigned a response activity and operating location, responding units periodically report their location and activities, thus maintaining accountability. These reports ensure that the Incident Commander remains aware of their presence when he or she makes choices on how to deal with hazardous conditions at the disaster scene. Such "unit level" accountability systems work best for response organizations that have defined and stable units. ${ }^{23}$ In other disaster response organizations, many of which are organized very differently, applying unit-based approaches may require forming responders into appropriate groups specifically for disaster response purposes. Such a strategy must be planned, exercised, and evaluated before an event occurs if it is to be successful in post-disaster conditions.

\footnotetext{
${ }^{20}$ In Hurricane Andrew, problems tracking what federal responders were on site led to confusion about who was deployed where and resulted in duplicative staff requests [FEMA 1993, 157].

${ }^{21}$ In the Oklahoma City bombing in April 1995, a volunteer nurse, who was not trained or equipped for urban search and rescue activities, was fatally injured by a piece of falling debris after arriving at the disaster scene [Irving 1995, 75; Cone et al. 2003].

${ }^{22}$ It should be noted that it is also critical to ensure that incident managers are not overwhelmed with too much accountability data, resulting in information overload. Determining the right amount and frequency of accountability information needed to protect responders and manage operations is a key component of preparedness planning.

23 This unit reporting mechanism has been developed extensively in the fire service [Brunacini 2002, 273; Coleman 2001, 17 18], for example, where a strong unit structure is maintained throughout a response.
} 
When unit-based approaches are used to support accountability, it should be noted that unit or crew integrity is essential. ${ }^{24}$ As units deploy to the disaster scene, they must account for all individual responders who are members of their unit. Requiring that units enter and depart the disaster scene together, and that they operate as coherent units, ensures that individual or small groups of responders are not placed in life-threatening situations without the knowledge of their commanders.

\section{Recommendation 4.6-Develop Personnel Identification and Credentialing Systems Better Suited to Major Disaster Response Operations}

If responder identification and accountability functions cannot be provided at the unit level (Recommendation 4.5), mechanisms must be put in place to provide safety managers with this information for individual responders. Different types of identification methods exist for identifying responders in major emergency responses. Some responding units make use of high-visibility vests to identify key personnel and colorcoded armbands to identify types of responder personnel. Issuing "event badges" to responders is another way of identifying personnel at the disaster scene and indicating their authorized activities. In addition to including individual and unit identification, badges can be color-coded by day or can indicate the areas at the disaster site where the responder is allowed access. Although such identification systems can provide some capabilities to visually identify responders, they cannot provide the accountability information safety managers need to adequately protect responders at disaster response operations. In addition, they do not provide necessary safety-related information about responders (e.g., expertise, training, and personal protective equipment levels) for effective safety management. As a result, it is clear that more robust identification and credentialing systems are needed to protect the safety and health of responders during major disaster responses. Incident Commanders must be able to identify authorized responders at a disaster scene, track their location and activity if needed, and have access to information on whether they possess the right qualifications for working in a specific environment.

Because of the practical difficulties in implementing identification systems after a disaster, ${ }^{25}$ providing these capabilities must be included in preparedness efforts. Systems must be designed not only to prevent unauthorized individuals from gaining

\footnotetext{
${ }^{24}$ For resource accountability in emergency operations, the recommended practice of the fire service is to have supervisors "maintain constant awareness of the position and function of all personnel assigned to operate under their supervision." One role of the ISO is to ensure that the department's personnel accountability system is being used. See NFPA, 2002c, pp. 7, 9.

25 In the Pentagon response, the initial computer production system for creating color-coded identification badges for responders was quickly overwhelmed, resulting in substantial delays for responder relief crews [Arlington County 2002, A-69, C-58]. Similar problems occurred during the Oklahoma City rescue and recovery effort. It took several days to establish a system and designate a central issuing agency [Oklahoma City MIPT 2002, 10 $11]$.
} 
access, e.g., by duplicating badges, but also to ensure that responders with legitimate needs to participate are not excluded. Any identification system should also provide information on responder credentials: their certifications, training levels, and other information on their general skills relevant to operating in a hazardous environment. ${ }^{26}$ It was also suggested that including information on any cross-training experience that individuals possess, as well as some medical information (e.g., vaccination history and possible antibiotic sensitivities), could be important for protecting safety in specific disaster situations. ${ }^{27}$

Responders cited a range of technological approaches that could make responder identification, credentialing, and accountability information much more readily available to safety managers. Key technology options cited include "smart cards" that could be rapidly scanned at a staging area or entry point at the disaster scene to authenticate the identity and qualifications of individual responders. ${ }^{28}$ Other options include the use of radio frequency tags that transmit the location and status of individual responders, or bar code identifiers or biometric systems suitable for tracking the movement of responders through entry/exit points. Responders emphasized that any new technological approaches should be subjected to pilot tests with operational units to ensure that such equipment will work well in actual disaster circumstances.

\section{Recommendation 4.7-Utilize Scene Control to Improve Cross-Agency Accountability}

Although technological solutions can contribute to improving personnel accountability, lower technology options can make a significant contribution as well. For events where a hard perimeter can be established around the incident scene, even recording units' response assignments and activities as they enter and leave the scene could improve accountability. ${ }^{29}$ Effective scene control has the benefit that it repre-

\footnotetext{
${ }^{26}$ Examples could include training levels for hazardous materials response, compliance with training standards such as those issued by the National Fire Protection Association, or fit testing or experience in different types or levels of protective equipment.

27 Alternative mechanisms for verifying responder credentials were also suggested during study discussions. Qualification information could be collected centrally— such as through a national registry of responders similar to that used in emergency medical services - providing incident managers with a quick route to assess the qualifications of potential responders. Another possibility is pursuing a "certified-organization" approach to evaluate and certify the training and skill levels of responder organizations as a whole.

${ }^{28}$ Responders cited the lack of nationwide standards for training and responder certification as a significant obstacle to developing credentialing systems for major disaster response. Setting minimum standards for certification and training of responder personnel would enable the Incident Command to more easily establish qualifications of responding units and their personnel.

${ }^{29}$ At the Pentagon, operations in some areas had tight perimeter control, while others did not [Arlington County 2002]. Such accountability strategies based on scene control are even more problematic in wide area disasters, such as Hurricane Andrew or the Northridge earthquake, where establishing a hard perimeter around the entire disaster area is not feasible.
} 
sents a critical means for ensuring multiagency accountability. Since all responders must cross the perimeter to participate in response activities, information can be collected from them independent of their "home organization." Taking advantage of this strategy requires that establishing clear scene perimeters, supported by personnel monitoring those who enter and leave the scene, is a priority in response operations. Means to do so must be included in preparedness plans to ensure that scene control can be established as early as possible in a response.

\section{Recommendation 4.8-Develop Minimum Standards for Safety and Health Training for All Responders Involved in Disaster Response Operations}

The need for safety managers to gather information on worker capabilities and training is created by the significant differences that exist among responding organizations. If safety managers could assume a common, base level of training for all responders involved at an incident, the need to gather such information would be significantly reduced. In addition to contributing directly to better safety management, not having to devote effort to gathering information on responder capabilities would allow safety managers to give more attention to other concerns. Study discussions indicated that the curriculum should include a basic familiarity with the following:

- the ICS approach to disaster response

- common terminology for safety and health issues

- an "all-hazards" perspective on the range of hazards that could be encountered during disaster response activities

- relevant protective equipment, and when and how to use it

- decontamination and rehabilitation processes

- an overview of the diverse organizations that are likely to become involved in major disaster response.

Models could be developed from existing safety standards and training programs, such as those related to satisfying OSHA requirements for emergency response workers or skilled support personnel at sites where hazardous materials are present. ${ }^{30} \mathrm{Be}-$ yond such minimum requirements, different response disciplines ${ }^{31}$ might add additional training requirements for their members. ${ }^{32}$

\footnotetext{
30 The OSHA regulation 29 CFR 1910.120 on Hazardous Waste Operations and Emergency Response (HAZWOPER) sets training requirements for skilled support personnel involved in the cleanup operations at sites containing hazardous materials [U.S. Department of Labor 2003].

31 One example from the fire service is the consensus standards and recommended practices on fire and safety issues developed by the NFPA, which are widely used within the fire service.

32 Related to the need for common responder training standards, study discussions also highlighted the importance of having means for verifying the quality of the safety and health training provided to responders. Without
} 


\section{Information on Responders' Health and Injuries: Collecting Injury, Exposure, and Health Status Data}

Information on responder injuries and health status is critically needed to allow safety managers to address safety problems and intervene to improve responder protection. The extent to which information on responder injuries and health status is available to Incident Commanders reportedly varies. For example, some study workshop participants indicated that current systems in many areas could provide this information; others, including responders involved in recent disaster response operations, contradicted that view. Project interviews indicated that the characteristics of disaster situations can make it particularly difficult to collect this information and provide it to safety managers.

Large Number of People Affected, Injured, or Killed. During project discussions, responders reported that the focus in disaster situations is on meeting the medical needs of victims, rather than on the needs of the responders serving them. The intense operational pressures compete with efforts to collect information on the health status of the responder workforce.

Large Geographic Scale. Just as the scale of disaster scenes hinders efforts to collect hazard information and maintain responder accountability, it also gets in the way of collecting needed health information on responders. Because responders are often treated at multiple locations (or individually by their peers), mechanisms are not routinely in place for injury or exposure information to feed back to safety management [Study Interviews]. ${ }^{33}$ This was a particular issue at Hurricane Andrew where both responders and victims were treated at broadly dispersed medical facilities [Study Interviews].

Wide Range of Needed Capabilities. The involvement of many different responding organizations also makes it difficult to collect needed health status information. Although some individual responder organizations may have mechanisms to collect information on injuries or exposures suffered by their own members, those mechanisms may not be effective in post-disaster conditions, and routes are often not in place to share such information to apprise safety management more broadly.

Influx of Convergent Volunteers and Supplies. Because convergent volunteers are generally not effectively organized or connected to the Incident Command System, no mechanism exists for managers to become aware of injuries or exposures that occur during such volunteer activities.

such verification mechanisms, it is difficult to assess the extent and quality of the safety and health training given to responders.

33 An exception was the World Trade Center response, where National Disaster Medical System (NDMS) Disaster Medical Assistance Teams (DMATs) treated many responders on-site, which made it easier to collect data. Even in that case, however, responders interviewed during the study indicated that the data did not reach them fast enough or in a form that could be readily integrated into safety management [Study Interviews]. 


\section{Recommendation 4.9-Develop Systems to Provide Timely Information on Responder Injuries and Exposures}

Currently, self-reporting by responders is the primary method used to document injuries during response operations. However, the significant operational pressures that exist in the early phases of a response may result in responders failing to report injuries. ${ }^{34}$ Getting a complete view of responder health status and potential risks is also impeded by underreporting of less serious injuries that, while not immediately disabling or life threatening, could be indicative of more serious problems [Study Interviews]. ${ }^{35}$ Without timely feedback on responder injuries, disaster safety managers will not have accurate information on the scope and extent of noncritical injuries, as well as the specific areas of the site where particular injuries are occurring [Study Interviews].

To ensure that necessary medical information is available, the types of injury and exposure information needed should be defined-depending on the nature of the incident and hazards present_-as an element of preparedness planning. Formal systems must be put in place to track injuries to emergency responders at major events. ${ }^{36}$ In light of the multiagency nature of disaster operations, these systems must provide mechanisms to collect such data across different responding organizations. In addition, to be most useful for injury prevention, these systems must be able to track injuries in as close to real time as possible under the circumstances. How such systems would be implemented would clearly differ depending on the specifics of a local community. If responder injuries are all treated at the disaster scene in a centralized manner, collecting it may only require consistent reporting to incident safety managers. If responders are treated at local hospitals or at other locations away from the disaster scene, data collection and coordination mechanisms would be required to

\footnotetext{
${ }^{34}$ Because of their desire to continue assisting victims, responders who sustain injuries often do not report them so that they can keep working. Responders suggested that more injuries would be reported if doing so did not necessarily result in an obligation to stop working [Study Interviews].

35 For example, routine eye injuries can be indicative of problems in protection that could result in permanent disability or, in an environment with significant pathogen risks, relatively minor cuts could develop into serious medical problems if not appropriately addressed.

36 We were able to find instances of systematic patient data collection systems in the literature. At Northridge, a single patient data collection system was used by DMATs and Veterans Administration clinics (that also mobilized to provide emergency medical care) to provide up-to-date data [Leonard et al. 1995]. However, this system was not specific to emergency responders, and it is not clear that the emergency responder data were available.
} 
gather the needed information. ${ }^{37}$ Whatever procedure is used, data collection must be systematic, using a defined set of terms and reported in a consistent manner. ${ }^{38}$

\section{Summary}

Major disasters present numerous barriers for gathering key types of information required for effective safety management. The nature of major disasters, particularly in terms of a multitude of potential hazards and the diverse responder workforce, makes the gathering of safety-related information critical for protecting emergency responders. Safety managers need timely and accurate information on the range of potential hazards present (or expected) at a disaster scene. Better personnel accountability systems, including credentialing mechanisms to provide information on responder capabilities, are needed to protect responders during incident operations. Finally, innovative means are needed to provide timely feedback on the injuries and health exposures responders suffer while carrying out disaster response assignments.

\footnotetext{
37 The privacy requirements of the Health Insurance Portability and Accountability Act of 1996 could affect the ability to collect and utilize health information on the emergency response workforce. The requirements of the act should therefore be addressed in any preparedness planning aimed at addressing this safety need.

38 Interviewees indicated that counting and data coding problems undermined data collection efforts at the World Trade Center response. For example, a visit to a medical team to get safety glasses was reportedly entered as an eye injury in the counting system [Study Interviews].
} 



\section{Analyzing Options and Making Decisions}

Once information is available to incident and safety managers, they must determine the relevance of that information to responder safety and make judgments on appropriate courses of action. Taking advantage of the disparate sources of information available to them, particularly in the early stages of a response operation, managers must identify the critical areas where action can be taken to protect the responders under their command. ${ }^{1}$ Their capability to effectively identify critical areas depends on management tools and capacities in three main areas (see Figure 5.1):

- Assessing Hazards. Access to guidelines or technical expertise that provide a clear understanding of the risk posed to responders by the hazard environment.

- Managing Risk. Knowledge of the response needs to allow comparison of the potential benefit of response actions to the risks they entail.

- Choosing Protective Options and Planning for Safety Needs. Management tools and processes to provide up-to-date information on available protective equipment and matching protective options to the hazard environment.

During routine emergency response operations, the requirements to make effective safety decisions are relatively well defined. In the course of their operational activities, responders in all disciplines build experience with the hazards routinely involved in their activities and develop methods to assess risk and appropriately match protective options to safety requirements. The nature of disaster situations, however, makes it difficult to assess safety issues or to carry out this type of deliberative decision process.

\footnotetext{
${ }^{1}$ Other response decisions can affect responder safety. The choice among response strategies can have safety implications, and some operational actions may affect the presence or intensity of hazards, e.g., when extinguishing fires. For the purposes of this discussion, these decisions are considered operational in nature, and although they would likely involve the input of safety managers, they are not categorized as safety management decisionmaking.
} 


\section{Figure 5.1}

Making Decisions and Assessing Options

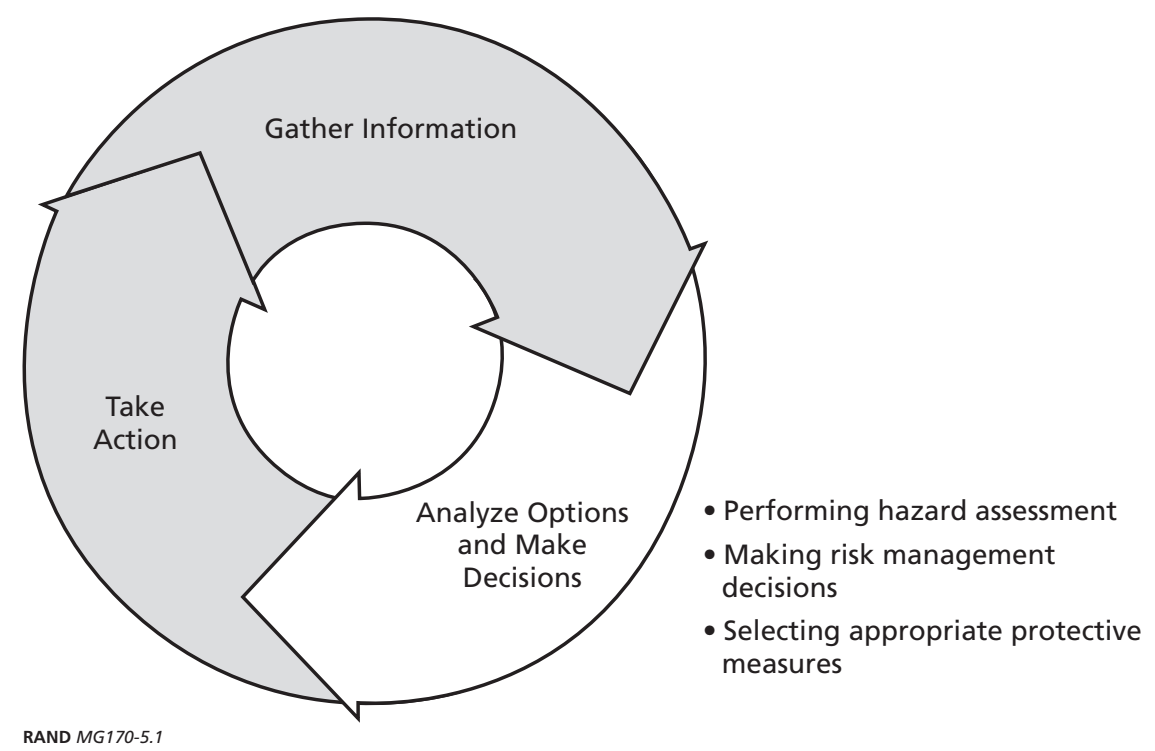

\section{Assessing Hazards: Judging the Level of Risk Faced by Responders}

Once hazard information is available to a safety manager, the data must be assessed to evaluate the danger posed to responders. In the earliest stages of response operations, this assessment will be based on information that is immediately available to the first responders at the scene. Although this initial "size up" will guide safety management efforts during the early stages of operations, the characteristics of disaster situations pose significant challenges to the continuation of effective hazard assessment.

Large Geographic Scale. The scale of major disasters, and the resulting magnitude of the safety concerns, can prevent safety managers from effectively assessing hazards. Because of the demands of the disaster, a single safety manager may be forced to address more safety issues than he or she can reasonably manage.

Large Numbers of People Affected, Injured, or Killed. The need to take immediate action when lives are at risk limits the time responders have available to make decisions. Such time constraints make it difficult for safety managers to effectively assess hazards and the risks posed to responders. ${ }^{2}$ In the most intense situations,

\footnotetext{
${ }^{2}$ Under time-constrained conditions, managers often rely on cues from their earlier experience to allow rapid decisionmaking [Klein 1998]. Most response organizations, however, lack experience in managing disaster-scale operations.
} 
safety managers may even be "pulled away" into operational activities, thus compromising efforts to consistently assess safety hazards [Study Interviews].

Multiple, Highly Varied Hazards. The unusual hazards in some post-disaster environments can make it difficult to translate monitoring information into practical and actionable hazard assessments. During day-to-day response activities, responders build considerable experience with the hazards they routinely face. In disasters, most responders face hazards that are unfamiliar and are more difficult to assess. For some hazards — such as environmental pollutants, unusual hazardous materials, or biological threats-hazard assessment information may be highly technical in nature. In some cases, there is no consensus on guidelines or regulatory requirements to define what constitutes a dangerous level for particular hazards [EPA 2002].

Wide Range of Needed Capabilities. The involvement of many responder organizations in large-scale responses can also complicate hazard assessment. If different organizations use different criteria to judge whether the area is dangerous, serious confusion can arise. At the World Trade Center site, for example, disparities in the hazard assessment efforts of different agencies occurred because differing standards were being applied [Lioy and Gochfeld 2002]. Different standards were used by various organizations measuring asbestos, for example, leading to confusion about the results [Lippy 2002].3 Data sharing problems among separate agencies can also complicate hazard assessment efforts.

\section{Recommendation 5.1-Identify and Connect with Experts in Hazard Assessment During Preparedness Planning}

The nature of some hazards involved in disasters requires that technical and safety experts from outside "traditional" response organizations become involved in safety management decisionmaking. Hazard assessment is a process of identifying the hazards present at the scene and determining their potential impact on responder health and safety. While knowing the level of a hazard is a first step, a safety manager also needs to understand how responders' exposures are affected by their activities. All relevant variables must be weighed in the context of the response situation to enable sound decisions on how the hazards can be effectively managed. Because disaster response operations are inherently time-limited environments, these assessment decisions must be made rapidly.

Making these assessments for many hazards requires technical input beyond simply providing information on the presence or level of a hazard at the disaster scene. As a result, technical experts and responders from safety-related organizations participating in safety management need to provide safety managers with the context and follow-up required for hazard information to be useful. In the case of complex

\footnotetext{
${ }^{3}$ Responders indicated that similar problems occurred in the Pentagon response [Study Interviews].
} 
respiratory hazards, for example, hazard assessment requires information beyond simply measuring the level of a contaminant in the environment. ${ }^{4}$ Such information includes the likely health effects of particular hazards, the applicability of different protective options to reduce hazard exposures, and the consequences on response operations and for responders from potential safety actions. Such assessment is straightforward for some hazards, such as the physical risks posed to responders by debris at some disaster scenes. For others, however, where the biological effects of particular materials are not fully understood or there is no consensus on appropriate protective options, significant expert input may be required for decisionmaking.

To ensure that appropriate expertise is available after a disaster occurs, relevant technical experts and organizations must be identified as a component of preparedness activities. Response safety managers must understand any procedural or legal requirements to call required experts in after a disaster and how rapidly they can respond to an evolving event. These experts could be drawn from federal, state, or local regulatory or technical agencies, universities, nongovernmental organizations, or the private sector. Depending on the nature of the disaster, individuals with knowledge relevant to safety management could range from military experts on unconventional weapons and infectious disease epidemiologists to industrial hygienists or occupational physicians. Integrating such assistance into decisionmaking also requires significant interagency coordination to foster the needed exchange between operational responders and outside hazard experts. ${ }^{5}$ When there is no mechanism for this interaction to occur or barriers between organizations get in the way of effective cooperation, critical technical information for protecting responder safety may not be effectively linked to safety and operational decisions.

\section{Recommendation 5.2-Develop a Better Understanding of Relevant Exposure Thresholds and Guidelines for Disaster Response Conditions}

In project interviews and workshop discussions, responders indicated that there are significant problems in defining the appropriate regulatory guidelines and exposure thresholds to interpret hazard data during emergency response.

\footnotetext{
${ }^{4}$ In project discussions, such data on levels were often criticized for being "non-actionable," since, on their own, the data did not provide enough information to guide safety decisions. On the other hand, when technical experts sought only to provide the "correct answer," i.e., what protective equipment should be worn or what policy implemented based on their hazard assessment efforts, the results might not sufficiently consider the operational needs of the response. For example, at the Pentagon response, some safety and health officials "pressed for a strict policy that would guarantee protection under the most severe conditions, including having all responders operate in Tyvek ${ }^{\circledR}$ suits, regardless of their particular assignment"[Arlington County 2002, A-68]. However, because of the heat stress risk involved in having responders wear these suits for extended periods, this strategy was deemed impractical. Instead, comprehensive decontamination and cleaning of responder equipment was substituted as a safety management strategy that struck a better balance between the operational mission and safety needs of responders engaged in rescue operations.

5 This need for integration was one component that drove the research team to consider the integrated, incidentwide approach described in Chapter Seven.
} 
Questions were raised about the appropriateness of existing occupational exposure guidelines for shorter-term, potentially very intense exposures during emergency response operations [Study Workshop; Lioy and Gochfeld 2002]. ${ }^{6}$ Differences must also be resolved between exposure thresholds defined for occupational environments versus those for overall exposure of the public at large [Study Workshop].

From the diversity of views observed, it is clear that there is no current consensus on appropriate thresholds and standards for interpreting monitoring data during disaster response conditions. To improve overall understanding of hazard exposures, there is a need for further scientific research and data collection to better understand intense short-term hazards exposures, simultaneous exposure to many hazards, and the potential long-term health effects that can result. Because of the complexity of these areas, such a research effort represents a long-term investment to improve understanding in these areas.

In the short term, guidelines are needed to assist Incident Commanders in making decisions as part of the overall risk-benefit analysis of response operations. Development of these guidelines must involve the full range of response organizations so technical disagreements about hazard data can be addressed and, to the extent possible, resolved as part of preparedness efforts. It is clear that such technical disagreement cannot be successfully resolved during the time-limited and highpressure conditions of an ongoing disaster response.

\section{Managing Risk: Balancing Risks and Benefits in Response}

Hazard information provides the basis for risk assessment-weighing the need for decisive operational action against the risks involved in doing so. Safety managers provide critical input on risks and safety options that Incident Commanders consider in the context of the practical needs of the response. Effective safety management therefore requires a clear judgment on whether disaster victims can still be rescued or whether response activities are in a recovery, or cleanup, mode [Worker Education and Training Program 2002]. The nature of disaster situations makes drawing this distinction particularly difficult, however.

Large Numbers of People Affected, Injured, or Killed. Because of the large number of individuals affected by a disaster, it is often difficult to determine the potential benefit from continued rescue operations. Although distinguishing between the rescue and recovery phases of a response seems clear in principle, making the distinction during particular responses is often problematic [Neal 1995]. Identifying extreme cases is straightforward. At the site of the September 11, 2001, crash of

\footnotetext{
${ }^{6}$ During the period that research for this study was being performed, OSHA was also carrying out an evaluation of the applicability of regulations and productive roles for regulatory agencies in post-disaster environments.
} 
Flight 93 in Shanksville, it could be quickly established that there were no survivors and a decision could be made to adjust response tactics [Grant and Hoover 2002]. Response activities at the World Trade Center site are an example of a much more difficult case because circumstances prevented local authorities from making a clear distinction between the rescue and recovery phases. ${ }^{7}$

Wide Range of Needed Response Capabilities. The involvement of multiple organizations in major disaster response can also create other complications for safety decisionmaking. Organizations from different response disciplines can have very different approaches to risk management [Jackson et al. 2002]. Such differences in approach can derive from the nature of their activities-e.g., law enforcement responders have different practical concerns about some risks compared with the concerns of emergency medical responders. Such differences can result in organizations coming to different judgments about appropriate risk levels.

\section{Recommendation 5.3-Address the Transition Between the Rescue and Recovery Phases of Disaster Response Operations in Preparedness Planning}

After a major event, making the decision that the diminishing chances of rescuing anyone alive no longer justify putting responders at an elevated risk is difficult. Views clearly differ on the right approach to this issue. Some responders indicated that, since victim survivability is so difficult to predict, it is important to maintain rescue operations as long as any possibility exists. Others voiced caution at that strategy, emphasizing the added risks involved in the faster pace of rescue operations.

In the aftermath of a disaster, concluding rescue operations will almost certainly be exceptionally difficult for responders and political leaders alike [Study Interviews]. However, a decision not to address such issues head on could have significant consequences for responder safety, depending on the incident. Although there was no consensus on the correct approach to solving this problem, it is clear that the politically and emotionally charged environment after a disaster is not an appropriate time to resolve such differences. Planning for this transition, including how the decision will be made and who will make it, should be included in pre-disaster preparedness activities.

\footnotetext{
${ }^{7}$ Study Interviews with a number of organizations involved in the World Trade Center operations, and examination of available literature, produced no discernable consensus on when the site transitioned from the rescue to the recovery mode [Study Interviews; NVFC (National Volunteer Fire Council) 2002; Jackson et al. 2002, 47; Lioy and Gochfeld 2002].
} 


\section{Choosing Protective Options and Planning for Safety Needs: Supporting Effective Decisionmaking in Responder Protection and Risk Mitigation}

A key component of safety management decisionmaking is choosing appropriate protective equipment and/or risk mitigating measures in light of available hazard information. To make good decisions, safety managers need a clear understanding of the equipment options available to them, how to choose among them, and how to project protection and resource needs as response efforts continue. However, the characteristics of major disasters complicate making these protection decisions.

Multiple, Highly Varied Hazards. The potential for unusual hazards in the postdisaster environment complicates protection decisions. During the earliest phases of response operations, detailed hazard assessment information is often not available to guide selection among safety equipment options. Furthermore, shortages of supplies may also mean that the best equipment for particular hazards is not immediately available.

Wide Range of Needed Response Capabilities. While many different responder organizations are needed to address the operational needs of disaster response operations, various organizations often come with very different equipment and safetyrelated capabilities. These variations can have a major effect on the range of safety options available to safety managers. In addition, the number and variety of individual responders involved make estimating equipment needs for the response more difficult.

Influx of Convergent Volunteers and Supplies. While different response organizations come to disaster response operations with differing equipment and capabilities, convergent volunteers often come without supplies or training in the use of protective equipment. Donations of safety-related equipment, while potentially important for both responders and volunteers, also challenge decisionmaking. This perspective was highlighted as a serious problem after both Hurricane Andrew and the Oklahoma City bombing [Study Interviews; Oklahoma Department of Civil Emergency Management 2000]. If such convergent supplies are not systematically inventoried, managers do not know what are available and cannot integrate them into safety management.

\section{Recommendation 5.4-During Disaster Planning, Address Issues Concerning Safety Equipment and Multiagency Coordination of Safety Logistics}

For safety managers to make good decisions among potential protective options, they require accessible and accurate information about the options available at the incident scene or from outside organizations. Safety managers need to know what particular organizations bring to an incident scene and where needed equipment can be obtained when an event occurs. In some cases, other responding organizations may 
be able to provide supplemental safety equipment. Prepositioned supply caches maintained by federal agencies should also be integrated into planning. In addition, safety managers may have to make arrangements with private firms to provide needed supplies. The high-pressure conditions immediately following a disaster are a difficult time to pursue new supplier relationships or seek out equipment from new sources. ${ }^{8}$

As a component of preparedness planning, responder organizations should maintain up-to-date inventories of their own resources and any external resources available through agreements or standing contracts. These lists should also include information on any requirements to activate mutual aid pacts, invoke interagency agreements, call on federal resources, or purchase supplemental supplies [Lewis 1993; NFPA 2000b]. To the extent possible, resource planning should also seek to address equipment interoperability concerns that can prevent most effective use of safety equipment in multiagency operations [Jackson et al. 2002]. It is also critical to plan for any training needed for responders to use equipment effectively. If responders are given equipment that is not properly fitted or are not instructed in its proper use, its effectiveness could be reduced or eliminated [Lippy and Murray 2002]. To the extent possible, these analyses should also try to identify if multiple response organizations in an area are relying on equipment support from the same external organizations or vendors. If this is the case, supplemental capabilities may not be available when a large-scale incident occurs.

Because disaster response operations may include organizations from outside the immediate area, groups that are not included in pre-planning activities may become involved in response operations. Methods to address these groups must be included as part of the planning process. Information on their equipment could be integrated into decisionmaking if they provide sufficient information to safety managers when they arrive at the incident scene. Alternatively, the credentialing systems discussed previously could provide safety managers with information on responders' equipment.

Promoting standardization and interoperability may be an effective strategy to address multiagency safety equipment coordination concerns at large-scale incidents. If safety equipment is standardized and interoperable, safety managers will no longer need to collect information on different organizations' resources since compatibility could be assumed. This could significantly reduce the logistical burden involved in providing supplies during an extended response and could free up managers' time and attention for other safety concerns.

\footnotetext{
${ }^{8}$ With respect to the private sector, responders reported that close relationships with supplier organizations were critical for supplying the response operations to the September 11, 2001, attacks.
} 


\section{Recommendation 5.5-Develop Guidelines for Selecting Protective Equipment to Use in the Early Phase of Response}

During the earliest phases of response operations, before technical expertise can be brought to bear or supplemental safety equipment can be located, responders and safety managers need guidelines, checklists, or other decisionmaking tools to assist in developing appropriate protection strategies. Such tools should provide guidance for selecting equipment based on the initial "size up" of the situation and processes to reevaluate protective options as response operations continue and additional information becomes available. ${ }^{9}$

\section{Recommendation 5.6-Develop Guidelines for Estimating the Safety Equipment Requirements for Disaster Response Operations}

In addition to determining the type of safety resources needed for a disaster response, safety managers (in coordination with the logistics section of response management, see Figure 3.1) must also estimate the amount of various safety resources that will be needed over the course of the response effort. ${ }^{10}$ To the extent that equipment needs can be defined, reasonable projections of required equipment help to avoid oversights in resource requests or, conversely, requests for supplies that are not needed, unnecessarily complicating logistics operations. Because of the complexity of large-scale, multiagency operations, safety managers need better methods to estimate resource needs to guide safety logistics efforts.

\section{Summary}

Safety management decisionmaking faces a series of challenges, exacerbated during the early phase of a major disaster response when time pressures are severe and substantial uncertainty exists. To effectively protect responders, safety managers need better guidelines and technical support to carry out hazard assessment and clearer risk assessment criteria as response operations transition from rescue to recovery phases. To support effective decisionmaking on responder protective equipment issues, preparedness efforts must ensure that safety managers can rapidly determine available equipment options, have guidelines to assist in choosing equipment in the absence of relevant or complete hazard information, and can reasonably estimate safety equipment needs for large-scale and extended response operations.

\footnotetext{
${ }^{9}$ For example, RAND and NIOSH are involved in an effort to develop guidelines of this type for protective equipment selection for response operations after a major building collapse.

${ }^{10}$ Such estimates must obviously be periodically revisited as response efforts continue, circumstances change, or better information is developed.
} 



\section{Taking Action}

Even if safety managers have access to accurate information and the resources needed to make safety decisions, the results of their efforts will have little effect on safety unless they are communicated effectively to the workforce and reliably implemented by responders. Disaster safety managers must have access to incident managers, sufficient authority, and the leadership abilities needed to carry out their roles within the incident management structure and to ensure that necessary safety decisions are put into practice. Doing so requires that organizational and preparedness measures are in place to support safety management. This third stage of the safety management cycle, taking action, relies on safety managers having the following (see Figure 6.1):

\section{Figure 6.1}

\section{Taking Action}

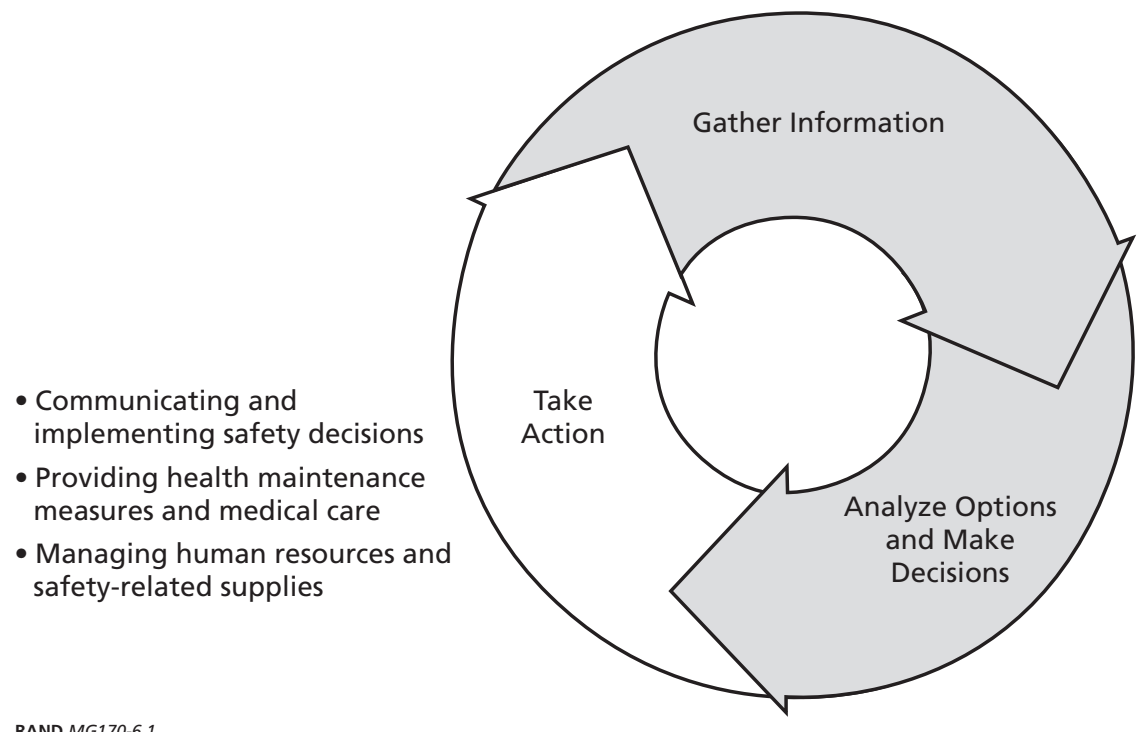


- Effective Mechanisms for Implementing Safety Decisions. Strategies to allow incident-wide communication of safety decisions and effective action in multiagency disaster response operations.

- Measures to Protect the Health of Responders. Enforceable practices to sustain responder health during long-term response operations.

- Human Resource and Equipment Management. Procedures to manage responder resources, disaster volunteers, and safety-related equipment.

During routine response operations, individual organizations develop standard approaches and enforcement authorities for implementing safety decisions. However, implementing safety management decisions at a disaster scene is much more complex. Clear lines of authority for safety management frequently do not exist at the incident level for major disasters. While the Incident Commander coordinates the activities of all the organizations involved, he or she does not have direct command authority over all of them. ${ }^{1}$ The involvement of many separate response organizations and, furthermore, the participation of independent, convergent volunteers in disaster response operations make taking effective action to protect responders more difficult.

\section{Effective Mechanisms for Implementing Safety Decisions: Improving Safety Implementation During Multiagency Response Operations}

Because individual responding organizations retain primary responsibility for protecting the safety and health of their members, centralized mechanisms do not exist to enforce even minimum levels of protection across different responder groups. While it is important that organizations retain clear responsibility to protect their members, responders indicated that this inability to establish a common protection strategy for an incident can undermine all organizations' efforts to implement safety measures. On the one hand, the presence of responders with little or no protection can lead others to question whether they really need to use protective equipment; conversely, if some responders use much higher levels of protection, this can result in questions and stress for others about whether they have been adequately protected.

\footnotetext{
${ }^{1}$ A fire service expert indicated that, in his view, labeling the leader of a large-scale response as the "Incident Commander" is a misnomer since that individual "doesn't really command most of the people involved" [Study Interviews]. For example, organizations at different levels of government may have their own statutory or functional responsibilities to carry out at an incident and could connect with the ICS through liaison rather than command relationships [USCG 2001]. Furthermore, many participants in study discussions cited the difficulties with response organizations and units that should be integrated into the ICS but instead are "freelancing" - taking operational action independently of the ICS during major disasters-as an ongoing problem from both operational and safety perspectives.
} 
These multiagency implementation difficulties are exacerbated by other characteristics of the post-disaster environment:

Large Geographic Scale. The size of disaster scenes makes it very difficult to implement safety decisions across all involved responders. Different groups often operate in different areas and may face different types and intensities of hazards, producing further barriers to effective coordination. The large scale of disaster sites also makes perimeter control less effective or impractical. In multiagency response operations, scene control can provide a critical safety enforcement mechanism because individuals monitoring the perimeter can verify that responders entering the scene are appropriately trained and equipped to operate safely.

Large Numbers of People Affected, Injured, or Killed. The selfless desire of responders to assist disaster victims as rapidly as possible can be a barrier to safety implementation. This drive to help victims can push responders to disregard safety practices perceived to reduce their response effectiveness. The perception among responders that respiratory protection hindered their ability to work was cited as a major reason for low usage of the equipment at the World Trade Center response [Jackson et al. 2002].

Damage to Infrastructures. Just as damage to technological and communications infrastructures hinders collection of safety-related information, it also presents a significant barrier to safety implementation as well.

\section{Recommendation 6.1-As Part of Multiagency Preparedness Efforts, Address the Issue of Safety Implementation}

Implementing consistent protection measures across multiagency disaster operations requires that all involved organizations abide by the safety decisions made by the disaster safety manager(s). ${ }^{2}$ Because the Incident Commander does not necessarily have direct command over responders from all other responding organizations, ${ }^{3}$ a common approach must be built from broad trust in the safety leadership and an overall consensus that the minimum safety requirements put forward are reasonable for the conditions of the response. Individual response organizations and units enforcing common minimum safety standards for their members-or agreeing to support common, incident-wide enforcement efforts—support adherence to these standards.

Because the high-pressure conditions after an event are not conducive to the development of such a multiagency consensus, safety implementation should be included in preparedness efforts. Responders collectively labeled these efforts as build-

\footnotetext{
2 This recommendation does not consider regulatory requirements that may apply to specific post-disaster situations, such as those included in OSHA Regulation 1910.120, Hazardous Waste Operations and Emergency Response. Such regulatory requirements, applied across response organizations, would centralize elements of safety enforcement even without fully centralized command authority.

${ }^{3}$ For example, agencies supporting or cooperating in the operation that connect to the command structure through liaison [USCG 2001].
} 
ing a common "culture of safety" among responding organizations [Study Interviews; Study Workshop]. Components that should be addressed in this preparedness process could include consensus safety policies for given disaster types and agreement on acceptable enforcement mechanisms for safety policies during response operations. Standardized planning tools — such as a model disaster safety and health management plan-could serve as a framework around which organizations could develop this consensus. ${ }^{4}$ Such a model plan could be adopted by emergency managers and responder organizations as a starting point for responder safety planning and modified to reflect the specific requirements of the local area. Use of Unified Command and regular multiagency exercises was also cited as an important mechanism to build this common understanding.

\section{Recommendation 6.2-As Part of Preparedness Planning, Include Safety and Risk Communication}

Given the communication problems often associated with disaster situations, it may be difficult for safety managers to effectively communicate hazard and safety information. Participants in study discussions indicated that improved mechanisms are required to communicate needed information in large-scale responses. For safety management, clear communication channels are needed to allow communication from incident command to response organizations, to response units, and, if appropriate, to individual responders. Because of the potential for disruptions after disasters occur, backup options are needed for critical communications. ${ }^{5}$ Because there are so many potential methods for providing communications-including a wide range of technological and organizational options_-study research did not identify specific solutions. However, based on experiences in recent disaster operations, study interviewees did highlight the potential usefulness of multiagency safety meetings, responder briefings, and safety-related public information strategies in multiagency response operations.

Periodic safety meetings were cited as useful in disseminating safety information to the range of organizations involved at a major incident. Such sessions provided a centralized way for this type of communication at both the Pentagon and the World Trade Center responses. However, responders indicated that the effectiveness of information being transferred from the safety meeting through organizations to responders could differ considerably. Some organizations were very effective at trans-

\footnotetext{
${ }^{4} \mathrm{~A}$ responder cited standardized health and safety planning that has been developed in hazardous materials response as an example of this approach.

${ }^{5}$ Disaster preparedness planning should include what responding organizations need to obtain particular types of information. Laying out information flows and, to the extent possible, identifying particular information requiring immediate command attention can prevent later communications breakdowns. This process has been referred to as defining "critical incident factors" [Brunacini 2002, 124 126] or "critical information requirements" [Department of the Army 2001].
} 
mitting new or updated guidelines to their members while others were less so. Interviewees cited particular problems in communicating effectively with skilled trade and other construction workers who are less frequently involved in disaster response operations. ${ }^{6}$

A primary strategy for communicating safety-related information is the consistent use of safety briefings or orientations before responders begin work at a response or at the beginning of daily work shifts. Because such briefings are familiar in a range of different response professions, they provide a structure that can be useful for a number of different groups. To be relevant throughout a sustained response, however, such briefings must be updated constantly and provided to responders regularly. Responders indicated that broader-based methods of communication could complement these on-site orientation briefings. Strategies and methods to get information directly to responders on protective equipment requirements or particular hazard information were seen as effective.

In particularly large-scale responses, study discussion participants indicated that the incident command's public information strategy could be a key component of safety communication to responders. Because information released to the media has many avenues to reach individual responders, public releases of hazard information can be an important route to increase responder protection. ${ }^{7}$ Responders emphasized, however, that the release of conflicting, misleading, or otherwise unclear information by multiple response organizations does not benefit safety. As a result, there must be effective coordination of the information being released by all responding organizations, ideally through a single point of contact, so the incident management structure speaks with a single voice. In addition, public information release efforts must make clear any differences between hazards involved in response activities and more general hazards to which the public is exposed to minimize general confusion over any disparities in required protection levels.

\section{Recommendation 6.3-Pursue Effective Scene Control As a Safety Enforcement Measure}

Study discussions with responders suggest that there is broad agreement on the importance of scene control as a safety enforcement strategy. If a hard perimeter can be put in place around a scene and the entry points controlled, crossing the perimeter becomes an opportunity to make certain that all responders entering the scene are informed, trained, and equipped in accordance with the response safety procedures. Responders who are not in compliance can be identified and denied access to the

\footnotetext{
${ }^{6}$ In a multilingual environment, serious problems can occur if safety information is not available in languages accessible to all responders [Study Interviews].

${ }^{7}$ For example, discussion participants indicated that they observed increased compliance with respiratory protection use at the World Trade Center following media reports on airborne hazards at the site [Jackson et al. 2002].
} 
scene. ${ }^{8}$ However, difficulties in establishing a perimeter at very wide area events, such as the Northridge earthquake and Hurricane Andrew, make this strategy problematic for enforcing safety for entire response operations. Establishing secondary or internal perimeters at a disaster scene is also crucial for enforcing safety practices for particular areas of the scene. At many disaster sites, particularly those involving the release or potential release of hazardous materials, Incident Commanders will seek to isolate areas of particular hazard by establishing an internal perimeter. ${ }^{9}$ Internal scene perimeters that define areas for equipment or other traffic, as part of an overall traffic safety plan for the incident scene, are also critical for protecting responders from vehicle-related hazards.

Although there is a range of operational reasons for why effective scene control is desirable at a major disaster scene, it can make a critical contribution to effective safety management and enforcement as well. Control of the scene perimeter and internal traffic provides the management structure with an enforcement mechanism that can cut across organizational boundaries. Therefore, response organizations should endorse and foster multiagency acceptance of scene control as a component of preparedness planning and rigorously implement scene control in the event of a major incident. ${ }^{10}$ This planning must include training for all relevant responders on effectively enforcing entry/exit, checking for required protective equipment, and other policies as part of monitoring the incident perimeter.

\section{Recommendation 6.4-Provide On-Site Training, But Not As a Substitute for Pre-Incident Training}

The diversity of response organizations involved in major disasters can result in some responders lacking needed information to follow safety policies or implement protective measures. One way of addressing these responder training needs is by providing workers necessary information on-scene at the disaster site. Although stressing the importance of on-scene efforts as an element of risk communication, site-safety orientation, or instruction in the use of particular protective equipment, individuals in the emergency response community interviewed for this study generally believe that such "just-in-time" training is an inadequate substitute for the more complete training that can be delivered before an incident occurs. ${ }^{11}$ Such efforts may also be effec-

\footnotetext{
${ }^{8}$ Examples cited where this was effective include the response to the bombing of the Murrah Federal Building in Oklahoma City [Jackson et al. 2002], portions of the World Trade Center site [California Task Force 3 2001; Study Workshop], and individual collapse sites in the Northridge earthquake [FEMA 1994a].

${ }^{9}$ Establishing operating zones is a standard practice at hazardous material incidents [Hawley 2000, 127 129].

${ }^{10}$ In addition, response commanders and other leaders visiting the site must follow the rules to set a good example, or else respect for scene control policies will be undermined [Study Interviews].

11 The experience at the World Trade Center site highlighted the challenges of undertaking on-site training for those in the construction trades and others, including the inevitable time lag in instituting such programs under the most difficult circumstances. One report notes that "months passed before the official training program" for
} 
tive in providing "refresher" training for personnel who had previously received instruction or in providing specific information on nonstandard equipment or response techniques. Otherwise, any individuals or responding units lacking the necessary preincident training for operating in the hazardous areas of a disaster scene should be removed from the site at the earliest possible time.

\section{Measures to Protect the Health of Responders: Adopting a Force Health Protection Approach}

In an analogy to concepts from the military, the study team drew on the idea of "force health protection" to broadly describe measures that can be employed by emergency response agencies to ensure that the force can "live to fight another day." However, the characteristics of disaster response situations make it difficult to effectively implement measures to provide for responder health maintenance and treatment needs.

Large Numbers of People Affected, Injured, or Killed. During the early phases of response, medical activities are often focused on the needs of disaster victims; in situations where many victims require assistance, responders may ignore their own injuries to continue helping others [Study Interviews].

Prolonged Duration. The duration of major disaster response operations creates the need for additional safety implementation activities that are not needed in routine emergency response. From a drive to rapidly address the needs of the victims, responders often work for extended periods. ${ }^{12}$ Such practices can result in exhausted responders losing their capacity to work effectively and, through poor decisions or direct action, hurting themselves or others. It was reported that responders and managers worked unsustainably long work shifts at Hurricane Andrew, the World Trade Center response, and the response to the anthrax attacks [Study Interviews]. ${ }^{13}$

Multiple, Highly Varied Hazards. Disaster-specific hazards can require health protection and treatment options that may not be routinely available to responder organizations. Beyond physical injury or hazardous exposures, the traumatic nature of major disaster situations can result in significant critical incident stress issues. ${ }^{14}$

skilled support personnel working at the World Trade Center site was approved and implemented. An envisioned two-day program of awareness training for workers was scaled back to three hours [Lippy and Murray 2002, 11].

12 These issues were cited as problems in every response operation examined [Study Interviews].

${ }^{13}$ In the response to major flooding in Pima County, Arizona, a public safety helicopter reportedly crashed as a result of responder fatigue due to "overwork in high-risk rescue operations and inadequate crew rest" [McHugh 1995].

${ }^{14}$ For example, after the Oklahoma City bombing, critical incident stress issues had significant effects on the fire department involved, including premature retirements of employees as a result of post-traumatic stress disorder [Bunch and Wilson 2002]. 
The effects of some hazards may not become manifest for some time, creating the potential for disaster-related impacts over extended periods.

\section{Recommendation 6.5-Improve Health Maintenance by Preparing and Implementing Sustainability Measures}

Workforce health protection encompasses a variety of activities designed to maintain the health of the responders through extended disaster operations. Regarding responder medical care, a study workshop participant described such sustainability efforts this way,

It's basic preventive medicine and public health: eating, sleeping, drinking, washing hands, showering. There is a need to break down the management mind-set that allows emergency responders to work beyond the point of exhaustion and not have basic sleep hygiene [Study Workshop].

These measures include the provision of rehabilitation to reduce fatigue and provide near real-time medical monitoring of emergency responders [NFPA 2002c, 8], the enforcement of work/rest ratios, and the development and enforcement of decontamination procedures appropriate to threats involved at the disaster site.

Rehabilitation. Response managers must recognize the long-term nature of disaster response operations early and put rehabilitation measures in place both for managers and for workers. These measures must be mandatory, and it is critical that response leadership "lead by example" because of the tendency of emergency responders to emulate leaders who continue to work despite obvious exhaustion [Study Workshop]. Study workshop participants, while concurring with the importance of rehabilitation to the sustainability of the workforce, suggested that this concept is poorly defined in many emergency response systems. They pointed to a lack of adequate pre-planning as part of the problem [Study Workshop].

Rehabilitation should include an opportunity for a break (both physical and mental) from response activities. Effective mechanisms to ensure that food and drink are available to responders are also critical components of planning; the practical requirements of delivering such necessities to responders can differ considerably among disaster types [FEMA 1992]. A formal rehab process also should include simple preventive health assessments (such as monitoring heart rate and checking blood pressure) as well as a quick assessment for stress. ${ }^{15}$ Rehabilitation can also provide an opportunity to relieve some stress via information dissemination and rumor control

\footnotetext{
15 Providing "mental health" assessments (that is, more than just a "quick look in the eyes") during rehabilitation may pose some difficult confidentiality problems because rehabilitation space is often limited at a disaster site [Study Workshop]. It may be more appropriate to have responders suffering acute stress reactions leave the site and to receive additional assessment and intervention in a more confidential environment.
} 
[Study Interviews]. ${ }^{16}$ In some major disasters, emergency responders and their families may be victims as well [Lewis 1993; Study Interviews]. Rehab breaks can provide an opportunity to reassure responders by giving them access to telephones to check in with their families.

The rehabilitation structure needs to be managed within the ICS and approached systematically rather than being left only to voluntary groups that deploy to the disaster site. It has also been argued that a formal process of rehabilitation, if used at every level of incident and not just major disasters, will become second nature to emergency responders, and that will help with compliance [Study Interviews]. Workshop participants endorsed the need for development of a "checklist" to help local communities prepare for responder rehabilitation activities, noting that a range of appropriate activities will be related to incident type and duration [Study Workshop].

Work/Rest Ratio. One of the specific issues in dealing with responder fatigue is the need for a near real-time mechanism for monitoring how long individual responders have been working at the disaster site. Although managing responder shift changes and work periods is a key function of the planning section of the ICS, when no one is monitoring how long individuals have been on-site, many will keep working well past exhaustion [Study Workshop]. In addition, as with rehabilitation policies, if leaders show no concern for their own welfare, the "troops" will follow their lead. Unfortunately, workshop participants felt that it was often true that "the ones least likely to give up the reins and put their weight behind rest and rehab are the ones at the top" [Study Workshop].

The appropriate work/rest ratio may change over the course of an incident. The first six hours may be the most physically and mentally demanding time for the Incident Commander and senior leaders at the scene [Study Workshop]. Therefore, although the pressure to stay at the scene may be intense, shift change in the most early phase of an emergency event may need to be sooner rather than later for senior leaders [Study Workshop]. An appropriate work/rest ratio has to be defined by what the emergency responders are doing and the equipment they are wearing; however, shifts of longer than 12 hours will undoubtedly result in risks brought on by fatigue [Brainard and Behrendt 1993]. ${ }^{17}$ It is also important to recognize in planning for manpower at the scene that, when decontamination is required and travel time is included, a 12-hour work shift actually may amount to 14 or 15 hours or more. Inclu-

\footnotetext{
${ }^{16}$ For example, there were rumors in Oklahoma City that human remains were contaminated with cholera, creating unnecessary stress in an already stressful situation [Study Workshop].

${ }^{17}$ For example, a responder working in fully encapsulating protective equipment would require far more frequent rest than a responder working a "regular 12-hour shift" in standard clothing. While the latter might only need rest every four to six hours, the demands of fully encapsulating equipment might mean the former should be resting after two hours or less [Study Workshop].
} 
sion of responders' personal needs in safety planning-providing opportunities for them to obtain food, sleep, and personal hygiene facilities near the incident scene-can enhance opportunities for rest by reducing needed travel. Where possible, rotation of multiagency emergency teams is an alternate mechanism to allow for longer periods of "downtime" for emergency responders [Study Interviews]. Shifts are also much easier to enforce if all responder agencies are following the same shift schedule. If that is not possible, color-coded event badges (discussed previously) could be used to help with the enforcement of the work/rest ratio and rehab [Study Workshop].

Decontamination. A key aspect of responder health protection is effective decontamination procedures. Decontamination may be critical to the prevention of illness, especially in the case of a nuclear, biological, or chemical attack, and yet compliance with decontamination procedures, especially in the early phase of a major disaster, has proven to be a problem. ${ }^{18}$ In order to be used, decontamination facilities have to be readily accessible, and it is critical that response managers lead "by example." If management neither takes responsibility for nor endorses decontamination efforts, any attempt at establishing a system will likely fail [Study Interview]. Insufficient decontamination can lead to the spread of contamination both on and away from the site. If workers who are contaminated at the site receive medical care, either on-site or in local hospitals, they can, in turn, contaminate emergency medical services (EMS) and hospital personnel [Study Workshop]. If workers who are contaminated leave the site to go home, they can contaminate their vehicles and homes, potentially exposing others to health risks.

There are some natural leverage points for enforcing decontamination procedures at major disaster sites. Hand washing can be required before access to food is allowed [Study Workshop]. If an effective perimeter has been established, trucks can be stopped for wash down before exiting the scene [Study Workshop]. Perimeter control also makes it possible to screen workers (including construction and trade workers and convergent volunteers) for contamination before they leave the disaster site [Study Interviews]. The FEMA Urban Search and Rescue (US\&R) Program Staffs after-action analysis of the September 11, 2001, response operations specifically highlighted the need for improved guidelines for "hygiene, gross decontamination, and technical decontamination” [FEMA US\&R Program Staff 2002].

\footnotetext{
${ }^{18}$ For example, although the National Medical Response Team (NMRT) Task Force set up three decontamination corridors at the Pentagon site, compliance was initially incomplete, even among responders involved in recovery of bodies and debris removal [Study Interviews]. This situation was far from unique, according to interviewees with knowledge of a variety of such response operations.
} 


\section{Recommendation 6.6—Provide Medical Care to Responders During the Early Phase of a Disaster Response Operation}

Based on study discussions, there is a need for better strategies to provide medical care to emergency responders in the earliest stages of response operations. Although medical care for responders is a function within the logistics section of the ICS, during the high pressure and chaotic environment in the early phases of disaster response, effectively treating responder injuries is difficult without having medical providers directly connected to responder units involved in operations. The need for effective treatment of responders would be even more critical in some terrorist scenarios (such as attacks with nuclear, biological, or chemical weapons) that could result in significantly more responder injuries than have been experienced to date. Disaster preparedness must therefore consider potential responder injuries in different types of response operations and include plans to treat them. Key information to be factored in includes the capabilities of the local EMS system and local hospitals. Planning should also consider the potential public and responder health implications if responders or hospital staff suffer casualties in performing their missions.

One model suggested during study discussions to provide immediate treatment for responder injuries at the disaster scene is development of a "tactical medic role." 19 Workshop participants observed that, in Desert Storm, military commanders anticipated that mass casualties were a possibility; so they deployed significant numbers of qualified medics to the front lines with the troops. The fact that many firefighters have EMS training or certification means that significant capacity exists within the response community to implement this approach, although any potential impact on response units' operational effectiveness would need to be considered. ${ }^{20}$ However, assigning responders to such a role would have implications on available staff resources for other response tasks. ${ }^{21}$ Access to mobilized, self-contained medical teams, such as DMATs, that can be deployed on short notice is also important, especially when individual DMATs can be specifically tasked to provide medical support to emergency responders [Study Interviews].

The delivery of medical care on-site (or near-site in staging areas) often involves EMS responders and other medical personnel deployed under mutual aid agree-

\footnotetext{
19 The decision whether to treat responders at the disaster scene or to transport them elsewhere is often a function of the local EMS infrastructure, including the capabilities available to the local responder organizations and the level of preparedness at nearby health care facilities. Differences among localities preclude a "one size fits all" solution to the problem of delivering acute medical care to emergency responders at major disaster sites [Study Workshop].

20 Workshop participants indicated that, if this model is adopted, it is important to define this medic role and designate particular responders to carry it out. In addition, those responders would need to be provided medical equipment-in addition to their firefighting gear-to carry out the medical support function [Study Workshop].

${ }^{21}$ An alternate mechanism suggested to help ensure that responders receive care for injuries is to rely on a "buddy system." While having pairs of responders assigned to look out for one another does not provide a new source of medical care, responders would be responsible for ensuring their partner obtained care if he or she were injured.
} 
ments. In certain disasters, such as the September 11, 2001, Pentagon response and Hurricane Andrew, military medical personnel were also involved in the delivery of medical care. Deployment of military medical personnel and personnel under mutual aid agreements may raise licensing and liability issues. Any legislative actions or interagency agreements necessary to make such deployments possible should be accomplished in the pre-planning period so that they can be implemented rapidly in the event of a major disaster. ${ }^{22}$

\section{Recommendation 6.7-Protect the Mental Health of the Response Workforce by Managing Critical Incident Stress}

Although the majority of responders exposed to critical incident stress are "normal people having normal reactions to abnormal situations" [Study Workshop], the traumatic nature of major disasters can have significant effects on individual responders and on response organizations as a whole. As a result, workshop participants indicated that there has been a "cultural change" in the responder community that has led to widespread implementation of some form of critical incident stress management in many organizations [Study Workshop]. Measures that seek to address these problems, including critical incident stress debriefing (CISD), ${ }^{23}$ are now well established as routine practice in many organizations. Although the attention being given to this issue is considered positive, there is evolving controversy surrounding whether the measures that have been adopted to address them are sufficient. ${ }^{24}$ The research performed in the course of this study was not focused on examining particular strategies to address critical incident stress. As a result, the recommendations are not focused on particular intervention methods or programs. Instead, the study examined this issue as an element of the overall hazard environment faced by responders to major disasters with respect to preparedness and response planning.

The central conclusion from both interviews and workshop discussions is that it is very important to consider critical incident stress in response planning. Beyond addressing the needs of traditional responder groups such as firefighters, police, and EMS personnel, planning should consider nontraditional responders as well. Many of those responder groups-including construction and trade workers, relief workers,

\footnotetext{
22 There may also be issues of legal liability for medical malpractice when military medical teams treat civilian responders as part of a disaster response [Study Interviews].

23 CISD is an intervention to prevent or mitigate post-traumatic stress disorder among emergency responders. Typically, the model calls for a single session group debriefing that takes place within days of exposure to a critical incident. The model is based on military post-action debriefing [Mitchell and Everly 1996].

${ }^{24}$ Several critical reviews of CISD have been published in recent years. Although it is important to acknowledge that CISD has been used, applied, and researched differently in different contexts, these reviews have found little evidence to suggest that CISD can prevent post-traumatic stress disorder among emergency responders, and some have suggested that debriefing may be harmful to some individuals. There have been three comprehensive reviews of studies of CISD [DHHS et al. 2001; Rose et al. 2002; van Emmerik et al. 2002].
} 
and volunteers - may not have any post-incident stress management resources available [Study Workshop].

Interviewees and workshop participants also highlighted the importance of support for the families of emergency responders in addition to directly supporting the response workers [Study Interviews; Study Workshop]. Depending on the nature of the disaster, response activities could have a significant effect on all members of responders' families. Addressing family needs can be an important component of addressing the needs of the responder, particularly when their families are at risk of being victims of the disaster.

As an element of preparedness, communities need to develop local resources for handling critical incident stress or have a plan to access other resources. Workshop participants indicated that employee assistance programs are one way to provide this sort of assistance within individual response organizations [Study Workshop]. The effectiveness of such programs is dependent on there not being barriers to employee use, such as stigma or other professional consequences.

Over the course of the study, responders suggested a range of more specific potential activities focused on periods before, during, and after the incident [Study Workshop]. For the pre-incident phase, suggestions focused on the need for responder agencies to address the overall wellness of their responders. As one workshop participant said, "if a responder went into an event with baggage, he will not come out with less baggage." Therefore, responder organizations should be encouraged to address such wellness issues as alcohol abuse and marital problems. ${ }^{25}$ Another workshop participant suggested that a routine assessment of stress issues could be done during the annual medical exam for firefighters, but the participant also indicated that not all responding organizations provide for annual medical exams.

"Stress inoculation" is another military concept that participants suggested may be applicable to the responder community. This "preventive" approach eliminates some of the element of surprise for the responder about to enter an area where there are known psychological stressors (such as dead or injured children). One workshop participant described this as similar to the model used in Vietnam with soldiers who had to transport dead bodies. Those leaving the scene would provide a "pre-briefing" for the next wave of responders, focused not on "feelings" but rather on operational issues such as what to expect in terms of sight, smell, dust, wind, and so forth. ${ }^{26}$ The

\footnotetext{
${ }^{25}$ A systematic study of psychiatric disorders among firefighters in the aftermath of the Oklahoma City bombing found high rates of alcohol disorders in firefighters post-disaster, with virtually no new cases occurring after the bombing, leading researchers to conclude that there is a need for ongoing programs targeting alcohol abuse. Generally, the researchers found that pre-existing problems strongly predicted post-disaster psychiatric problems [North et al. 2002].

${ }^{26}$ Along similar lines, one responder agency in New York City paired new arrivals to the World Trade Center site with experienced responders, both to provide safety orientation/training and to perform an initial "monitoring" role to assess the individual's reaction to the disaster itself.
} 
tactic of pre-briefing received widespread support among workshop participants, although it was noted that there is little research on stress inoculation and almost nothing on pre-briefing.

As mentioned previously, there is considerable controversy surrounding the efficacy of various approaches to stress debriefing and treatment after a traumatic incident has occurred. This lack of consensus indicates a need for further examination of this issue and further development of strategies to address the effects of traumatic incidents on individuals. In light of the potential long-term effects on individuals and response organizations, responders indicated that it was important to monitor workers during an incident for signs of excessive stress and follow up afterwards to ensure that individuals in need of treatment get it.

\section{Recommendation 6.8-Improve Long-Term Surveillance of Responders' Health Following Major Response Operations}

The unusual hazard exposures and working conditions involved in major disaster response operations create the potential for significant, long-term health consequences of disaster response. Although there are long-term care and surveillance systems for World Trade Center responders, ${ }^{27}$ such ad hoc efforts do not address the broader need for follow-up care and surveillance for responders to major disasters.

To effectively characterize the consequences to responders' long-term health, it is clear that an accurate registry of involved responders, preferably compiled as the response is under way, is a prerequisite to any eventual surveillance or treatment effort. Workshop participants delineated a number of points of leverage during a response and in the post-incident period. As described above, perimeter control can provide the accountability information needed to determine who might have been exposed to what at the disaster site. Without information on who was involved, there is no guide for who should be screened for which potential long-term effects [Study Workshop]. Understanding where people were and what they were doing during the event is key for post-event intervention, and it is very difficult to reconstruct after the fact if the data were not originally collected. ${ }^{28}$ Tracking of post-disaster health problems is also complicated by lack of baseline data and accountability information for responder activities during the response.

\footnotetext{
27 For example, the World Trade Center Worker and Volunteer Medical Screening Program (http://www. wtcexams.org/factsheet.html).

${ }^{28}$ Particular concern was raised about two groups of responders who may be overlooked in long-term follow-up efforts. These include nontraditional responders such as construction workers and day laborers (especially laborers not represented by unions) and employees deployed under federal response systems [Study Workshop].
} 


\section{Human Resource and Equipment Management: Safety Effects of Responder Deployment and Supply Logistics}

Although responders and equipment are needed to address the operational demands of a disaster, the uncontrolled entry of either one into a disaster scene can complicate safety management and create new safety problems. As a result, effective management of the flow of human resources and equipment into the response is critical for safety as well as operational reasons. The characteristics of disaster situations make it particularly difficult to address these areas during response management.

Large Geographic Scale. In all the disasters examined for the study, the size of the operational areas made it more difficult to effectively use responder and supply resources. In Hurricane Andrew, the uncoordinated entry of response units to the disaster area led to commanders "losing" units and significantly hindered attempts at coordinated action [Holsenbeck 1994, 191]. At the World Trade Center site, the size of the area complicated logistics and made it difficult for responders to get the supplies they needed [Jackson et al. 2002].

Prolonged Duration. Because disaster responses extend over long periods, logistics efforts must be put in place to sustain operations over days, weeks, or even months.

Multiple, Highly Varied Hazards. The presence of unusual hazards in some disaster operations creates the need for safety-related equipment that may not be maintained by all responder groups. This is particularly true for nontraditional responders. The need to provide supplementary protective equipment appropriate to the hazards increases the complexity of response logistics efforts.

Wide Range of Needed Response Capabilities. Differences in operating procedures among disaster response organizations can lead to units responding to a disaster without coordinating with the ICS. This was a central challenge at the Pentagon response [Arlington County 2002, 25 26, A-49] and in the response to Hurricane Andrew [Study Interviews]. When they do respond, members of different organizations may be equipped very differently or, in some cases, may not be equipped at all. Occasionally, interoperability and incompatibility problems among different organizations' equipment make it even more difficult to ensure that all responders are properly equipped. ${ }^{29}$

Damage to Infrastructures. Disaster effects on transportation systems can keep safety managers from getting needed supplies or response resources. For example, the shutdown of the air transport system on September 11, 2001, was a serious impediment to supplying the World Trade Center response operation and hampered FEMA

\footnotetext{
29 This was cited as a particular problem at the Pentagon and World Trade Center response operations for breathing apparatus [Arlington County 2002] and respirator cartridges [NVFC 2002, 85; Jackson et al. 2002], among other supplies.
} 
US\&R Incident Support Teams' ability to respond at both the World Trade Center and the Pentagon [Jackson et al. 2002]. After Hurricane Andrew, traffic clogging surface transportation infrastructure had a similar effect [Study Interviews]. ${ }^{30}$

Influx of Convergent Volunteers and Supplies. Convergent volunteers, who are often not connected with any defined organization, present significant challenges to management systems. ${ }^{31}$ Similarly, uncoordinated delivery of supplies or equipment to the disaster scene can choke responder logistics systems. When incoming supplies are not systematically catalogued, responders may not be able to use them to support their efforts. At Hurricane Andrew, even though the state was inundated with over 2,400 tractor trailer loads of donated goods, the emergency support organizations frequently still sought supplies through contractors rather than trying to determine if the needed supplies had already arrived [Haynes and Charney 1993].

\section{Recommendation 6.9-Adopt Better Measures to Manage the Recall and Mutual Aid Processes for Responders}

Safety management depends on knowing who is operating at the disaster scene and in what capacities. Personnel accountability systems are a source of this information; however, a more effective strategy is to put measures in place to regulate how external assistance comes to, and is utilized at, the disaster scene. Although many response organizations do have such policies in place, the experiences at both the Pentagon and the World Trade Center demonstrated that the disruptions inherent in a major event can significantly hinder efforts to manage responder deployment.

Several operational and administrative measures can be employed to reduce the chances of individual responders, or even units, proceeding directly to the disaster scene without the knowledge of overall Incident Commanders. Local emergency organizations are likely to have contingency plans for managing the deployment of their own responders to the scene of a large disaster. However, such plans need to be exercised under realistic conditions that take into account the likelihood of communication failures, command problems, and strong psychological pressures on commander and rank-and-file responders to deploy directly to the disaster scene.

Similarly, local governments need to evaluate and exercise their workforce recall procedures. Entry of personnel to both the World Trade Center and Pentagon scenes was marked by substantial confusion as off-duty responders and volunteers deployed to the disaster scene and other locations [Arlington County 2002, A-39 A-41; McKinsey \& Company 2002b, 10, 35 37]. The same situation occurred in Hurri-

\footnotetext{
${ }^{30}$ Also, communications infrastructure problems can impede operational, logistical, and other functions [FEMA US\&R Program Staff 2002].

31 In the case of terrorism, individuals converging on the scene could actually represent a direct threat to responder safety. One RAND interviewee cited the experiences in Israel with suicide bombings to make the point that some "volunteers" arriving at a disaster scene could easily bring secondary explosive devices with them [Study Interviews].
} 
cane Andrew over an even larger incident scene [Study Interviews]. Well-designed workforce recall procedures can reduce the inclination of off-duty responders to rush directly to the disaster scene rather than reporting to predesignated personnel reporting sites. Better plans, redundant communications, and periodic and realistic recall exercises all strengthen workforce discipline. ${ }^{32}$ Given the protracted nature of major disaster responses, some responding units must be initially withheld so that they can eventually support multiple-duty shifts.

Mutual aid agreements with neighboring jurisdictions, within states, or at regional levels are also key mechanisms for regulating the flow of external assistance to a disaster response. To avoid exacerbating personnel accountability problems, units responding from outside the immediate area of the incident must be given and must accept authoritative guidance on how they should support the disaster response. Realizing the full value of mutual aid requires not only general compacts but also achieving a detailed understanding of how corresponding units are organized, trained, and equipped [Francis 1997]. In addition to putting effective compacts in place, this process of coordination requires significant preparedness efforts. Measures to address this issue have been under way for some time across the responder community (e.g., extensive local, statewide, or multistate assistance compacts).

\section{Recommendation 6.10—Implement Better Mechanisms to Utilize and Manage Disaster Volunteers}

Volunteers make substantial contributions during major disasters. Local, state, and federal agencies historically have relied on nongovernmental organizations, such as the American Red Cross and Salvation Army, to provide needed mass (population) care and support to responders. ${ }^{33}$ Because of the scale of major disasters, the efforts of such groups are integral to serving the needs of both the victims of and responders to the events. Because of their experience in disaster response operations, such relief organizations are also better prepared to connect with the ICS at these events. This linkage makes it possible for the Incident Commander to coordinate volunteer activities and to link them to the safety management efforts for the response. Convergent, or independent, volunteers at the scene lack this organizational structure. Absence of this structure makes it more difficult to manage the incident scene and to protect these volunteers' safety.

Effective safety management requires mechanisms to provide for the safety needs of all responders, including any volunteers. For some disasters, where the haz-

\footnotetext{
32 Although self-deployment of responders directly to an incident may enable more rapid rescue of some victims, the problems it generates for incident management have the potential to cost the lives of both responders and victims as the response effort continues.

33 During the World Trade Center response, for example, the American Red Cross and Salvation Army took leading roles in supplying food services, dry clothing, first aid, and moral support for the responders at Ground Zero [Spadafora 2002].
} 
ard environment is such that volunteers cannot be sufficiently protected, doing so would require all unaffiliated volunteers to depart the disaster scene as soon as possible. Effective scene controls, including identification and credentialing systems, will enable the Incident Commanders to "filter out" convergent volunteers and others from the hazardous areas of the disaster scene. If the efforts of convergent volunteers are needed, and measures can be instituted for their safety needs, then arrangements must be put in place to integrate them into the overall management system at the incident.

As cited above, a significant strength of volunteer organizations with experience in disaster response is their understanding of and capability to connect with incident management structures. As a result, responders urged connecting convergent volunteers to established organizations as a way of coordinating their activities and improving overall personnel accountability. This approach was used to good effect during the Hurricane Andrew response, where the scope of the devastated area and limited responder resources necessitated the use of volunteers in supporting emergency activities [Lewis 1993]. Integrating such volunteer coordination measures into preparedness, either through established organizations or as a separate activity, is critically important to ensuring that the response effort can benefit from volunteer efforts while still providing necessary safety and health protection [Florida Commission on Community Service 2003]. ${ }^{34}$ Putting this into practice would require a significant outreach component to educate the public on how volunteers can be most effective and useful in disaster response operations.

\section{Recommendation 6.11-As Part of Preparedness Efforts, Establish Systems for Managing the Logistics of Safety Equipment}

During the early phases immediately following a disaster, when resources are usually very constrained, safety equipment and supplies donated or provided by outside organizations can be very important in providing protection for responders. However, uncontrolled flows of supplies into the disaster zone as efforts continue can choke response logistical systems and prevent responders from getting needed safety resources. Responders emphasized that rigorous planning for equipment needs is the first step to controlling post-event logistics. If Incident Commanders have a clear idea of what supplies are needed, they can put out consistent messages about those needs and increase the chances that supplies sent to the area will be useful. In the wake of the huge amount of supplies that were sent to Florida after Hurricane Andrew, Miami-Dade County set up a hotline to coordinate donations and provide a

\footnotetext{
${ }^{34}$ In addition to addressing volunteer management, preparedness should include systems to draw on critical volunteers after an incident. Skilled volunteers can make significant contributions to safety and to operational activities. For example, drawing on volunteer psychological counselors can be helpful [Brainard and Behrendt 1993]. Systems must be in place to call on these individuals to ensure their availability after an incident [Pine 1993].
} 
way to educate people about what was needed and what was not [Johnson 2002]. In addition, just as scene control is important to organize personnel at an incident, maintaining staging areas to collect and organize donated equipment is also critical [Williams 1992]. Also, information systems are needed to inventory supplies and equipment delivered to the disaster scene. Without rapid methods to match on-site supplies to response needs, responders may not receive needed equipment [Haynes and Charney 1993].

\section{Summary}

Taking actions for safety management during disaster response involves implementing effective measures to protect the safety and health of responders and convergent volunteers. Response managers must be able to count on risk communication mechanisms for timely dissemination of safety policies and guidelines to the entire responder workforce. For the safety of all responders, enforcement measures are also needed to ensure that no individuals or responding units are permitted to be ignorant of, or to disregard, these safety practices, except under exceptional circumstances. Adopting a force health protection approach would go a long way toward providing a coherent organizing concept for identifying, treating, and monitoring responder injuries and health problems during disaster response operations and afterwards. Finally, responding organizations need improved tools and greater pre-planning to ensure that they are prepared for sustaining the safety and health needs of responders during protracted disaster response and recovery operations. 

In developing recommendations to improve safety management during the response to a major disaster, the research team initially focused on the three phases of the safety management cycle. Yet as the research progressed, we realized that providing better ways for individual response organizations to gather information, to analyze risk and make decisions, and to take action would not be enough to fully address the safety management needs during large-scale operations. ${ }^{1}$ Rather, the complexity and demands of post-disaster environments call for solutions based on improved coordination among the multiple organizations that become involved in major disaster response operations.

Nothing demonstrated this better than the September 11, 2001, response operations at the Pentagon and World Trade Center. What we learned from those examples led us to the central organizational finding of this study: The emergency response community should put in place structures and preparedness efforts that will formalize an integrated, incident-wide approach to safety management at major disaster response operations. Just as a key goal of the ICS is to facilitate integration of many operational assets as the demands of a response operation increase, mechanisms must be available to allow safety management efforts to scale up as well.

Indeed, the solutions to key problems in each functional phase of the safety management cycle are inherently interorganizational, relying on multiagency safety efforts:

\section{- Gathering Information}

- Required hazard monitoring capabilities may reside in different response organizations.

\footnotetext{
${ }^{1}$ In principle, all shortfalls in disaster safety management could be addressed at the individual organization level. However, preparing every response organization for the full range of potential disaster safety problems would be, at best, a challenging and resource intensive strategy. To adequately address all potential safety shortfalls would require significant augmentation of all organizations' information-gathering capacity, decisionmaking and assessment expertise, and implementation capability-much of which would not be beneficial for their routine response activities.
} 
- Information on responder accountability, training, equipment, and health status information must come from many separate organizations.

- Analyzing Options and Making Decisions

- Technical expertise to assess hazards must frequently be drawn from multiple responding organizations.

- Effective decisionmaking requires coordination of equipment and hazard mitigation options brought to the incident by all responding organizations.

- Taking Action

- Difficulties in uniform safety enforcement can be addressed only via interagency coordination and agreement.

- Sustainability measures to protect responder health must be applied across organizational boundaries.

- Management of human and material safety resources must be coordinated among multiple responding organizations.

Only by building the capability of response units and agencies to coordinate at the organizational level can they be most prepared to successfully manage the functional challenges they face.

Developing such an integrated approach requires a transition from viewing safety management as an activity primarily carried out by individual organizations alone to understanding it as a multiagency function within the ICS that can scale up to meet the needs of complex disaster response operations. This transition must encompass organizations across the full range of the disaster response community-all levels of government, nongovernmental groups, and the private sector. In addition, recognizing the high-pressure and severely time-constrained post-disaster environment, this functional approach to safety must facilitate rapid initiation of multiagency coordination and safety management activities.

\section{Benefits of an Integrated, Incident-Wide Safety Management Approach}

The capability to draw on the safety resources of many organizations and effectively apply them to safety management for the overall incident would provide several important opportunities to better meet the safety needs of all involved responders:

- access to the specialized safety capabilities of multiple organizations

- a strategic approach to safety management

- a mechanism to address inherently multiagency safety issues

- a route to take advantage of diverse response capabilities. 


\section{Access to the Specialized Safety Capabilities of Multiple Organizations}

When organizations from different response disciplines come together at major disaster operations, they bring significantly different levels of safety management capability. Such differences in expertise and equipment can result in safety shortfalls when organizations without necessary expertise or equipment are "on their own" to manage responder safety. However, when safety management efforts are coordinated among multiple agencies, such differences represent an opportunity to draw on organizations' relative strengths to bolster protection for responders overall.

Many of the different organizations involved in carrying out response tasks at an incident scene bring not only operational capabilities, but safety expertise and resources to the operation. Government agencies at all levels, nongovernmental organizations, and private-sector entities with safety-related responsibilities at the scene may bring additional safety resources and knowledge. ${ }^{2}$ Examples include

- law enforcement and intelligence expertise on potential threats and security hazards after terrorist events

- fire department expertise with thermal hazards and hazardous materials operations

- public health organizations' capabilities in disease surveillance and health monitoring

- Departments of Defense and Energy expertise on nuclear, radiological, and other weapons of mass destruction

- utility, transportation, or construction capabilities in their areas of specialization and responsibility

- federal, state, local or other organizations' expertise to assess hazards and measure environmental and occupational exposures.

It would be impractical for individual organizations to maintain the equipment and expertise needed to cope with all the hazards that could arise during a response to a major disaster. An integrated, incident-wide approach to safety makes better safety management resources accessible than would be possible for organizations operating alone.

\section{A Strategic Approach to Safety Management}

Just as the Incident Commander needs to take a strategic viewpoint of a disaster operation, a safety manager must be able to consider safety needs from an overall, strategic perspective. If the individuals responsible for managing responder safety are too close to or absorbed in the details of an operation, it is much less likely that they will

\footnotetext{
${ }^{2}$ Some of these organizations may have statutory requirements to respond to the incident or specific responsibilities related to responder protection.
} 
be able to fully understand and address the risks at a complex disaster scene. This can make it difficult or impossible to make good safety decisions and meet worker safety needs. Similarly, if safety managers cannot take a long-term view of safety concerns-for example, anticipating response safety concerns and projecting safety requirements-safety management will also suffer.

For the safety manager of an individual organization, the complexity and operational demands of a major disaster make it exceedingly difficult to get this overall perspective or to project future safety needs. But in the context of an integrated approach, the additional expertise, capabilities, and resources that can be brought to bear on safety issues can help build and maintain this more strategic approach to the incident. By delegating specific tasks—such as technical monitoring of hazards, equipment logistics, or accounting for personnel - to the right experts or organizations, safety managers can focus their attention on building an overall understanding of the incident safety needs, providing better support to the Incident Commander on the safety components of operational decisions, and anticipating safety and health concerns that may arise as the incident evolves.

\section{A Mechanism to Address Inherently Multiagency Safety Issues}

A coordinated safety management effort provides a mechanism for sharing necessary safety information among response organizations. This coordination is particularly important to address the possibility that response activities can produce new and unfamiliar safety hazards for other responders. ${ }^{3}$ Similarly, integrating multiagency activities can improve the effectiveness of safety measures by allowing better coordination of safety logistics efforts. Such integration would reduce the chance of duplicative resource requests from separate organizations, a situation often observed in major disaster responses, and potentially make it possible to better allocate safety resources across the response overall.

An integrated approach to safety management can also make it possible to begin addressing a potentially more serious problem - the difficulty in uniformly implementing and, if necessary, enforcing safety policies across the disaster response operation. By bringing together representatives from relevant organizations, integrating different organizations' safety management efforts provides a route to build consensus on safety policies and procedures among all response organizations. Such an incident-level consensus would enable more uniform implementation of safety measures across an incident, even in the absence of centralized safety enforcement authority. If incident-wide enforcement measures become necessary to ensure use of critical safety measures, an integrated approach provides a way to develop the necessary multiagency commitment to put them in place.

\footnotetext{
${ }^{3}$ For example, when ongoing firefighting operations are occurring side by side with construction or demolition work, each activity could adversely affect the safety of the other responders.
} 


\section{A Route to Take Advantage of Diverse Response Capabilities}

Responders from different disciplines come to an event with unique types of expertise. In addition, organizations that more frequently face particular types of disasters-for example, responders from areas that experience specific natural disasters-develop expertise in responding to those sorts of incidents. Specialized expertise may also reside in response organizations from areas with elevated risk of particular events - such as high-profile cities at higher risk of terrorist attack-because of increased preparedness or participation in exercises aimed at those events. Accordingly, particular response units may be significantly more qualified to operate safely in particular risk environments. ${ }^{4}$ An integrated approach to safety management permits decisionmakers to draw upon this diversity to ensure that responders are assigned those tasks they are especially qualified and equipped to perform safely, lowering the safety risks for other responders. ${ }^{5}$

\section{Implementing Integrated, Incident-Wide Safety Management}

Responders to recent large-scale disasters have recognized the need to integrate their efforts in order to address the complex safety concerns of emergency workers. At both the Pentagon and World Trade Center, the practical difficulties associated with managing responder safety led response organizations to implement ad hoc arrangements to coordinate their safety efforts. Responders at the World Trade Center, for example, formed a large safety team, held daily safety-focused meetings, and brought safety experts into incident command meetings [Study Interviews]. This safety team initially instituted an accident prevention plan for the site and eventually developed a comprehensive safety and health management plan with input from the four primary contractors and 26 federal, state, and local agencies operating at the Trade Center site [Vincoli et al. 2002, 25].

Although these ad hoc efforts broke important ground by recognizing the need to implement an integrated, incident-wide approach to safety management, they also had significant shortcomings. First, because these expedient arrangements were developed during the course of the response, they took time to put in place. During the days before the structures were set up, the safety efforts of responding organizations had no effective mechanism for integration. In general, depending on the specific

\footnotetext{
${ }^{4}$ Examples of such responders include members of FEMA-sponsored Urban Search and Rescue teams operating in collapsed structure environments, trained hazardous materials responders countering spills of such substances, or police tactical teams facing situations with particularly high potential for violence.

${ }^{5}$ For example, if a disaster response required helicopter operations, it would be critical to select an appropriate pilot for the conditions. For operations during severe weather and high winds, calling on a Coast Guard pilot experienced in rescue operations would be appropriate. For a situation requiring a more tactical approach in urban terrain, a pilot from the local police force might be a better choice [Study Interview].
} 
hazards involved in an incident, such delays could have significant consequences for the safety of responders. Second, improvised groups also may overlook the involvement of important, but less obvious, sources of expertise needed for managing responder safety and health. For example, it was not always fully clear to responders at the World Trade Center disaster how the participants in the safety meetings were determined. It sometimes seemed to require significant "negotiation" to gain access to the meetings [Study Interviews].

In addition, some responders perceived it as a weakness that these safety management structures existed outside the formal ICS. Interviewees indicated that it was not always clear how effectively the deliberations of the safety committee were connected with the ICS. When safety is managed by an ad hoc group, one interviewee commented, it is less clear "how decisions are actually being made," and both the perceived validity of the decisions and accountability of the decisionmakers can be weakened [Study Interviews].

Although these ad hoc efforts were valuable, they also showed the very real need for the emergency response community to plan and practice integration and coordination mechanisms well before a disaster occurs. Doing so requires a transition from viewing safety management as a role primarily carried out by organizations individually to viewing safety as a formalized multiagency function within the ICS that can scale up to meet the needs of complex disaster response operations. Toward this end, we present the following recommendations.

\section{Recommendation 7.1-Build an Integrated Safety Function into the Incident Command System}

To ensure that safety management is closely linked to overall incident management, an organizational structure must be defined within the ICS for an integrated safety management effort. In the standard ICS, the ISO is part of the Command Staff (see Figure 3.2). No information collected for this study suggested a compelling rationale to position a multiagency safety function differently. But we recommend that safety management be approached not as a staff position but as a scalable multiagency function. In fact, a precedent exists for just such an integrated function on the management staff. The ICS includes a Public Information Officer supporting the Incident Commander for information dissemination [FEMA 1998]. In recognition of the need for coordinated release of information at large-scale, multiagency incidents, this role can be upgraded to a Joint Information Center (JIC) that integrates the public information staffs and efforts of all involved agencies [U.S. National Response Team, not dated]. Replacing the single ISO with an integrated, incident-wide safety function is analogous to replacing a single Public Information Officer with the JIC.

Disaster response operations often involve multiple levels of response management, including government emergency management organizations at the local, state, or federal level. Development of an integrated approach to safety management must 
therefore also address the potential safety roles for these different management levels. These additional levels of response management often do not take a direct role in safety management [Study Interviews; Study Workshop]. Because of their overarching viewpoint and inherently multiagency approach, however, they could be uniquely positioned to make significant contributions to an incident-wide approach to responder safety. Specifically, responders suggested that emergency operations centers or the command centers established by federal response agencies during major responses could take on management and coordination of broader, overarching safety issues thereby shifting some safety demands from incident scene safety managers. ${ }^{6}$

To organize the diverse safety resources and responders coming to a disaster scene, an internal organization must be defined for the integrated safety function. The ICS overall is divided into four sections (see Figure 3.1): Operations, Logistics, Planning, and Administration/Finance. This division, and the additional structures defined within each section, allows incoming resources to "plug into" the appropriate part of the operational effort. The integrated safety function needs a similar internal structure to organize safety assets drawn from multiple organizations.

Elements of this internal structure should be common for all disasters. For example, it is reasonable to assume that an integrated safety function would need a hazard monitoring subfunction to organize all the resources and responders involved in assessment activities. Other common subfunctions could include the following: personnel accountability, safety equipment logistics (in coordination with the ICS Logistics section), safety planning and forecasting (in coordination with the ICS Planning section), and responder medical care/health maintenance [see Morris 2001]. ${ }^{7}$ Within these subfunctions, specific roles and tasks will vary among different types of disasters. For example, protecting responders after a large-scale structural collapse will likely require significant monitoring for airborne hazards; safety management after a major flood may require greater attention to waterborne contaminants. However, starting from a common organizational template will facilitate efforts to accommodate disaster-specific differences in safety needs. ${ }^{8}$

Such organizational templates are especially critical since the earliest stages of most disaster response operations will be handled predominantly at the local level.

\footnotetext{
${ }^{6}$ There are also technological reasons these additional management levels could make significant safety contributions. For example, the fact that some of these management organizations work from fixed-site emergency operations centers enables them to have information management and resource coordination systems in place that would be difficult, if not impossible, to build at an incident scene.

${ }^{7}$ It should be noted that any organizational structure within a safety management function should not duplicate efforts taking place in other parts of the ICS.

${ }^{8}$ Analogous templates have been produced to support use of the ICS at a range of different types of incidents. For each incident, model command structures with their component subfunctions are provided as starting points for rapidly putting an ICS in place when an incident occurs. A variety of examples can be found in the U.S. Coast Guard Incident Management Handbook [USCG 2001].
} 
For safety management to function well later in the response, local responders must put structures in place that can scale up as the number of responding organizations increases. How successful they are in beginning an effective, integrated safety management effort will significantly influence the potential success of safety management for the entire incident.

\section{Recommendation 7.2-As Part of Preparedness Efforts, Coordinate Plans for Implementing Safety Management}

Beyond necessary management structures, effectively carrying out integrated safety management requires multiagency preparedness efforts to define how responder safety needs will be addressed in the difficult and high-pressure conditions after a major disaster. Successfully putting into practice an integrated approach to incident safety management requires

- defining requirements for, and sources of, safety assets and expertise

- ensuring that reinforcing safety assets will be able to "plug into" an integrated effort

- defining management and coordination processes.

Defining Requirements for, and Sources of, Safety Assets and Expertise. Planning efforts must identify the safety capabilities, technical expertise, and other resources needed to perform the necessary roles and tasks for effective safety management. Defining these needs before the event occurs is particularly important because after a disaster, any confusion about what resources are needed and where to obtain them can significantly delay implementation of safety management and hinder responder protection.

Necessary safety resources and expertise will clearly differ among disaster types. For example, although experts on radiation effects and specific protective equipment would be important after a radiological event, a tornado response would require significantly different knowledge and supplies. Determining the likely safety needs for particular disaster types is clearly a critical part of multiagency planning at all levels of government. ${ }^{9}$ Beyond such disaster-specific requirements, study discussions did highlight several specialties that could be broadly valuable for a range of different disasters. Public health is one discipline cited as particularly useful and often not well connected to response management [Study Workshop]. Responders also said that

\footnotetext{
${ }^{9}$ The safety assets that may be needed could clearly differ markedly based on local situations. For example, a tornado in a rural environment could result in very different hazards and responder safety needs than a similar event in an industrialized area.
} 
medical expertise is often disconnected from safety decisionmaking [Study Workshop]. ${ }^{10}$

In addition to identifying necessary safety assets, study discussions also indicated that better mechanisms are needed to enable responders to call on these outside sources. Among operational responders at the state and local levels, this problem was generally framed in terms of not knowing "who to call" to gain access to particular types of capabilities or resources for different disaster events. ${ }^{11}$

To the extent possible, the agencies that will provide particular capabilities and carry out specific safety management tasks should be defined in multiagency preparedness planning. During project interviews, for example, responders pointed out that confusion over what organization was responsible for which tasks risks duplication of effort while other safety needs go unmet. Such "prescripted" mission assignments can speed response and also minimize the effect of damage to communications or other infrastructures on responding to the disaster. ${ }^{12}$

Once necessary safety capabilities and designated sources have been defined, this information needs to be captured in checklists, flowcharts, contact lists, and decision aids to assist responders in implementing safety management after a disaster. A common understanding of safety needs and where to obtain them is a prerequisite for integrating safety efforts. Such shared management tools that help build this common understanding across response organizations at all levels of government could be especially valuable. In addition, such tools help ensure that all responders have rapid access to the information they need to effectively initiate safety management after an event occurs. ${ }^{13}$

Ensuring That Reinforcing Safety Assets Will Be Able to "Plug into" an Integrated Effort. In preparing for integrated safety management, response organizations must take steps to ensure that external organizations have a safety management struc-

\footnotetext{
${ }^{10}$ In the traditional incident management structure, medical support to responders is placed within the Logistics section (see Figure 3.1) [FEMA 1998]. As a result, without a specific effort by Incident Commanders to draw on their expertise, medical experts will not necessarily have the opportunity to contribute to safety decisionmaking. Several interviewees cited this as a particular problem during the responses to the anthrax incidents [Study Interviews]. Integration of a medical doctor into the safety function would be similar to the military practice of having a "staff surgeon" as an element of the Command Staff of major units [Department of the Army 1997].

11 To ensure that responders know "who to call" during an event, planning efforts should identify safety-relevant capabilities that are available locally. This planning should include the private sector and other nontraditional response groups. In addition, safety management resources that are available from state, regional, or national response organizations should be identified.

12 However, the unpredictability of disaster situations makes it impossible to plan for every eventuality. Such agreements will likely have to be adjusted for particular events to ensure that unforeseen safety needs can be addressed. As a result, decisionmaking mechanisms also need to be defined to allow safety management to better adapt to evolving disaster situations.

13 The need for better safety management tools—planning checklists for particular types of events, issues that should be addressed and hazards assessed early in a response, etc. - was highlighted independently of the need for better multiagency coordination and integration at these events.
} 
ture to "plug into" when they arrive on scene. If such a structure is not in place when other response organizations become involved, they may initiate their own strategies for safety management and, having done so, become more difficult to integrate into a coordinated effort.

At the beginning of a disaster response operation, local agencies initiate safety management based on their standard operating procedures. Just as a decision must be made to scale up the ICS - as it becomes clear that larger numbers of resources or multiple organizations are needed for a major incident - a decision must also be made on when to expand safety management. The decisionmaking criteria and process for scaling up the safety management function must be included in preparedness activities to ensure a smooth transition to an integrated management approach. ${ }^{14}$

It is also necessary for external organizations to come to the scene prepared to "plug into" an integrated safety function. Participating groups must have appropriately trained individuals as part of their response to contribute to safety management. Depending on the role of the organization within the safety function, the characteristics of that individual or those individuals might differ. Participants in study discussions indicated that some responding organizations do not include designated "safety representatives" in their planning, making it much more difficult to connect them to safety management [Study Interviews; Study Workshop]. ${ }^{15}$

Defining Management and Coordination Processes. Making the right connections between first responders and external safety resources is an important initial strategy for safety management coordination. However, the nature of disaster situations makes it impossible to plan for every eventuality. As a response operation continues, management processes must be in place to bring the right technical expertise into decisionmaking, ensure that the practical needs of all involved responders are included in risk management, allow reallocation of safety tasks to address changing circumstances or improve effectiveness, and allow effective implementation or enforcement of safety policies. For the operational components of a disaster response, this dynamic coordination among different response organizations is a primary role

\footnotetext{
${ }^{14}$ It should be noted that any effort at integrated safety management depends on first responding organizations initiating safety activities in a way that can scale up as the response evolves. Especially during the early phases of response activities, the demands of a disaster can pull responders away from safety responsibilities and involve them in operational action [Study Interviews]. If this occurs, safety management does not take place. In addition to hindering initial safety efforts, later organizations will have no way to connect with the management structure-to "plug into" - when they arrive at the scene.

${ }^{15}$ Not all organizations involved at a disaster scene need to have a representative directly participating in an integrated safety function. Only representatives from organizations with necessary safety expertise or capabilities need to be directly involved to allow coordination of their activities. The identity of these organizations will likely differ in different regions, as well as from disaster to disaster. Organizations that need to receive only the "output" from the safety function must be sufficiently connected to get the required information, but they will not necessarily require a dedicated representative.
} 
of the Incident Commander. ${ }^{16}$ A similar coordinating authority structure within the safety function is needed for effective integrated safety management.

Preparedness efforts must include development of management processes that can effectively link the efforts of multiple safety-relevant organizations during response operations. For example, there currently is no consensus in the response community regarding the best means for safety decisionmaking in multiagency response operations or how issues such as safety enforcement should be addressed for complex disaster scenes. ${ }^{17}$ It is clear, however, that the high-pressure and timelimited environment that exists after a disaster is not amenable to addressing such difficult issues. ${ }^{18}$ As a result, these questions should be included in planning efforts so that consensus can be built on appropriate ways to address these problems.

There is a range of potential organizational structures that could be used to manage an integrated, multiagency safety function. Although not comprehensive, three examples are illustrative of the variety of options that exist: (1) augmenting the capabilities of the Incident Safety Officer within the ICS, (2) broadly inclusive safety management based on the approach developed in the September 11, 2001, responses, and (3) safety management based on the concept of Unified Command in operational response management.

Current strategies to address safety needs during major incidents build on safety management processes developed for routine emergency response. Within the context of the ICS, these strategies provide ways to augment the capabilities of an Incident Safety Officer to address larger incident scenes and more complex problems. These strategies include providing the Incident Safety Officer with assistants ${ }^{19}$ and creating a "Safety" section within the Incident Command Staff to more significantly

\footnotetext{
16 Depending on the particular disaster, such management roles could be carried out by the on-scene Incident Commander; by individuals in the local, state, or federal emergency management/operations center; or both. For this discussion, no distinction is made between these different levels of management.

${ }^{17}$ It should be noted that the focus on incident-wide approaches to safety management in this chapter is not intended to minimize the importance of actions taken at the individual, unit, or organization level for protecting responders during response operations. In the case of safety enforcement, for example, any incident-wide consensus on appropriate safety measures and the need to enforce them will be largely implemented by the actions of organizations to inform their members and ensure that they comply.

18 This need for community consensus on organizational structures and processes also applies to the operational components of response. For example, in a study of a major flood response operation in Arizona, this factor was highlighted as the key driver for the area's improved response effectiveness [McHugh 1995].

19 The primary rationale behind the addition of assistant safety officers is to provide the ISO greater capability to monitor, assess, and manage a more demanding incident scene. "Complex incidents or those that cover a large geographic area may require the appointment of Assistant Safety Officers" [NFSIMC 2000, 63]. For incidents that involve unfamiliar hazards, such as the presence of hazardous materials or other unusual threats, "additional safety officers may be needed [to] ... provide an increased level of competency for the Incident Safety Officer" [Kipp and Loflin 1996, 202].
} 
increase the response resources devoted to safety..$^{20}$ Each of these approaches increases the resources and expertise dedicated to safety activities at large-scale operations. In addition, by preserving a centralized authority for safety (either the Incident Safety Officer or the head of the Safety section), decisionmaking is simplified.

The focus of these approaches is not multiagency coordination, however. In literature sources on emergency incident safety and in project discussions, it was suggested that drawing assistant Incident Safety Officers from different response organizations could provide some multiagency involvement in safety management. ${ }^{21}$ Assuming that all response organizations with relevant safety expertise and resources are amenable to this model-responders acting as assistants to a central ISO or Safety section manager from one organization - this approach could be successful.

Taking the safety committees formed during the September 11, 2001, responses as an example, a second, more inclusive model for integrated safety management could be utilized where a larger number of organizations are directly involved in discussion and decisionmaking. During project interviews, a significant number of responders were positive about the way these safety committees linked a wide variety of organizations. Because of the lack of clear management and authority relationships, however, others indicated that they did not allow rapid decisionmaking and were not sufficient to coordinate the safety activities of the involved organizations.

A third option identified during the study draws on the ICS concept of Unified Command as a model for safety management. ${ }^{22}$ In a Unified Command, organizations with legal or jurisdictional responsibilities for an incident form a management team to allocate resources and make decisions for the incident. A safety analogue of a Unified Command team could bring a more limited number of organizations with particular safety responsibilities or critical knowledge into decisionmaking. Like an operational Unified Command, other safety-related organizations would provide support to the unified safety team. Such a structure could be useful for integration if multiple organizations have specific statutory or other responsibilities for safety issues during disaster response.

When considering models for an integrated safety effort, it is clear that there are decisionmaking and managements trade-offs as the number of participants in the ef-

\footnotetext{
20 The other strategy that has been explored for particularly demanding incidents is creating a Safety section and, as a result, significantly augmenting the manpower devoted to responder safety concerns. The Safety section is staffed by a number of responders to make it possible to monitor and manage safety in multiple areas of a complex incident. It also provides a management structure to coordinate their efforts. By increasing the resources devoted to safety, this strategy provides a way to gather better and more complete safety information, carry out more rigorous risk assessment, and provide more effective implementation [Brunacini 2002; Morris 2001].

${ }^{21}$ This model of a central safety officer supported by assistants from other responding agencies is also suggested in Chatfield and Robertson, 1997.

22 One responder involved at the Pentagon even referred to their safety coordination effort as "a Unified Command of safety officers" [Jackson et al. 2002, 46].
} 
fort increases. Because of the time and effort that can be required to develop consensus among large groups, direct involvement of too many individuals in management decisionmaking could reduce the ability of the safety function to act decisively in rapidly evolving response conditions. The need to involve specialized organizational expertise in management must therefore be weighed against the increased complexity of making decisions among larger numbers of individuals.

The exact structure for an integrated safety management function remains to be determined during implementation efforts. It is clear that the legal responsibilities of different organizations may affect the permissibility of various management options. For example, some approaches may not be consistent with the legal or operational requirements of environmental, regulatory, or other agencies at the local, state, or federal level. Furthermore, because of the responsibilities and legal requirements that all organizations have for protecting their members and because of differences among jurisdictions or geographic areas, some centralized models of safety management may be problematic for individual responding organizations. These potential legal and practical constraints suggest that pilot testing of candidate safety management models is needed to evaluate their strengths and weaknesses for different operational situations and local circumstances.

\section{Recommendation 7.3-Develop a Group of Highly Trained Safety Managers to Facilitate Coordination at Major Incidents}

Although integrated safety management focuses on multiagency cooperation, effective organizational integration often requires key individuals to initiate and oversee the required coordination. One key role of an effective Incident Commander is serving as a bridge among separate organizations. We found that safety managers serving a similar role are needed to initiate and support multiagency coordination. We have labeled these individuals "disaster safety managers."

Because of the significant interagency component of disaster safety management, it is rare for individuals to gain the necessary "crosscutting" management and subject matter expertise in the course of their routine experience [Study Interviews]. Safety specialists from the fire service, law enforcement, or health organizations are knowledgeable about the safety needs of their own organizations; however, they generally do not develop the needed understanding of the safety requirements of other response disciplines or the management skills needed for very large multiagency operations. ${ }^{23}$

Although the specifics could vary based on individuals' backgrounds, disaster safety managers need to possess expertise in a range of areas, including

\footnotetext{
${ }^{23}$ For example, although the training programs that currently exist for fire service Incident Safety Officers were cited as positive by many study discussion participants, they also indicated that the programs were "not enough" to prepare individuals to manage safety at incidents of this size [Study Interviews, Study Workshop].
} 
- significant expertise in coordinating multiagency operations

- general knowledge of likely and potential hazards across a range of contingencies and responder types

- information on safety resources and their availability

- hazard assessment

- decision support

- human resources and equipment for safety

- understanding of the processes and requirements to call on external capabilities

- knowledge of relevant decisionmaking criteria for managing responder safety

- experience operating within Incident Command Systems.

By possessing a broad-based understanding of disaster situations, these managers not only would have a working knowledge of the safety issues involved in most incidents, but would also know when supplementary technical expertise was required. Perhaps most important, placing an individual with significant multiagency coordination expertise in the Safety function is critical to promote coordination and integration of the safety-related efforts of all organizations involved in a response.

To ensure that disaster safety managers possess all the necessary expertise included above, curricula need to be developed addressing the specific skills and knowledge necessary for managers to carry out their roles. Drawing on the example of the wildland fire community, multiple levels of qualifications for safety managers might be devised, recognizing that different levels of knowledge and experience are needed for incidents of increasing size [Study Workshop; National Wildfire Coordinating Group 2000]. Because the disaster safety manager must serve the needs of all the responders involved in an incident, the contents of the curricula must be developed and validated with input from organizations across the responder community. Similarly, participation in joint exercises is important for these individuals to build their management and coordination expertise.

Within the responder community, there are strong precedents for maintaining specialized resources that can be called upon to assist during incidents that go beyond local capabilities. In the responses studied for this work, the roles of US\&R Task Forces, Forest Service Incident Management Teams, and specialized medical teams were highlighted [Study Interviews; Study Workshop]. Members of such a national body of disaster safety managers could similarly be drawn from experienced and senior personnel identified across the emergency response community (e.g., emergency management, fire service, law enforcement, public health, public works, state or federal response organizations, and others). Individuals serving as part of this group could remain in their existing response organizations but would be provided with 
necessary training and support to participate in major disaster exercises. ${ }^{24}$ Ideally, part-time salary support would also be provided to allow these safety managers to carry out ongoing planning and coordination activities among response organizations in their regions that go beyond their duties in their home organizations.

To ensure that one or more of these individuals could arrive rapidly at any major disaster, a small number of safety managers could be trained in each state. In the event of a major incident, individuals could be deployed to provide assistance based on their proximity and familiarity with the affected jurisdictions as well as their expertise in the particular types of hazards that are present. Depending on the specific situation and the wishes of the local response organizations involved in the disaster, these individuals could either adopt a leading or core supporting role for safety management when they arrive at the incident.

Although the information developed in this study indicated the need for a group of highly capable disaster safety managers, it did not address the mechanics of how such a resource should be put in place. While some federally managed assets such as US\&R and Incident Management Teams could be a model for such a resource, it does not necessarily follow that such a group would be built by the federal government. Indeed, mechanisms could be devised at the state, regional, or national level. ${ }^{25}$ It is also straightforward to envision models by which response community organizations-through standard-setting and coordinated-implementation activities - could contribute to putting the necessary capabilities in place. However, because of the need for uniformity in these managers' capabilities and expertise, if this group is not built in a centralized way, any separate efforts will have to be well coordinated.

\section{Recommendation 7.4-Improve Joint Exercises and Training by Incorporating Realistic Safety and Health Issues}

It is broadly accepted in the emergency response community that, to be effective at an incident, organizations must train and exercise their capabilities in preparation. However, responders indicated that, because of the operational focus of most training and disaster response exercises, safety management is seldom sufficiently addressed during these activities. In many, safety concerns are included as a "footnote" to the operational focus of the exercise. Other exercises also tend to simplify the safety and

\footnotetext{
${ }^{24}$ The group of trained safety managers could play a significant role in improving safety management in routine response and in bolstering the treatment of safety in disaster preparedness activities. Preparedness roles could include participating in designing, arranging, and monitoring the results of multiagency exercises that practice and evaluate safety and health concepts. In addition, this continuing involvement of the disaster safety managers in both day-to-day safety issues and preparedness activities would help maintain their expertise and skills until they were needed.

${ }^{25}$ For response activities more generally, examples of assistance arrangements and compacts can be found at the local, multicounty, state, regional, and federal levels.
} 
health problems for decisionmakers by deliberately or inadvertently alerting the participants in advance to the types of disaster problems they will be facing. This is in marked contrast to real disasters where the first critical safety concern is determining the nature of the event and the hazards involved. In addition, bringing together multiple organizations for a tabletop or field exercise is not an easy task, particularly if different jurisdictions and various levels of government are involved. These difficulties may result in safety-relevant organizations not being included in these activities.

Taking a more realistic approach to how safety and health issues are addressed in multiagency exercises could have substantial benefits. Multiagency or "joint exercises" are an important way of educating responders, both managers and rank-andfile personnel, on what is necessary to effectively manage safety during large-scale responses. ${ }^{26}$ Other benefits arising from joint activities include building personal relationships among responders from different organizations and the opportunity to identify unexpected shortfalls in coordination processes. ${ }^{27}$ Achieving these benefits requires that exercises be held frequently enough to maintain relationships and incorporate changes in response processes or systems. Such activities also provide the opportunity to identify best practices in responder safety and health or for undertaking pilot tests on new concepts, procedures, and technologies. Exercises can also play an important role in educating officials from outside the responder community about the realities and requirements for effective and safe disaster response.

\section{Recommendation 7.5-Develop a Common Terminology for Disaster Safety and Health Issues and Processes for Use During Response Operations}

In order for different organizations to communicate, they need a common vocabulary. The need for such a common terminology was, in fact, a key driver for developing the ICS itself. ${ }^{28}$ "Common terminology is essential in joint operations by di-

\footnotetext{
${ }^{26}$ Because of the size and diversity of the U.S. responder community, it is difficult to provide sufficient opportunities for exercise participation for all responders. As a result, other strategies for broadly disseminating needed safety and health information should also be pursued. For example, volunteer responder units located in rural areas will typically have far less resources available for travel, training programs, and acquiring specialized educational materials compared with their career responder counterparts in more populated areas. In addition, both volunteers and career responders benefit from having more flexible mechanisms to work training into their schedules. Although such materials are not equivalent to operational and classroom training, they can play an important role in providing needed safety and health information.

27 Because it is important to build relationships between representatives from safety-relevant organizations and operational responders, some exercises must include both types of organizations. "Safety focused" exercises, concentrating on safety managers and organizations that provide critical safety assets to response operations, could also be valuable to address technical safety issues and bolster coordination among the safety specialists within the response community.

${ }^{28}$ Common terminologies were highlighted as key for the ability of groups of responders from different areas to work effectively together. For example, in managing urban search and rescue operations, FEMA US\&R and FEMA Incident Support Teams (teams that support US\&R operations by assisting in operational coordination, logistics, and management) may be drawn from different areas of the country. The fact that both teams have
} 
verse users of such critical elements as: organizational functions; resource identification, classification, and allocation; and facilities" [FEMA 1987]. Even if the technical and organizational systems needed to support interagency communication function perfectly, in the absence of a common terminology, effective communication may still not occur.

Similarly, responders indicated that common definitions and terminology for safety and health management is needed for more effective interagency safety cooperation. ${ }^{29}$ Differences in how key tasks are labeled, the absence of precise definitions for safety terms, or the use of different terminologies and nomenclature by responders from different agencies or different technical disciplines all impede integrated management. ${ }^{30}$

\section{Summary}

The complexity of disaster situations makes it difficult to fully address responder safety needs simply by bolstering individual response organizations' capabilities to gather information, assess risk, and implement safety decisions. However, the safety capabilities available across a variety of responder organizations present a significant opportunity for improving safety management on an incident-wide level. Effective integration among responding organizations can allow better application of specialized expertise and capabilities to safety problems, help preserve a strategic approach to safety management, provide a mechanism to address inherently multiagency safety issues, and more fully address the differences in capability among response organizations.

Ad hoc efforts at integrated safety management were implemented during the World Trade Center and the Pentagon response operations on September 11, 2001. Although supporting the concept of integrated safety management, ad hoc structures have significant shortcomings that reduce their effectiveness for protecting responder safety. As a result, a range of preparedness and implementation efforts are needed to formalize this approach to safety management and more effectively link it to disaster incident management systems.

common training and use common terminologies supports their working to respond together in rescue operations [Study Interview].

${ }^{29}$ Standardization in a wide range of areas can facilitate integration of multiagency efforts.

30 Problems cited in study interviews or at the workshop included (1) different topics being considered "safety" versus "health" issues by different agencies, thereby affecting how they were managed; (2) differences in what was meant by particular terms by different organizations, e.g., "responder rest and rehabilitation"; and (3) use of different technical terms in hazard monitoring processes and results, causing confusion among agencies. 

CHAPTER EIGHT

\section{Moving Forward: Improving Preparedness Efforts for Responder Safety}

The difficult conditions that exist during a major disaster pose serious impediments to protecting the safety of emergency responders. In the high-pressure, complicated environment of a devastating event, safety managers face serious problems in gathering necessary information, assessing hazards and making decisions, and taking action. However, at the same time that the characteristics of disasters challenge safety management, they present clear opportunities to improve responder safety.

In defining the framework for this study of safety management, we focused our analysis on the practical requirements managers face and the activities they carry out as they strive to protect the responders under their command. With this in mind, we specifically examined safety management while response operations are under way and responders are at risk. Our analysis, and this report, started with a model of management actions taken once an incident occurs - a safety management cycle. In addition to producing the recommendations for improving safety managers' capabilities to carry out their critical functions, that analysis also led to the conclusion that better structures are needed to coordinate the safety efforts of response organizations. Effective integration of safety management capabilities across organizations could benefit all components of disaster safety management.

Even though the analysis addressed the actions managers take during response operations, as is clear from the recommendations throughout the report, effective safety management predominantly depends on actions taken before a disaster occurs. Protecting responders during an event depends on the measures, systems, relationships, and capabilities put in place long before, during disaster preparedness activities. Consequently, the majority of the recommendations are aimed at strengthening safety management during preparedness efforts. Even recommendations addressing actions during response operations - such as improved scene control or implementation of sustainability measures - rely on preparedness efforts to make them possible once a disaster occurs. 
The recommendations described in this report lead to a range of potential implementation paths for response organizations at all levels of government, nongovernmental organizations, and in the private sector. Some present short-term, more immediate payoff opportunities to improve safety, while others require long-term implementation efforts but could result in broad-reaching and large safety benefits.

\section{Immediate Implementation Opportunities}

Based on the lessons of the disasters examined during the study, there is a clear need to integrate responder safety management more effectively into preparedness planning. To carry out all phases of the safety management cycle, responder organizations must define their safety requirements should a disaster occur in their community. In each area this includes determining the following:

- What information and resources will be needed for particular disaster circumstances?

- How can those needs be filled?

- If providing needed resources and information relies on others, what is required to access them and manage their efforts during a response operation?

- When they become available, how can the safety resources be linked to response management?

- Are implementation and decision processes in place to effectively utilize them when they become available?

Such planning concerns are not dissimilar to those that must be addressed to prepare to carry out response operations in general. However, because the requirements for safety management can differ considerably from those for operational response activities, it is critical they be included in planning.

Within this overall framework, a significant number of the recommendations described in the preceding chapters could begin to be implemented immediately by individual response organizations, groups of organizations, or as a component of local or regional preparedness efforts. Such steps can build on relationships and planning processes that are already under way in many jurisdictions and areas for both safety and operational reasons. Efforts can be initiated to do the following:

- Put Hazard Monitoring Capabilities in Place—Relevant steps include addressing monitoring needs in plans, procuring needed technologies for high-priority hazards, locating external expertise and capabilities, and determining how information will be collected, coordinated, managed, and used at an incident. 
- Address Personnel Accountability Needs-While improvements in technology may provide better strategies to maintain personnel accountability in the future, interim steps utilizing scene control and organizational procedures could be implemented to provide more information to Incident Commanders on responder positions, activities, capabilities, and training.

- Develop Mechanisms to Provide Medical Care to and Monitor the Health Status of Responders-Coupling better information collection on responder health status with efforts to provide needed care can help address both the health needs of responders and the information needs of Incident Commanders.

- Put Necessary Procedures in Place to Make Safety Decisions and Implement Safety Policies-Many measures focused on the operational needs of disaster response can also provide safety benefits. Improved communication, scene control, and personnel management benefit response effectiveness as well as safety. Others, such as procedures to determine what safety equipment is needed and to ensure it is available, are safety specific and must be addressed separately in planning.

- Begin to Move Toward an Integrated, Multiagency Approach to Safety Management-To begin to build better safety coordination, responder safety issues should be included in interagency preparedness efforts. Mechanisms should be developed to ensure that organizational roles are well defined and that relationships and agreements are in place to draw on the other organizations' safety assets and capabilities.

Steps taken by individual responder organizations to bolster capabilities in these areas could produce immediate safety management benefits in future response operations.

\section{Long-Term, Potentially High-Payoff Safety Implementation Opportunities}

Other courses of action recommended in the previous chapters require long-term efforts to put into practice. In some cases, the recommendations themselves are conceptual, and specific application strategies remain to be developed. As a result, pilot projects and evaluation efforts are also needed to validate the potential for changes in management processes or the application of new technologies to improve responder safety management. For other recommendations, multiagency implementation efforts are necessary. To build a core group of disaster safety managers or to fully integrate responder safety into disaster exercises requires the efforts of multiple response organizations and levels of government. Lastly, some study recommendations require leadership and coordination at the national level to significantly benefit responder safety. While these long-term recommendations may require sustained efforts to be 
put into practice, they have the potential for broad and large benefits in improving responder safety management.

\section{Pilot and Validation Efforts}

Many of the study recommendations can be implemented in a number of ways. In some cases, several different strategies could accomplish similar safety goals. In others, the recommendations described are conceptual in nature, and there is either no obvious strategy to put them into practice or no consensus in the response community on the most promising approach. In most cases, the study research did not suggest individual strategies to implement recommendations. This is because differences among response organizations, geographic areas, jurisdictions, and risk environments may result in different solutions being more effective. The diversity of responders included within the scope of this study-career and volunteer, traditional and nontraditional, full time and disaster or hazard specific_carries with it a diversity of implementation challenges that need to be addressed in efforts to improve safety management. Further efforts are required to determine the specific needs of particular areas and situations, and how those needs can be addressed in the context of a broad, consistent approach to managing responder safety.

As a result, implementing these recommendations will require significant pilot efforts to determine, under realistic conditions, which strategies are most effective to improve responder safety. Such pilot efforts would be intended to develop prototypes to serve as a model for broader implementation in responder organizations. To ensure that courses of action are applicable to the full range of the response community, pilot efforts should be held in several different locations, from large metropolitan to rural areas.

Pilot and experimental efforts are also critical to evaluate the potential of technological approaches to improving responder safety. Although technology evaluation was not a central aim of this study, a number of management tools and technologies were described in the course of project discussions that could improve safety management for individual responder organizations and as elements of an integrated, incident-wide approach to safety management. As a result, a range of technical opportunities exist that could contribute to improved safety management. They include

- information and planning resources such as guidelines, checklists, and contact lists

- hazard monitoring technologies and assessment aids

- databases to manage safety-relevant information such as hazard data, responder accountability or capability information, and response logistics inventories

- responder identification, credentialing, and accountability technologies

- improvements to protective equipment, addressing interoperability problems, improving functioning in post-disaster situations, or bolstering usability 
- communications technologies to aid the effective exchange of information among responders and response organizations

- technologies facilitating responder health status monitoring and collection of injury or exposure information.

In each area, a wide range of technology options exists to implement the desired function. For example, for hazard assessment guidelines and decision aids, the desired functionality could be built into low-technology options such as laminated cards for responders to carry or into much higher-technology systems such as portable computers and decision-support software. In many of these areas, potential solutions exist, but their operational feasibility, affordability, and timely availability must be carefully assessed within the responder community. Some have been developed specifically for the response community; others could come via technology transfer from other organizations such as the military. Because its focus was on management concepts and processes rather than specific management or safety-related technologies, this research did not address the particular advantages or disadvantages of any individual system or solution. However, in the course of the study, the potential of such systems - and the need to continue to improve and adapt them to better meet responders' needs in post-disaster environments-became clear.

\section{Building a Core Group of Major Disaster Safety Managers}

Because of the central role that individual safety managers could play in coordinating the efforts of multiple response organizations, building a group of such individuals is an attractive initial goal. Doing so would require defining the body of knowledge needed for safety managers to effectively spearhead an integrated safety management function and developing a curriculum to serve as the basis for training. Development of such a curriculum could be accomplished by a variety of groups within the response community, including professional organizations and standards bodies, or via cooperative national-level planning efforts.

Once the preparation needed for disaster safety managers is defined, implementation mechanisms must be developed to identify individuals from the responder community to fill the roles. The results of this study do not suggest any particular model for implementation. However, it is clear that selection criteria must be defined that ensure that individuals trained to be safety managers are appropriately distributed geographically to ensure that they can rapidly respond to a disaster. Preliminary estimates of the number of such individuals needed to provide national coverage are relatively small; a few safety managers based in each state would allow rapid response to most potential disasters. ${ }^{1}$

\footnotetext{
${ }^{1}$ Depending on the specifics of the conditions within particular states, the total number of such safety managers would be in the very low hundreds for the nation overall.
} 
The managerial demands of major disaster response also indicate that the individuals trained to be disaster safety managers must have significant management skills and leadership capabilities. Taking a central role in coordinating the efforts of many different organizations is challenging and requires skillful leadership to be carried out successfully. As a result, it is critical that the position of disaster safety manager be approached as a high-level appointment, to ensure that the responders filling the role possess the necessary authority and influence.

An effort to build a group of disaster safety managers as a national asset must also ensure that these individuals will be available to fulfill their roles during both disaster operations and preparedness activities. For the safety managers to be effective, they must be able to respond when disasters occur. Such responses may involve participating in operations outside their immediate area, which requires a commitment by both the responders and their home organizations to ensure that they can respond when called on. Beyond disaster operations, many of the potential benefits of such a group of trained safety managers involve their participation in preparedness activities throughout their regions, helping bolster preparation for safety management and laying the groundwork for effective coordination during response efforts. Implementation efforts must also include developing mechanisms to support a portion of these individuals' time to make that participation possible.

\section{Integration of Safety into Disaster Exercises}

Because of the importance of disaster exercises as a route for building both interorganizational relationships and testing capabilities, integration of responder safety issues into disaster exercises is a particularly attractive early step for improving safety management. To do so, safety information and scenarios must be developed that facilitate the inclusion of these issues in exercises at all levels of government and in large-scale multiagency, multilevel disaster drills. In addition to exercises involving both operational and safety-related organizations, exercises focusing primarily on safety issues and organizations could be valuable to improving coordination among safety specialists within responder organizations. Because of the diversity of disaster exercises, implementation of this recommendation could also benefit from pilot efforts to test different mechanisms for including safety in these activities.

\section{Areas Requiring National Coordination and Leadership}

For some recommendations, the majority of the benefits to safety management will occur only if common practices are developed and adopted by a large percentage of the responder community. Implementation of a number of the recommendations described in this report would require coordination and leadership at the national level. These areas include 
- consistent organizational structures for safety management

- common terminologies

- standards for equipment and other technologies

- hazard and risk assessment guidelines

- responder credentials

- training curricula.

Such national-level leadership could come from a range of sources, including the federal government, responder community and governance organizations, multidisciplinary standards organizations, or partnerships built among multiple agencies or organizations. In some cases, these efforts are already under way. For example, the ongoing federal effort to implement a National Incident Management System initiated by HSPD-5, 2003, represents a major opportunity for ensuring the use of common organizational structures during disaster response. Similarly, standards and policy efforts already in place are considering or could consider many of the equipment, training, and other issues relevant to these safety concerns. Just as this study often highlighted safety needs without identifying particular implementation routes, the research was not focused on where national coordination of these issues should originate. However, the need for such leadership, both to heighten focus on these safety concerns and to bridge the significant diversity that exists within the response community, is clear.

\section{Concluding Remarks}

In the wake of the September 11, 2001, terrorist attacks, the risk of terrorism and the demands of homeland security must be a central component of any discussion of protecting emergency responders. Although the information developed over the course of this study does indeed indicate that some things have changed in this postSeptember 11 era, many things have remained the same. The nation still faces the risk of hurricanes, earthquakes, large industrial incidents, and other natural disasters. Often striking without warning, such events can overwhelm local response capabilities as effectively as intentional acts of our nation's adversaries. In responding to their effects, responders face the risk of physical injury, traumatic stress, and hazardous exposures. Effectively addressing such risks requires bringing together the capabilities of a range of response organizations from agencies at all levels of government, nongovernmental organizations, and the private sector.

In the context of such an all-hazards approach, bolstering preparedness efforts aimed at protecting emergency responders can therefore benefit national preparedness against both terrorism and the inevitable consequences of natural or technological disasters. Doing so requires putting the capabilities in place so safety managers 
have access to the information, the resources necessary to protect responders, and the management structures necessary to address safety during multiagency response operations. While the demanding circumstances that exist during disasters will likely present unforeseen challenges to responder safety, the recommendations described here represent promising opportunities to improve safety in future response operations. It is our hope that this research, by bringing together safety management concerns relevant to both natural disasters and the potential effects of terrorism, can contribute to efforts in all parts of the response and homeland security communities to strengthen protection of the nation's emergency responders. 
APPENDIX A

\section{Interviewees and Workshop Participants}

Shakeel Ansari

New York Police Department

Michele Baker

Pasco County Office of Emergency Management

Donna Barbisch

RAND Corporation (consultant)

Sharon Beard

National Institute of Environmental Health Sciences

Craig Beasley

Environmental Protection Agency

Raymond Biagini

National Institute for Occupational Safety and Health

Louis Bison

New York Police Department

Donnie Booher

National Institute for Occupational Safety and Health

Leo Bosner

Federal Emergency Management Agency

Gary Briese

International Association of Fire Chiefs

Thomas M. Burau

Los Angeles Fire Department

Ronald C. Burger

Centers for Disease Control and Prevention, Emergency Response

Claude Cadoux

Response Safety Consultant 
Kathy Callahan

Environmental Protection Agency

Duane Caneva

United States Marine Corps, Chemical-Biological Incident Response Force

Bob Canfield

City of Los Angeles—Emergency Preparedness Department

Carlos Castillo

Miami-Dade Fire and Rescue

Gary Cecchine

RAND Corporation

Noreen Clancy

RAND Corporation

Nancy Clark

New York City Department of Health and Mental Hygiene

Terrence Cloonan

National Institute for Occupational Safety and Health

Larry Collins

Los Angeles County Fire Department

Joe Conaty

International Union of Operating Engineers, Local 14-14B, AFL-CIO

Jeffrey R. Davis

Pennsylvania State Police

Norman Deitch

Occupational Safety and Health Administration

Scott Deitchman

National Institute for Occupational Safety and Health

Dominic DePaolis

Metropolitan Washington Airports Authority

Robert Dubé

Fairfax County Fire and Rescue

Richard Duffy

International Association of Fire Fighters

M. T. Dunn

Miami-Dade Fire and Rescue 
Jeff Dyar

United States Fire Administration

Michael Dyer

Los Angeles County Fire Department

Don Ellenberger

Center for the Protection of Workers' Rights

Mike Fagel

International Association of Emergency Managers

John Flynn

The Port Authority of New York and New Jersey

Mark Foggin

New York City Department of Health and Mental Hygiene

Maryann Garrahan

Occupational Safety and Health Administration

Robert Garvey

Occupational Safety and Health Administration

Jim Gass

Oklahoma City Memorial Institute for the Prevention of Terrorism

Gus Georgiades

Occupational Safety and Health Administration

Gil Gillen

Occupational Safety and Health Administration

R. Eugene Godwin

United States Navy, Office of the Assistant Secretary of the Navy for Installations and Environment

Phil Goldsmith

Federal Emergency Management Agency

Manuel Gomez

American Industrial Hygiene Association

Thomas Graham

New York Police Department

Daniel Gray

Fairfax County Fire and Rescue

Ellery Gray

Florida Department of Health, Emergency Operations 
Sandra Gross

Federal Emergency Management Agency

James P. Harris

Los Angeles County Sheriffs Department

Allen Hay

Fire Department of New York

Peter Hayden

Fire Department of New York

Michael Healey

New York Police Department

Linda Heiberger

Florida Department of Community Affairs, Division of Emergency Management

Jeff Herold

Metropolitan Police Department, Washington, DC

John Higgins

Environmental Protection Agency

Paula Higgins

United States Army Corps of Engineers

Carl E. Hildebrand

Executive Office of the President, Office of Science and Technology Policy

Kevin Holloran

New York Police Department

Arthur Holmes

Miami-Dade Fire and Rescue

Gary Holt

Center for Domestic Preparedness, Department of Justice

Jim Hone

City of Santa Monica Fire Department

Robert Howe

RAND Corporation

David Howell

RAND Corporation

Joseph Hughes

National Institute of Environmental Health Sciences 
James J. James

American Medical Association

John Jester

Pentagon Force Protection Agency

Bill Johnson

Miami-Dade Office of Emergency Management

David Johnson

RAND Corporation

Edward Kalletta

Fire Department of New York

William Kang

International Association of Fire Chiefs

David Kassing

RAND Corporation

Melody Kawamoto

National Institute for Occupational Safety and Health

Jim Kerr

conEdison

Kirby Kiefer

United States Fire Administration

Robert Koedam

National Institute for Occupational Safety and Health

Frank Koutnik

Florida Department of Community Affairs, Division of Emergency Management

Richard Kramp

American College of Occupational and Environmental Medicine

Alan Krebs

Florida Department of Community Affairs, Division of Emergency Management

Steve Kreis

Phoenix Fire Department

Beth Lachman

RAND Corporation

Eric Lamar

International Association of Fire Fighters 
Kevin Landkrohn

Occupational Safety and Health Administration

Dore LaPosta

Environmental Protection Agency

Cortez Lawrence

United States Fire Administration

Vicki Lee

International Association of Fire Chiefs

Henry Leonard

RAND Corporation

Jeffrey Liebold

Arlington County Fire Department

Scott Linsky

United States Coast Guard

Bruce Lippy

National Clearinghouse for Worker Safety and Health Training

Julia Lorau

New York Police Department

Douglas MacDonald

Los Alamos County Fire Department, Los Alamos, N.M.

Paul Maniscalco

National Association of Emergency Medical Technicians

Philip Mannheim

Occupational Safety and Health Administration

MaryAnn E. Marrocolo

American Public Works Association

Ralph Masi

RAND Corporation

Ray Master

Bovis Lend Lease

Dino Mattorano

National Institute for Occupational Safety and Health

Barbara McCabe

International Union of Operating Engineers 
Jack McCartt

Boca Raton Fire Department

Charles McCool

Florida Department of Community Affairs, Division of Emergency Management

Kelly McKinney

New York City Department of Health and Mental Hygiene

Ken Mead

National Institute for Occupational Safety and Health

Mary Mears

Environmental Protection Agency

Rich Mendelson

Occupational Safety and Health Administration

Tommey Meyers

United States Coast Guard

Paul Middendorf

National Institute for Occupational Safety and Health

Stacy Milligan

Police Executive Research Forum

Jeffrey Mishula

New York Police Department

Jeffrey Mitchell

University of Maryland (Baltimore City)

John Moran

National Institute of Environmental Health Sciences

Joseph Morris

The Port Authority of New York and New Jersey

Patrick Morrison

International Association of Fire Fighters

David Mosher

RAND Corporation

Robert Murgallis

United States Fire Administration

David Mussington

RAND Corporation 
Bob Neamy

Los Angeles City Fire Department

Gary Niki

American Red Cross

John Norman

Fire Department of New York

Carol North

Washington University

Thomas O'Conner

The Port Authority of New York and New Jersey

Ron Olin

International Association of Chiefs of Police

Scott O'Neil

United States Army

Philip Parra

Fire Department of New York

Kara Perritt

National Institute for Occupational Safety and Health

D. J. Peterson

RAND Corporation

Joseph Pfeifer

Fire Department of New York

Scot Phelps

New York City Department of Health and Mental Hygiene

Mary Plaskon

The Port Authority of New York and New Jersey

Edward Plaugher

Arlington County Fire Department

Franklin Pratt

Los Angeles County Fire Department

Dran Pryce

New York Police Department

Pete Quinn

New York Police Department 
Amir Rasheed

New York Police Department

Stephen Rattien

RAND Corporation

Raymond Reilly

Fire Department of New York

Brian Rettmann

Stimson Center

Irene Richardson

U.S. Army Center for Health Promotion and Preventive Medicine

Tom Richardson

Fire Department of New York

Helga Rippen

RAND Corporation

Elspeth Cameron Ritchie

Office of the Assistant Secretary of Defense for Health Affairs

Joseph Rizzuto

International Union of Operating Engineers, Local 14-14B, AFL-CIO

Charles G. Roper

Los Angeles Police Department

John Roquemore

National Association of Emergency Medical Technicians

Jimmie L. Ryland

Los Angeles County Fire Department

Carol Saulnier

Arlington County Fire Department

James Schwartz

Arlington County Fire Department

Gary Scott

Campbell County Fire Department, Gillette, Wyo.

Kevin Shanley

National Governors Association

John W. Sniderhan

Buffalo Office of Disaster Preparedness 
Jerry Sollinger

RAND Corporation

Ronald Spadafora

Fire Department of New York

Michael Spall

conEdison

Bradley Stein

RAND Corporation

Carol Merry Stephenson

National Institute for Occupational Safety and Health

Steve Storment

Phoenix Fire Department

Cynthia Striley

National Institute for Occupational Safety and Health

Ronald Stryker

The Port Authority of New York and New Jersey

John Sullivan

Los Angeles Sheriffs Department

Terri Tanielian

RAND Corporation

Phil Taylor

The Port Authority of New York and New Jersey

Bruce Teele

National Fire Protection Association

Adam Thiel

Virginia Department of Fire Programs

Robert Thomas

New York Police Department

Patricia Thompson

National Institute of Environmental Health Sciences

Michael Tobia

The Port Authority of New York and New Jersey

Gary Tokle

National Fire Protection Association 
Michael Tseng

RAND Corporation

James E. Turner

Delaware Emergency Management Agency

Robin Valerioti

Miami-Dade Fire and Rescue

Richard Verlinda

Seattle Fire Department

Scott Ward

Boca Raton Fire Department

Richard Warford IV

Los Angeles Fire Department

James Washington

Miami-Dade Fire and Rescue

Michael Wermuth

RAND Corporation

Ronald Werner

Fire Department of New York

Rodney Winchel

National Institutes of Health

James Woodey

U.S. Army Corps of Engineers

Bergmann Yu

New York Police Department

Lydia Yu

Baltimore County Department of Health

Ralph Zumwalde

National Institute for Occupational Safety and Health 



\title{
Workshop Agenda
}

\author{
Protecting Emergency Responders: \\ Safety Management in Major Disaster \& Terrorism Response \\ Arlington, Virginia \\ February 27, 2003
}

\section{MEETING AGENDA}

7:30-9:00 a.m.

$7: 30-8: 15$

$8: 15-9: 30$

$9: 30-9: 45$

$9: 45-11: 45$

11:45-12:15 p.m.

$12: 15-2: 00$

2:00-2:15

$2: 15-4: 15$

$4: 15-4: 30$

$4: 30-5: 30$
Registration

Continental Breakfast

Introduction, Overview, and Instructions to Panels

Break

Breakout Session I (Concurrent Sessions)

Break

Breakout Session II (Concurrent Sessions-Working

Lunch)

Break

Breakout Session III (Concurrent Sessions)

Break

Presentation of Breakout Highlights, Open Discussion, and Conference Closing

\section{Concurrent Breakout Session Titles and Potential Discussion Areas:}

1. Integration of Safety Management in Disaster Incident Management/Command Systems

- Placement and structure for safety management within incident management systems

- Inter-agency safety management versus intra-agency safety management

- Integration of multiagency safety resources into incident management 
- Interaction of different command levels and interagency commands

- Sectoring of response into manageable commands

2. Improving Coordination and Control of Personnel and Resources During Disaster Response

- Coordination of responders and resources in major incidents

- Resource assignment and allocation

- Personnel accountability

- Scene control, credentialing, and security

- Role of regulations, guidance, and enforcement activity in response

3. Hazard Information, Intelligence, and Risk Assessment

- Responsibility and methods for hazard monitoring during response

- Collection and sharing of intelligence and threat information

- Evolution of information needs through response

- Increasing speed of information acquisition and sharing

- Coordination of information from different agencies and sources

- Risk assessment and communication during major incident response

4. Improving Training for Disaster Response

- Pre-incident training-needs, participants, methods, and topics

- On-site training-mechanisms, topics, and interaction with incident command

- Improved training methods

5. Responder Health Care

- Delivery of medical care to responders during incident response

- Capture and use of injury and exposure data in safety management

- Responder health maintenance activities during response

- Fatigue

- Decontamination

- Health monitoring

- Traumatic stress issues 


\section{Selected Bibliography}

ALSAC (Air Land Sea Application Center) [2001]. Risk management. Washington, DC: ALSAC, FM 33-100.12, MCRP 5-12.1C, NTTP 5-03.5, AFTTP(I) 3-2.34.

Anderson L [2002]. Using technology to manage the information overflow. Fire Engineering May [http://fe.pennnet.com]. Date accessed: May 2003.

Arlington County, Virginia [2002]. Arlington County after-action report on the response to September 11 terrorist attack on the Pentagon. [http://www.co.arlington.va.us/fire/edu/ about/pdf/after_report.pdf]. Date accessed: May 2003.

Auf der Heide E [1989]. Disaster response: Principles of preparation and coordination. St. Louis, MO: CV Mosby.

Barry D [2002]. Where Twin Towers stood, a silent goodbye. The New York Times, May 31; sect. A:1.

Brainard J, Behrendt B [1993]. The storm: Six months later: Next storm, county plans to be ready. Citrus Times, Sept 12; sect. A:1.

Brunacini AV [2002]. Fire command. Quincy, MA: National Fire Protection Association.

Budd C [not dated]. Information gathering and technology use during disaster deployments. [http://mediccom.org/public/tadmat/training/NDMS/Information_Technology.pdf].

Date accessed: April 2003.

Bunch KP, Wilson TG [2002]. Counselors on call. Fire Chief, June 1. [http://www.firechief. com]. Date accessed: June 2003.

Burkell CJ, Wood H [1999]. Make the right call. Fire Chief, March 1. [http://www. firechief.com]. Date accessed: May 2003.

California Office of Emergency Services [1993]. The Southern California wildfire siege: October-November 1993-After action report. [http://www.ucfpl.ucop.edu/UWI\% 20Documents/068.PDF]. Date accessed: May 2003.

California Task Force 3, National Urban Search and Rescue Response System, Federal Emergency Management Agency [2001]. World Trade Center after action report: September 18-30, 2001. [http://www.menlofire.org/pdf_file/WTC\%20FEMA\%20After\% 20Action\%20Report.pdf]. Date accessed: April 2003. 
Cardwell MD, Cooney PT [2000]. Nationwide application of the Incident Command System: Standardization is the key. FBI Law Enforcement Bulletin Oct:10 15.

Center for Army Lessons Learned [1993]. Operations other than war, Vol. II: Disaster assistance. Newsletter 93-6, October.

Chatfield M, Robertson A [1997]. Safety: An essential component of emergency management. Australian Journal of Emergency Management 12(3):36 38.

Christen H, Maniscalco P, Vickery A, Winslow F [2001]. An overview of incident management systems. Perspectives on Preparedness 4 (Sept.) [http://bcsia.ksg.harvard.edu/ BCSIA_content/documents/An_Overview_of_Incident_Management_Systems.pdf]. Date accessed: May 2003.

Cole D [2000]. The Incident Command System: A 25-year evaluation by California practitioners. March 28. [http://www.usfa.fema.gov/pdf/efop/efo31023.pdf]. Date accessed: May 2003.

Coleman J [2001]. Managing major fires. Tulsa, OK: PennWell Corporation.

Collins L [1999]. Lessons learned from the Northridge and Kobe earthquakes. [http://imagecatinc.com/reportspubs/epedatpp.pdf]. Date accessed: May 2003.

— [2003]. Collapse rescue operations at the Pentagon 9-11 attack: A case study on urban search and rescue disaster response. [http://www.ukfssart.org.uk/files/pentagon\% 20report.PDF]. Date accessed: April 2003.

Cone DC, Weir SD, Bogucki S [2003]. Convergent volunteerism. Annals of Emergency Medicine 41(4):457 462.

Davis LM, Blanchard JC [2002]. Are local health responders ready for biological and chemical terrorism? Santa Monica, CA: RAND Corporation, IP-221-OSD.

Department of the Army [1997]. Field manual 101-5: Staff organization and operations. [http://www.adtdl.army.mil/cgi-bin/atdl.dll/query/download/FM+101-5]. Date accessed: April 2003.

- [2001]. Field manual 3-0: Operations. [http://www.adtdl.army.mil/cgi-bin/atdl.dll/ $\mathrm{fm} / 3-0 / \mathrm{fm} 3-0 . e x e]$. Date accessed: May 2003.

DHHS et al. (Departments of Health and Human Services, Defense, Veterans Affairs, and Justice; and American Red Cross) [2001]. Mental health and mass violence: Evidencebased early psychological intervention for victims/survivors of mass violence: A workshop to reach consensus on best practices. Airlie Conference Center, Warrenton, VA, October 29-November 1, 2001.

EPA (Environmental Protection Agency) [2002]. Lessons learned in the aftermath of September 11, 2001. February 1. Washington, DC: EPA. [http://www.greenpeaceusa.org/ toxics/lessonslearned.pdf]. Date accessed: May 2003.

Faranda C [1992]. Lauderhill Fire Department memorandum: Hurricane Andrew, submitted to the Florida Governor's Disaster Planning and Response Committee, November 23. 
FEMA (Federal Emergency Management Agency) [1987]. Exemplary practices in emergency management: The California FIRESCOPE program. Emmitsburg, MD: FEMA, National Emergency Training Center, Emergency Management Institute.

[1992]. Urban search and rescue in the Santa Cruz area following the Loma Prieta earthquake. Emmitsburg, MD: FEMA, United States Fire Administration. [http://www. usfa.fema.gov/downloads/pdf/publications/fa-124.pdf]. Date accessed: September 2003.

[1993]. FEMA's disaster management program: A performance audit after Hurricane Andrew. Washington, DC: FEMA, Office of the Inspector General.

[1994a]. Search and rescue operations following the Northridge earthquake. Emmitsburg, MD: FEMA, United States Fire Administration. [http://www.usfa.fema.gov/ downloads/pdf/publications/fa-163c.pdf]. Date accessed: August 2003.

[1994b]. Search and rescue operations in California after flooding-January to March 1995. Emmitsburg, MD: FEMA, United States Fire Administration. [http://www.usfa.fema.gov/downloads/pdf/publications/fa-163e.pdf]. Date accessed: May 2003.

[1994c]. Report of the joint fire/police task force on civil unrest. Emmitsburg, MD: FEMA, United States Fire Administration. [http://www.usfa.fema.gov/downloads/pdf/ publications/fa-142.pdf]. Date accessed: May 2003.

[1998]. ICS: Incident Command System—independent study course. Emmitsburg, MD: FEMA, Emergency Management Institute [http://transit-safety.volpe.dot.gov/ training/EPSSeminarReg/CD/documents/EmerPrep/IS195comp.pdf]. Date accessed: April 2003.

[1999a]. Incident Safety Officer: Student manual. Emmitsburg, MD: FEMA, United States Fire Administration, National Fire Academy.

[1999b]. Wanton violence at Columbine High School. Emmitsburg, MD: FEMA, United States Fire Administration. [http://www.usfa.fema.gov/applications/publications/ tr128.cfm]. Date accessed: May 2003.

FEMA US\&R Program Staff [2002]. FEMA US\&R Program Staff after action executive summary-1391-DR-NY, 1392-DR-VA. Washington, DC: FEMA, National Urban Search \& Rescue Response System.

Fischer R [1997]. Emergency in the Everglades: The recovery of ValuJet Flight 592. FBI Law Enforcement Bulletin Sept:8 13.

Florida Commission on Community Service [2003]. Unaffiliated volunteers in response and recovery. [http://www.fccs.org/disaster\%20relief/downloads/UNAFFIL1.ATE.pdf]. Date accessed: April 2003.

Francis AA [1997]. Mutual aid: Not just any duck will do. The ASPEP Journal:31 33.

Ghilarducci M [1995]. Earthquake response: Lessons learned from Kobe, Japan. Street Skills, May/June; 2630.

Grant NK, Hoover DH [2002]. Terrorism in Shanksville: A study in preparedness and response. Boulder, CO: Natural Hazards Research and Applications Information Center, 
University of Colorado, Quick Response Report \#157. [http://www.colorado.edu/ hazards/qr/qr157/qr157.html]. Date accessed: May 2003.

Greene RW [2002]. Confronting catastrophe: A GIS handbook. Redlands, CA: ESRI Press.

Harrald JR [2002]. Observing and documenting the inter-organizational response to the September 11 attacks. Presentation at Countering Terrorism: Lessons Learned from Natural and Technological Disasters, The National Academies, Washington, DC, February 28-March 1. [http://www7.nationalacademies.org/ndr/1Harrald_Presentation.pdf]. Date accessed: August 2003.

Haughney C [2003]. Ground zero workers afflicted, study finds: Tests show physical, psychological ills persist nearly a year after rescue efforts. The Washington Post, January 28; sect. A:6.

Hawley C [2000]. Hazardous materials response and operations. Albany, NY: Delmar Publishing.

Haynes T, Charney C [1993]. After action report Hurricane Andrew-Florida—Donations. Washington, DC: FEMA.

Heath P [1992]. Personal letter to the Florida Governor's Disaster Planning and Response Committee, not publicly available, November 23.

Higham S, Donnelly J [1992]. "It's time to go home," military says. Miami Herald, Oct 14; sect. A:1.

Hill J [2002]. High-speed police pursuits: Dangers, dynamics, and risk reduction. FBI Law Enforcement Bulletin July: 15.

Holsenbeck CLS [1994]. Joint force Andrew: The 44th medical brigade mental health staff officer's after action report. Military Medicine 159(3):186.

Homeland Security Presidential Directive (HSPD)-5 [2003]. 39 Weekly Comp. Pres. Doc. 280, February 28.

Institute for Crisis Disaster and Risk Management, George Washington University [2002]. Observing and documenting the inter-organizational response to the September 11th attack on the Pentagon. July 15. [http://www.gwu.edu/-icdrm/nsf_9_11.htm]. Date accessed: May 2003.

International Association of Fire Chiefs (IAFC) [2002]. Crew resource management: A positive change for the fire service. Washington, DC: IAFC.

Irving C, ed. [1995]. In their name: Oklahoma City: The official commemorative volume. New York, NY: Random House.

Jackson BA, Peterson DJ, Bartis JT, LaTourrette T, Brahmakulam I, Houser A, Sollinger J [2002]. Protecting emergency responders: Lessons learned from terrorist attacks. Santa Monica, CA: RAND Corporation, CF-176-OSTP.

Johnson B [2002]. Hurricane Andrew: 10 years later. Presentation at 16th Annual Governor's Hurricane Conference, May 20-24, Tampa, FL. [http://ghc.digiscript.com/]. Date accessed: June 2003. 
Kane J [2001]. The Incident Command System and the concept of Unified Command at a terrorist incident. Proceedings of the Public Entity Risk Institute, Community Response to the Threat of Terrorism Internet Symposium. [http://www.riskinstitute.org/ptrdocs/ CommunityResponse-Terrorism.pdf]. Date accessed: May 2003.

Kelly K, Prezant D [2002]. WTC medical monitoring results. WNYF (With New York Firefighters) 3:2 4 .

Kendra J, Wachtendorf T [2001]. Rebel Food . . . Renegade supplies: Convergence after the World Trade Center attack. [http://www.udel.edu/DRC/pp316.pdf]. Date accessed: April 2003.

Kipp JD, Loflin ME [1996]. Emergency incident risk management. New York, NY: John Wiley \& Sons, Inc.

Klein G [1998]. Sources of power: How people make decisions. Cambridge, MA: The MIT Press.

LaTourrette T, Peterson DJ, Bartis JT, Jackson BA, Houser A [2003]. Protecting emergency responders, Vol. 2: Community views of safety and health risks and personal protection needs, Santa Monica, CA: RAND Corporation, MR-1646-NIOSH.

Leonard RB, Stringer LW, Alson R [1995]. Patient-data collection system used during medical operations after the 1994 San Fernando Valley-Northridge earthquake. Prehospital and Disaster Medicine 10(3):178 183.

Lewis P. [1993]. The governor's disaster planning and response committee final report. January 15. [http://www.floridadisaster.org/dem/files/lewisr.pdf]. Date accessed: June 2003.

Lioy PJ, Gochfeld M [2002]. Lessons learned on environmental, occupational, and residential exposures from the attack on the World Trade Center. American Journal of Industrial Medicine 42:560 565.

Lippy B [2002]. Safety and health of heavy equipment operators at Ground Zero. American Journal of Industrial Medicine 42:539 542.

Lippy B, Murray K [2002]. Improving the training of skilled support personnel for responding to terrorist actions: A review of the problems and feasible solutions. [http://www.wetp.org/front/NIEHS_rev_010303.pdf]. Date accessed: May 2003.

Los Angeles Fire Department [not dated]. Northridge earthquake January 17, 1994. [http://www.lafd.org/eq.htm]. Date accessed: June 2003.

Los Angeles Fire Department and Los Angeles County Fire Department [1994]. Historical overview report of the January 17, 1994 Northridge earthquake. Los Angeles, CA: Los Angeles Fire Department and Los Angeles County Fire Department.

Lubnau TE II, Okray R [2002]. Crew resource management for the fire service. Fire Engineering Aug. [http://fe.pennnet.com]. Date accessed: April 2003.

Maniscalco PM, Christen HT [2001]. Understanding terrorism and managing its consequences. Upper Saddle River, NJ: Prentice Hall. 
Manning WA, ed. [1993]. The World Trade Center bombing: Report and analysis. Washington, DC: FEMA. [http://www.usfa.fema.gov/downloads/pdf/publications/tr-076.pdf]. Date accessed: May 2003.

Manzi C, Powers MJ, Zetterlund K [2002]. Special report: Critical information flows in the Alfred P. Murrah Building bombing: A case study. [http://www.cbaci.org/ murrahcasestudyfinal.pdf]. Date accessed: May 2003.

McHugh CP [1995]. Preparing public safety organizations for disaster response: A study of Tucson, Arizona's response to flooding. Disaster Prevention and Management 4(5):25 36.

McKinsey \& Company [2002a]. Improving NYPD emergency preparedness and response. New York, NY: McKinsey \& Company. [http:/www.nyc.gov/html/nypd/pdf/ nypdemergency.pdf]. Date accessed: May 2003.

— [2002b]. Increasing FDNY’s preparedness. New York, NY: McKinsey \& Company. [http://www.nyc.gov/html/fdny/html/mck_report/toc.html]. Date accessed: April 2003.

Mitchell JT, Everly J [1996]. Critical incident stress debriefing: An operations manual for the prevention of traumatic stress among emergency services and disaster workers. 2nd ed. Ellicott City, MD: Chevron Publishing.

Mitchell KA [1995]. First-hand account of Andrew's impact. Forum for Applied Research and Public Policy 10:16 21.

Morris G [2001]. Many faces of safety. Fire Chief April 1. [http://www.firechief.com]. Date accessed: May 2003.

National Disaster Medical System [2003]. Web site. [http://ndms.dhhs.gov]. Date accessed: June 2003.

NFPA (National Fire Protection Association) [2000a]. NFPA-1250: Emergency service organization risk management. Quincy, MA: NFPA.

[2000b]. NFPA-1600: Standard on disaster/emergency management and business continuity programs. Quincy, MA: National Fire Protection Association.

- [2002a]. NFPA-1500: Standard on fire department occupational safety and health program. Quincy, MA: NFPA.

— [2002b]. NFPA-1521: Standard for fire department safety officer. Quincy, MA: NFPA.

[2002c]. NFPA-1561: Standard on emergency services incident management system. Quincy, MA: NFPA.

NFSIMC (National Fire Service Incident Management Consortium), Model Procedures Committee [2000]. Model procedures for structural firefighting. 2nd ed. Oklahoma City: Oklahoma State University, Fire Protection Publications.

—. [2003]. Web site. [http://www.ims-consortium.com]. Date accessed: April 2003.

National Wildfire Coordinating Group, Incident Operations Standards Working Team [2000]. National Interagency Incident Management System: Wildland and prescribed fire 
qualification system guide. [http://www.nwcg.gov/pms/docs/310-1new.pdf]. Date accessed: May 2003.

Neal DM [1995]. Transition from response to recovery: A look at the Lancaster, Texas tornado. Boulder, CO: Natural Hazards Research and Applications Information Center, University of Colorado. Quick Response Report \#79.

Nordgrén M, Goldstein E, Izeman M [2002]. The environmental impacts of the World Trade Center attacks: A preliminary assessment. Washington, DC: Natural Resources Defense Council. [http://www.nrdc.org/cities/wtc/wtc.pdf]. Date accessed: May 2003.

North CS, Tivis L, McMillen JC, Pfefferbaum B, Spitznagel EL, Cox J, Nixon S, Bunch KP, Smith EM [2002]. Psychiatric disorders in rescue workers after the Oklahoma City bombing. American Journal of Psychiatry 159(5):857 859.

The numbers [2002]. Milwaukee Journal Sentinel, September 12; sect. A:15.

NVFC (National Volunteer Fire Council) [2002]. Final report: The role of the volunteer fire service in the September 11, 2001 terrorist attacks. [http://www.nvfc.org/pdf/ rolevolfiresvc911.pdf]. Date accessed: May 2003.

Oklahoma City MIPT (Oklahoma City Memorial Institute for the Prevention of Terrorism) [2002]. Oklahoma City 7 years later: Lessons for other communities. [http://www. mipt.org/pdf/MIPT-OKC7YearsLater.pdf]. Date accessed: May 2003.

Oklahoma Department of Civil Emergency Management [2000]. After action report: Alfred P. Murrah Federal Building bombing, 19 April 1995 in Oklahoma City, Oklahoma. [http://www.odcem.state.ok.us/archives/fema/1048/aar-table.htm]. Date accessed: May 2003.

Pangi R [2002]. Consequence management in the 1995 Sarin attacks on the Japanese subway system. Studies in Conflict and Terrorism. 25:421 448.

Paulison RD, Montes MF, Castillo CJ, Brown JJ [1993]. Metro-Dade Fire Department: A comprehensive look. Fire Engineering June:64 84.

Pine JC [1993]. Systems view of emergency response to Hurricane Andrew. Boulder, CO: Natural Hazards Center, University of Colorado, Quick Response Report \#58.

Quarantelli EL [1992]. The case for a generic rather than agent specific approach to disasters. Disaster Management Jan:191 196.

___ [2000]. Emergencies, disasters and catastrophes are different phenomena. [http://www.udel.edu/DRC/preliminary/pp304.pdf]. Date accessed: April 2003.

RAND Corporation and the Oklahoma City National Memorial Institute for the Prevention of Terrorism (MIPT). [2003]. The RAND-MIPT terrorism incident database. (http://www.rand.org/psj/rand-mipt.html; last accessed December 2003).

Rielage DC [2001]. Cycles of command. Fire Chief March 1. [http://www.firechief.com]. Date accessed: March 2003. 
Rose S, Bisson J, Wessely S [2002]. Psychological debriefing for preventing post traumatic stress disorder (PTSD), Cochrane Review in The Cochrane Library, Issue 4, Chichester, West Sussex, U.K.: John Wiley \& Sons Limited and Update Software.

Rymer $\mathrm{T}$ [not dated]. Occupational health and the disaster response worker. [http://mediccom.org/public/tadmat/training/NDMS/personal_health_and_deployment_ issues.pdf]. Date accessed: May 2003.

Salvation Army [2002]. Salvation Army's unprecedented relief effort comes to a close at Ground Zero. [http://www.salvationarmy-usaeast.org/disaster/]. Date accessed: April 2003.

Smitherman MW [2000]. British styles of incident safety: Command decisionmaking and team knowledge. Proceedings of the Public Entity Risk Institute, Firefighter Safety at Emergency Incidents Internet Symposium. [http://www.riskinstitute.org/ptrdocs/ firefightersafety.pdf]. Date accessed: May 2003.

Sniezek J, Wilkins D, Wadlington P, Baumann M [2002]. Training for crisis decisionmaking: Psychological issues and computer based solutions. Journal of Management Information Systems 18(4):147 168.

Spadafora R [2002]. FDNY safety and health issues at the World Trade Center complex (Ground Zero)—Part I. WNYF (With New York Firefighters) 1:5 6.

Stay safe or uphold the law-police safety advisors in a quandary [1998]. The Safety and Health Practitioner, Nov:5.

Stratton SJ, Price Hastings V, Isbdll D, Celentano J, Ascarrunz M, Gunter CS, Betance J [1996]. The 1994 Northridge earthquake disaster response: The local Emergency Medical Services Agency experience. Prehospital Disaster Med 11(3):172 179.

Taylor P, Sanchez C [1992]. Bush orders troops into Los Angeles. The Washington Post, May 2; sect. A:1.

Taylor RC [1992]. Personal letter and attachments submitted to the Florida Governor's Disaster Planning and Response Committee, not publicly available. November 24.

Thomas P [1997]. Evidence links Atlanta clinic, club bombings, U.S. says. The Washington Post, June 5; sect. A:3.

Tierney KJ, Goltz JD [1994]. Emergency response: Lessons learned from the Kobe earthquake. [http://www.udel.edu/DRC/preliminary/260.pdf]. Date accessed: May 2003.

USCG (U.S. Coast Guard). [2001]. U.S. Coast Guard incident management handbook: Incident Command System (ICS). Washington, DC: USCG.

U.S. Department of Labor, OSHA (Occupational Safety and Health Administration). [2003]. Web site. [http://www.osha.gov; last accessed June 2003].

U.S. Forest Service [2003]. National interagency incident management system. Washington, DC: U.S. Forest Service. [http://www.fs.fed.us/fire/operations/niims.shtml]. Date accessed: April 2003. 
U.S. National Response Team, NRT Response Committee, U.S. Environmental Protection Agency [not dated]. Incident Command System/Unified Command (ICS/UC): Technical assistance document. [http://nrt.org/production/nrt/home.nsf/resources/Publications1/ \$File/ICS_UC_Technical_Assistance_Document.pdf]. Date accessed: May 2003.

van Emmerik AA, Kamphuis JH, Hulsbosch AM, Emmelkamp PM [2002]. Single session debriefing after psychological trauma: A meta-analysis. Lancet 360:766 771.

Vincoli JW, Black NH, Burkhammer SC [2002]. SH\&E at Ground Zero. Professional Safety 47(5):21 28.

Weber R, McEntire D, Robinson R [2002]. Public/private collaboration in disaster: Implications from the World Trade Center terrorist attacks. Boulder, CO: Natural Hazards Research and Applications Information Center, University of Colorado, Quick Response Report \#155.

West K [2003]. Scene safety vs. duty to care. Emergency Medical Services May:84 89.

Williams MS [1992]. Personal letter to the Florida Governor's Disaster Planning and Response Committee, not publicly available, November 23.

Williamson RA, Baker JC [2002]. Lending a helping hand: Using remote sensing to support the response and recovery operations at the World Trade Center. Photogrammetric Engineering and Remote Sensing 68(9): 870875.

Worker Education and Training Program, National Institute of Environmental Health Sciences. [2002]. Learning from Disasters: Weapons of Mass Destruction Preparedness Through Worker Training, report of technical workshop, Washington, DC: Worker Education and Training Program, National Institute of Environmental Health Sciences, April 25-26. [http://wetp.org/oldchfiles/awardee_mtgs/spring02/WMDreport.pdf]. Date accessed: May 2003. 
